\title{
AN EXPERIMENTAL INVESTIGATION OF THE STOL PERFORMANCE OF CAL POLY'S AMELIA IN THE NFAC
}

\author{
A Thesis \\ Presented to \\ the Faculty of California Polytechnic State University \\ San Luis Obispo
}

\author{
In Partial Fulfillment \\ of the Requirements for the Degree \\ Master of Science in Aerospace Engineering
}

by

Jonathan Andrew Lichtwardt

April 2013 
(c) 2013

Jonathan Andrew Lichtwardt

ALL RIGHTS RESERVED 


\section{COMMITTEE MEMBERSHIP}

TITLE:

An Experimental Investigation of the STOL Performance of Cal Poly's AMELIA in the NFAC

AUTHOR: Jonathan Andrew Lichtwardt

DATE SUBMITTED: April 2013

COMMITTEE CHAIR: David Marshall, Ph.D.

Aerospace Engineering Department

COMMitTeE MeMBeR: Jin Tso, Ph.D.

Aerospace Engineering Department

COMMITTEE MEMBER: Russell Westphal, Ph.D.

Mechanical Engineering Department

COMMITTEE MEMBER: Robert Fong, M.S.

Fluid Mechanics Laboratory

NASA Ames Research Center 


\begin{abstract}
An Experimental Investigation of the STOL Performance of Cal Poly's AMELIA in the NFAC
\end{abstract}

Jonathan Andrew Lichtwardt

Results from Cal Poly's recent wind tunnel test, during the Winter of 20112012, in the 40- by 80-foot test section at the National Full-Scale Aerodynamics Complex (NFAC) at NASA Ames Research Center are presented. AMELIA, the Advanced Model for Extreme Lift and Improved Aeroacoustics, is the first fullspan, cruise efficient, short take-off and landing (CESTOL) model incorporating leading- and trailing-edge blowing wing circulation control and over-the-wing mounted turbine propulsion simulators (TPS) to date. Testing of the 10 foot span model proved successful and was the result of a 5 year NASA Fundamental Aeronautics Program Research Announcement. The test generated extensive lowspeed experimental aerodynamic and acoustic measurements. All of the results associated with Cal Poly's effort will be available in an open-source validation database with the goal of advancing the state-of-the-art in prediction capabilities for modeling aircraft with next generation technologies, focusing on NASA's N+2 generation goals.

The model's modular design allowed for testing of 4 major configurations. Results from all configurations are presented. Out of a total of 292 data runs, 14 repeat run configurations were obtained. Overall repeatability of test data are good. Factors contributing to non-repeatability in the test data were assessed and showed high pressure air line temperature to be a primary factor. Test data shows drastic improvements in performance are obtained when incorporating leading edge blowing: wing stall can be delayed to more than 25 degrees angle-of-attack 
at lift coefficients exceeding six. Without the introduction of leading edge blowing to increase boundary layer momentum and maintain flow attachment around the leading edge, STOL performance suffers. Similar runs for isolated trailing edge blowing show a reduction in maximum lift coefficient to three with stall occurring at zero angle-of-attack. Testing at two engine pylon heights allowed for the highly coupled propulsion and flow control system to be characterized. 


\section{Acknowledgements}

This research effort was sponsored by NASA's Subsonic Fixed Wing Program, NASA Research Announcement contract \#NNL07AA55C. Thank you to Craig Hange and Clif Horne for serving as technical advisors. Special thanks to Mike Rogers for his unwavering support throughout the project.

To Dr. Marshall my advisor, thank you for supporting all of us throughout this project. You and Dr. Jameson have provided me with the opportunity to succeed and I thank you for that. Dr. Jameson, thank you for not giving up on me.

The success of this test can largely be attributed to the help and technical expertise of the Fluid Mechanics Laboratory at NASA Ames Research Center. Specifically Rabi Mehta, Rob Fong, Jim Ross, Steve Smith, Nate Burnside, Kevin James, Ted Garbeff, and Barry Porter. Also, the skilled work of John Wallace saved the test on more than one occasion. The AMELIA project was largely a collaborative effort and the contributions from NASA Langley Research Center's Greg Jones, Bob Englar, and the rest of the GTRI team are recognized. The support of the staff at the NFAC is much appreciated.

To Rob Fong, I owe you a large debt of gratitude. Without you, this test would not have achieved the successes that it did. The countless life lessons and experiences you have passed on to Eric and I have stuck with us and set us up for successful careers.

To the guys in the lab, Eric Paciano, Rory Golden, Bobby Ehrmann, Bryan Blessing, Jay Marcos, Kevin Lane, and John Pham: I have had some of the best times of my life being a part of the lab, thanks. Bobby, you are my go-to guy for bouncing ideas off of. Bryan, thank you for mentoring me in my early days 
on this project; the wisdom you have imparted sticks with me to this day. I am grateful to have met you guys throughout this journey, it has been quite the (bike) ride...

To Eric Paciano: We have known each other since the first day of our college career at Cal Poly. We were brought on to the project at the same time, and though I am just the substitute, we experienced virtually everything together as partners in crime. We learned many things that resulted from our time at Cal Poly and at Ames. For that, I have found a lifelong friend and I thank you.

Lastly, I must thank my family. To my father, your support has gotten me to where I am today and I am a better man because of you. To my sister, Kristen, you are the only person who has been with me throughout my life, I love you.

And with that, let the show begin... 


\section{Contents}

List of Tables $\quad$ x

List of Figures $\quad$ xi

Nomenclature xiv

1 Introduction 1

2 Description of Experiment $\quad 4$

2.1 Test Facility - NFAC . . . . . . . . . . . . . . . 4

2.2 Test Article - AMELIA _. . . . . . . . . . . . . 7

2.2.1 Slot Blowing System - Low Pressure Supply . . . . . . . . 10

2.2.2 TPS Units - High Pressure Supply . . . . . . . . . . . . 16

2.3 Test Measurements and Instrumentation . . . . . . . . . . . . . 20

2.3.1 Data Acquisition ............... 26

2.4 Test Procedure and Data Reduction . . . . . . . . . . . . . . . 27

2.4.1 Test Conditions . . . . . . . . . . . . . . . 27

2.4.2 Coordinate Systems . . . . . . . . . . . . . . 31

2.4.3 Data Reduction . . . . . . . . . . . . . . . . 31

2.4.4 Data Corrections . . . . . . . . . . . . . . 35

3 Model Configurations $\quad 37$

3.1 TPS Removed . . . . . . . . . . . . . . . . . . . 38

3.1 .1 Clean Wing . . . . . . . . . . . . . . . . 38

3.1.2 Isolated Trailing Edge Blowing . . . . . . . . . . . . 39

3.2 TPS Mounted . . . . . . . . . . . . . . . . . 44

3.2.1 Low Pylon Height . . . . . . . . . . . . . . . . . . . 44 
3.2 .2 High Pylon Height . . . . . . . . . . . . . . . . . 45

4 Data Repeatability and Uncertainty Analysis 50

4.1 Repeatability Analysis Method . . . . . . . . . . . . . . 51

4.2 Factors Contributing to Non-Repeatability . . . . . . . . . . 67

4.2.1 Balance Calibration Accuracy . . . . . . . . . . . . . 67

4.2 .2 Angle of Attack . . . . . . . . . . . . . . . . 68

4.2 .3 Flow Conditions . . . . . . . . . . . . . . . . . . . . 81

4.3 Uncertainty Summary . . . . . . . . . . . . . . . . 8 86

5 Aerodynamic Performance Results $\quad 90$

6 Conclusions and Suggestions for Future Work 111

$\begin{array}{ll}\text { Bibliography } & 115\end{array}$ 


\section{List of Tables}

2.1 Wing dimensions $\ldots \ldots \ldots \ldots \ldots \ldots$

2.2 Slot height summary . . . . . . . . . . . . . . . . . . 14

2.3 Flow conditions . . . . . . . . . . . . . . . . . . . . 28

2.4 Nozzle pressure ratio . . . . . . . . . . . . . . . . . . 30

2.5 Nominal TPS operating conditions . . . . . . . . . . . . 31

4.1 Repeat run numbers . . . . . . . . . . . . . . . . . . 52

4.2 Balance calibration accuracy . . . . . . . . . . . . . . . 68

4.3 Flow condition repeatability . . . . . . . . . . . . . . 83

4.4 HPA temperature repeatability . . . . . . . . . . . . 84

4.5 Summary of force and moment coefficient repeatability . . . . . 87

4.6 Model pressure repeatability . . . . . . . . . . . . . . . . . . . 89

5.1 Test statistics $\ldots \ldots \ldots \ldots \ldots \ldots \ldots$ 


\section{List of Figures}

1.1 AMELIA concept renderings . . . . . . . . . . . . . . 2

2.1 Aerial view of the NFAC $\ldots \ldots \ldots \ldots \ldots$

2.2 AMELIA internal layout $\ldots \ldots \ldots \ldots \ldots$

2.3 AMELIA mounted in the NFAC . . . . . . . . . . . . . 9

2.4 Wing planform . . . . . . . . . . . . . . . . 11

2.5 Low pressure supply . . . . . . . . . . . . . . . . . . . . . 12

2.6 Wing section and plenum detail . . . . . . . . . . . . . . 13

2.7 Spanwise flow uniformity . . . . . . . . . . . . . . . 15

2.8 High pressure supply . . . . . . . . . . . . . . . . . . . . . . . . 18

2.9 Wing pressure ports $\ldots \ldots \ldots \ldots \ldots$

2.10 Wing planform with plenum instrumentation . . . . . . . . . 24

2.11 Aft view of AMELIA mounted in the NFAC . . . . . . . 24

2.12 CAD view of TPS core and fan flow instrumentation . . . . . 26

3.1 Representative clean wing $C_{L}$ vs. $\alpha$ performance . . . . . . 39

3.2 Representative clean wing $C_{L}$ vs. $C_{D}$ performance . . . . . 40

3.3 Representative clean wing $C_{m}$ vs. $\alpha$ performance . . . . . . 40

3.4 Representative isolated TE blowing $C_{L}$ vs. $\alpha$ performance . . . 42

3.5 Representative isolated TE blowing $C_{L}$ vs. $C_{D}$ performance . . 43

3.6 Representative isolated TE blowing $C_{m}$ vs. $\alpha$ performance . . . 43

3.7 Low and high pylon heights . . . . . . . . . . . . . 44

3.8 Representative low pylon $C_{L}$ vs. $\alpha$ performance $\ldots \ldots \ldots \ldots$ 
3.9 Representative low pylon $C_{L}$ vs. $C_{D}$ performance . . . . . . . . 46

3.10 Representative low pylon $C_{m}$ vs. $\alpha$ performance . . . . . . . . 47

3.11 Representative high pylon $C_{L}$ vs. $\alpha$ performance . . . . . . . . . . 48

3.12 Representative high pylon $C_{L}$ vs. $C_{D}$ performance . . . . . . . . . 49

3.13 Representative high pylon $C_{m}$ vs. $\alpha$ performance . . . . . . . . 49

4.1 Group 1: repeatability statistical regression results . . . . . . . 56

4.2 Group 2: repeatability statistical regression results . . . . . . . . 57

4.3 Group 3: repeatability statistical regression results . . . . . . . 58

4.4 Group 4: repeatability statistical regression results . . . . . . . . 59

4.5 Group 5: repeatability statistical regression results . . . . . . . 60

4.6 Group 7: repeatability statistical regression results . . . . . . . . 61

4.7 Group 8: repeatability statistical regression results . . . . . . . . 62

4.8 Group 9: repeatability statistical regression results . . . . . . . 63

4.9 Group 10: repeatability statistical regression results . . . . . . . . 64

4.10 Group 12: repeatability statistical regression results . . . . . . . 65

4.11 Group 13: repeatability statistical regression results . . . . . . . 66

4.12 Balance calibration accuracy . . . . . . . . . . . . . . 69

4.13 Group 1: balance calibration accuracy bounds . . . . . . . . . . . 70

4.14 Group 2: balance calibration accuracy bounds . . . . . . . . . . 71

4.15 Group 3: balance calibration accuracy bounds . . . . . . . . . . . 72

4.16 Group 4: balance calibration accuracy bounds . . . . . . . . . . 73

4.17 Group 5: balance calibration accuracy bounds . . . . . . . . . . . 74

4.18 Group 7: balance calibration accuracy bounds . . . . . . . . . . . 75

4.19 Group 8: balance calibration accuracy bounds . . . . . . . . . 76

4.20 Group 9: balance calibration accuracy bounds . . . . . . . . . . 77

4.21 Group 10: balance calibration accuracy bounds . . . . . . . . . . 78

4.22 Group 12: balance calibration accuracy bounds . . . . . . . . . . 79

4.23 Group 13: balance calibration accuracy bounds . . . . . . . . . . 80

5.1 Isolated trailing edge blowing, $C_{L}$ vs. $\alpha \ldots \ldots . . \ldots . . . . . .92$

5.2 Isolated trailing edge blowing, $C_{L}$ vs. $C_{D} \ldots \ldots 93$ 
5.3 Isolated trailing edge blowing, $C_{m}$ vs. $\alpha \ldots \ldots 93$

5.4 Increasing flap deflection, $C_{L}$ vs. $\alpha \ldots \ldots \ldots$

5.5 Increasing flap deflection, $C_{L}$ vs. $C_{D} \ldots \ldots \ldots$

5.6 Increasing flap deflection, $C_{L}$ vs. $\alpha \ldots \ldots \ldots$

5.7 Increasing flap deflection, $C_{L}$ vs. $C_{D} \ldots \ldots \ldots \ldots$

5.8 Powered-lift matrix, $C_{L}$ vs. $\alpha \ldots \ldots \ldots \ldots \ldots$

5.9 Powered-lift matrix, $C_{L}$ vs. $\alpha \ldots \ldots \ldots \ldots$

5.10 Variation in thrust coefficient, $C_{L}$ vs. $\alpha \ldots \ldots \ldots$

5.11 Variation in thrust coefficient, $C_{L}$ vs. $C_{D} \ldots \ldots \ldots$

5.12 Variation in thrust coefficient, $C_{m}$ vs. $\alpha \ldots \ldots \ldots 101$

5.13 Variation in thrust coefficient, $C_{L}$ vs. $\alpha \ldots \ldots \ldots 2$

5.14 Variation in thrust coefficient, $C_{L}$ vs. $C_{D} \ldots \ldots \ldots \ldots$

5.15 Variation in thrust coefficient, $C_{m}$ vs. $\alpha \ldots \ldots \ldots$

5.16 Performance of high and low engine pylon height, $C_{L}$ vs. $\alpha \ldots 104$

5.17 Performance of high and low engine pylon height, $C_{L}$ vs. $C_{D} \ldots 105$

5.18 Performance of high and low engine pylon height, $C_{m}$ vs. $\alpha \ldots 105$

5.19 Model configuration performance, $C_{L}$ vs. $\alpha \ldots \ldots \ldots$

5.20 Model configuration performance, $C_{L}$ vs. $C_{D} \ldots \ldots \ldots$

5.21 Model configuration performance, $C_{m}$ vs. $\alpha \ldots \ldots$

5.22 Inboard wing $C_{P}$ vs. ${ }^{Z} / c$ comparison . . . . . . . . . . . . 109

5.23 Outboard wing $C_{P}$ vs. $Z / c$ comparison $\ldots \ldots \ldots \ldots$

6.1 Crew Photo . . . . . . . . . . . . . . . . . . . . . . . 114 


\title{
Nomenclature
}

\author{
Acronyms \\ $A E D C \quad$ Arnold Engineering Development Center \\ $A I A A \quad$ American Institute of Aeronautics and Astronautics \\ AMELIA Advanced Model for Extreme Lift and Improved Aeroacoustics \\ CCW Circulation Control Wing \\ CESTOL Cruise Efficient, Short Take-Off and Landing \\ CFD Computational Fluid Dynamics \\ CNPR Core Nozzle Pressure Ratio \\ $D A S \quad$ Data Acquisition System \\ ERA Environmentally Responsible Aviation \\ FISF $\quad$ Fringe Imaging Skin Friction \\ FNPR Fan Nozzle Pressure Ratio \\ HPA High Pressure Air \\ LEIB Leading Edge Inboard \\ LEOB Leading Edge Outboard \\ $M R S A \quad$ Multivariable Regression Statistical Analysis \\ NFAC National Full-Scale Aerodynamics Complex \\ NPR Nozzle Pressure Ratio \\ NRA NASA Research Announcement
}




\begin{tabular}{|c|c|}
\hline$R A N S$ & Reynolds-Averaged Navier-Stokes \\
\hline$S E$ & Standard Error \\
\hline$S F W$ & Subsonic Fixed Wing \\
\hline$S T O L$ & Short Take-Off and Landing \\
\hline TEIB & Trailing Edge Inboard \\
\hline TEOB & Trailing Edge Outboard \\
\hline \multicolumn{2}{|c|}{ English Symbols } \\
\hline$c$ & wing chord \\
\hline$C_{A}$ & axial force coefficient \\
\hline$C_{D}$ & drag coefficient \\
\hline$C_{L}$ & lift coefficient \\
\hline$C_{\mu}$ & momentum coefficient \\
\hline$C_{m}$ & pitching moment coefficient \\
\hline$C_{N}$ & normal force coefficient \\
\hline$C_{P}$ & pressure coefficient \\
\hline$C_{P}^{*}$ & critical pressure coefficient \\
\hline$C_{T}$ & thrust coefficient \\
\hline$D$ & diameter \\
\hline$h$ & local slot height \\
\hline$K$ & order of least-squares curve fit \\
\hline$\dot{m}$ & mass flow rate \\
\hline$M$ & Mach number \\
\hline$N$ & total data sample size \\
\hline$P$ & pressure \\
\hline$q$ & dynamic pressure \\
\hline$R$ & gas constant \\
\hline
\end{tabular}




$\begin{array}{ll}R^{2} & \text { coefficient of determination } \\ R e & \text { Reynolds number } \\ S_{r e f} & \text { wing reference area } \\ T & \text { temperature } \\ u & \text { velocity } \\ X, Y, Z & \text { coordinate directions } \\ Y & \text { a variable }\end{array}$

\section{Greek Symbols}

$\begin{array}{ll}\alpha & \text { angle of attack } \\ \delta & \text { deflection angle or pressure ratio } \\ \Delta & \text { residual or incremental coefficient } \\ \eta & \text { non-dimensional semi-span location } \\ \gamma & \text { specific heat ratio } \\ \rho & \text { density }\end{array}$

\section{Subscripts}

$\begin{array}{ll}c & \text { mean aerodynamic chord } \\ \infty & \text { freestream property } \\ i & \text { an index } \\ j, \text { jet } & \text { with respect to the jet flow } \\ T, 0 & \text { total or stagnation property }\end{array}$




\section{Chapter 1}

\section{Introduction}

With the advent of the Environmentally Responsible Aviation Project (ERA), NASA has showed its continued support for the need to research technologies that will enable the next generation of regional commercial transports to fly quieter, on less fuel, and produce fewer emissions. Increased congestion at airports, and noise regulations have prompted NASA to evaluate how short take-off and landing (STOL) capabilities can be integrated into cruise efficient geometries, enabling larger airplanes to operate within the existing infrastructure of smaller

civilian airports [1]. One specific project, with goals similar to those of ERA, is a NASA Research Announcement (NRA) funded by NASA's Subsonic Fixed Wing Program (SFW). The project focuses on the design and wind tunnel test of a low-noise, cruise efficient, short take-off and landing (CESTOL) airliner that will improve prediction methods and technologies that can enable lower noise, emissions, and fuel burn [2]. Starting in 2007, California Polytechnic State University, San Luis Obispo, began the first of two phases of a 5-year NRA to develop a typical $\mathrm{N}+2$ airplane configuration that addresses the currently perceived needs of the civilian air transportation system. The second phase of the project focused 
on planning and executing a large-scale wind tunnel test using the configuration design from the first phase. The overall goal of the project is to generate validation data for Computational Fluid Dynamics (CFD) prediction tools that model aircraft with next generation capabilities. Developing a complete aircraft experimental database with the intent of validating predictive tools, able to predict the complex flow physics that an advanced transport presents, offers the unique prospect of reducing wind tunnel testing costs and the design cycle time of the next generation jet transport [3]. Cal Poly's design, AMELIA (Advanced Model for Extreme Lift and Improved Aeroacoustics), is seen in Figure 1.1. This novel configuration utilizes circulation control wings (CCW) through leadingand trailing-edge blowing, as well as over-the-wing mounted engines. Technologies aimed at progress towards improved noise and field length performance are the focal point of the configuration.
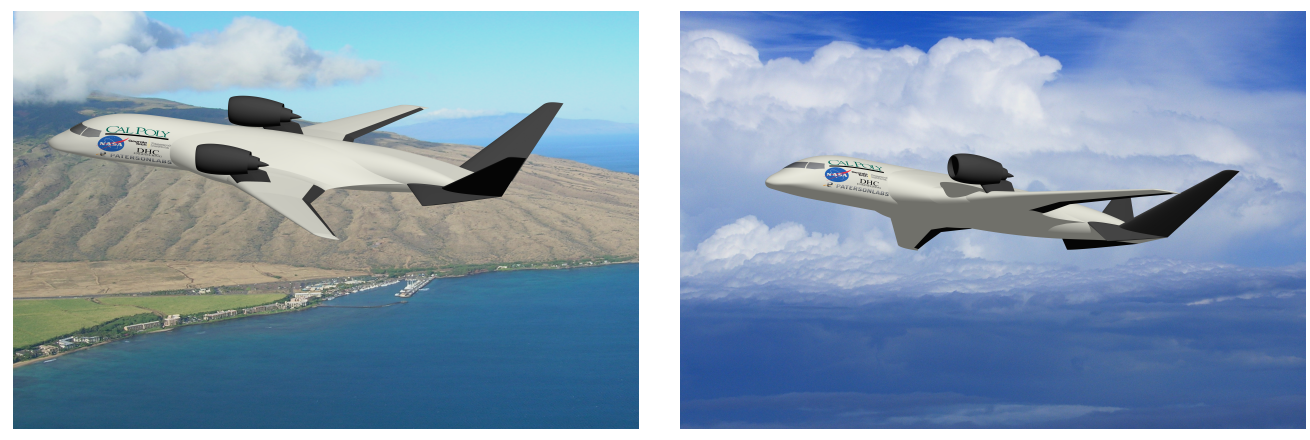

\section{Figure 1.1: CAD Renderings of the AMELIA CESTOL Concept}

The use of circulation control (and other advanced flow control systems) coupled with advanced propulsion technologies can enable aircraft to exceed the take-off and landing goals and stringent noise regulations that accompany the escalating airport congestion, and meet the goals laid out by NASA's N+2 generation. The current work focused on evaluating technologies, specifically those to improve noise and field length performance, with a technology readiness level of 
4 to 6 with the aim of implementing an aircraft of similar design by 2020 (designated $\mathrm{N}+2$ ). The $\mathrm{N}+2$ goals are defined as a $25 \%$ reduction in aircraft fuel burn, $-52 \mathrm{~dB}$ cumulative noise reduction below Federal Aviation Regulation 36 Stage $3,80 \%$ reduction in aircraft emissions, and a field length of less than $3000 \mathrm{ft}$.

The literature is well documented with publicly available research efforts focused on circulation control testing intended for CFD validation $[4,5,6,7,8,9]$. The majority of these tests, though, focus on 2-D, constant chord models with only trailing edge blowing. There are, however, significantly fewer efforts for 3-D tests with complete aircraft configurations. Collins [10] and Lin [11] completed a 3-D test of a full-span, hybrid wing STOL model with blown flaps. Most recently, Milholen [12] documents the testing of a semi-span model with trailing edge blowing; the model is intended to test circulation control concepts at realistic flight Reynolds numbers for both low speed and transonic cruise conditions. Whereas the smaller scale tests are still relevant to the CFD community because many of the issues presented to the numerics are common between the 2-D and 3-D simulations (e.g. boundary layer separation, shear layers, and wake interactions), the present effort seeks to not only identify these complex flow physics, but evaluate the highly coupled nature of these advanced flow control systems. This work seeks to fill the need for a complete aircraft configuration, open source, aerodynamic and acoustic data set intended for CFD validation.

This thesis focuses on the experimental efforts and resulting data generated from the wind tunnel test completed in February, 2012. It provides a concise presentation of the results gathered during the wind tunnel test, with a significant portion focusing on data repeatability and uncertainty analysis. 


\section{Chapter 2}

\section{Description of Experiment}

The dedicated test team from Cal Poly was comprised of Professors David Marshall and Tina Jameson, with support of graduate students Jonathan Lichtwardt and Eric Paciano. Full time support was provided by Rob Fong, Nate Burnside, and Clif Horne, from NASA Ames Research Center's Fluid Mechanics Laboratory. Additional support was provided by the Fluid Mechanics Laboratory's Rabi Mehta, Jim Ross, Kevin James, Ted Garbeff, and Barry Porter.

\subsection{Test Facility - NFAC}

The wind tunnel test was conducted in the 40 - by 80 -foot test section at the National Full-Scale Aerodynamics Complex (NFAC) located at NASA Ames Research Center, Moffett Field, California. The NFAC is leased and operated by the Air Force's Arnold Engineering Development Center (AEDC). There are two test sections at the NFAC, comprising the largest wind tunnels in the world - the 40- by 80 -foot and the 80 - by 120 -foot. The tunnels share a common fan drive, made up of six $40 \mathrm{ft}$ diameter, 15-blade, variable-pitch fans, each powered by a 
22,500 horsepower motor. An 8:1 contraction accelerates flow to a maximum test section velocity of $300 \mathrm{kts}$, or 0.45 Mach. There are no flow conditioning screens or treatments in the settling chamber or elsewhere in the circuit. The 40- by is a closed-circuit atmospheric wind tunnel with semi-circular walls, and a flat floor and ceiling. The test section walls are acoustically treated, permitting aerodynamic and acoustic data to be acquired simultaneously. The acoustic treatment is composed of sound absorbing fiberglass wedges sunken in cavities below the liner, bringing the actual test section dimensions to $39 \mathrm{ft}$ high by $79 \mathrm{ft}$ wide (at the horizontal centerline). The test section is instrumented with 192 wall pressure ports. The ports are sunk below the acoustic treatment of the $4 \mathrm{ft} \times 4 \mathrm{ft} \times 3.5 \mathrm{ft}$ cavities that line the tunnel walls. There are twelve streamwise rows of pressure ports, spaced around the perimeter of the test section. Each row contains 15 to 17 pressure ports in the streamwise direction. Before the contraction cone, the flow passes through a reference ring of four connected wall pressure ports; then, just before the flow enters the test section, the flow passes through a second set of four connected wall pressure ports. Test section dynamic pressure is obtained from the difference of these two rings, with a correction applied. Tunnel centerline static pressure is obtained from the second set of static rings, with a correction applied. An aerial view of the NFAC is provided in Figure 2.1.

The model utilized the NFAC's high pressure air (HPA) system. The facility system provided dry, heated air to AMELIA in two separate flow paths, each regulated by a 14-poppet Emco Digital Valve. The facility is capable of providing much greater flow capacity than what was required. The engine simulators were supplied air at up to $2 \mathrm{lbm} / \mathrm{sec}$ at $190 \mathrm{psig}$ and $110^{\circ} \mathrm{F}$. The engine simulator air supply is routed internally through the sting/model support system. The CCW blowing plenums, or slots, were supplied up to $2.8 \mathrm{lb} / \mathrm{sec}$ at $210 \mathrm{psig}$ and 
$110^{\circ} \mathrm{F}$. The slot blowing air supply is routed externally through a 3 in diameter braided steel flex hose. The flex hose connects to the orifice plate assembly before terminating at the bottom of the blade attachment, see Figure 2.11.

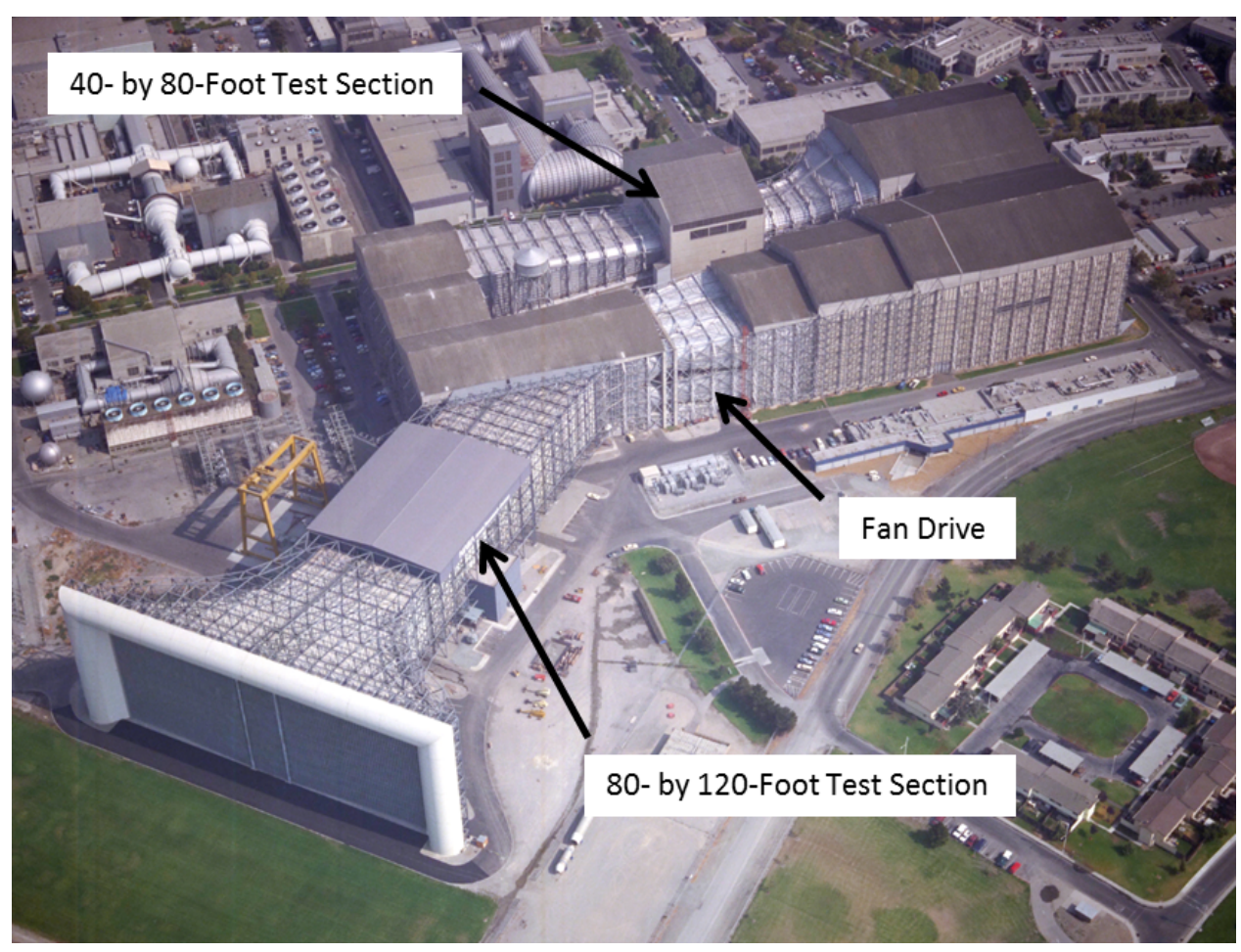

Figure 2.1: Aerial view of the National Full-Scale Aerodynamics Complex. ${ }^{1}$

In selecting the wind tunnel for the test, Cal Poly was cognisant of choosing a tunnel that was sufficiently large to accomodate the downwash created by the circulation control wings (predicted to be at least 1 span below the model) with minimum interference from the tunnel walls. With the NRA constraining the wing span to greater than $8 \mathrm{ft}$, and as aerodynamic and acoustic measurements were to be taken, the availability of wind tunnels across the country was limited. The NFAC was the only tunnel that could support the expected model loads, HPA requirements, and downwash created by the CCW within Cal Poly's budget

\footnotetext{
${ }^{1}$ Image courtesy of the National Full-Scale Aerodynamics Complex
} 
and calendar constraints. The NFAC is located in close proximity to Cal Poly. Though this was not a factor in the final trade studies, it was of great convenience and contributed to improved communication in test planning and execution.

\subsection{Test Article - AMELIA}

The Advanced Model for Extreme Lift and Improved Aeroacoustics, shown in Figure 2.2, served as the test article. AMELIA is a $1 / 11^{\text {th }}$ scale, $10 \mathrm{ft}$, full span model with leading- and trailing-edge blowing wing circulation control and over-the-wing mounted engine simulators. Here, circulation control is achieved by blowing a tangential jet onto a highly curved aerodynamic surface through slots at the leading- and trailing-edges of the wing. The outer mold lines of AMELIA form a hybrid blended wing body, whose design stems directly from NASA's N+2 generation goals. The design work was largely the focus of the first phase of the project in which this configuration was traded between three other concepts. The reader is encouraged to refer to Reference [13] for further detailed information regarding the model's design.

In the tunnel, the model is sting supported and mounted on a faired blade, sitting just over $2 \mathrm{ft}$ above the test section centerline. The blade and sting mounting provided the best solution to non-intrusively support the model. Figure 2.3 shows the model mounted in the test section. The acoustic instruments -7 sideline microphones and the 48-element phased microphone array - can be seen in the figure as well.

The model was manufactured to be modular. The engine simulators sit atop removable pylons, enabling testing at 2 different engine heights. The empennage were manufactured, although the model was tested with the tails removed. Future 


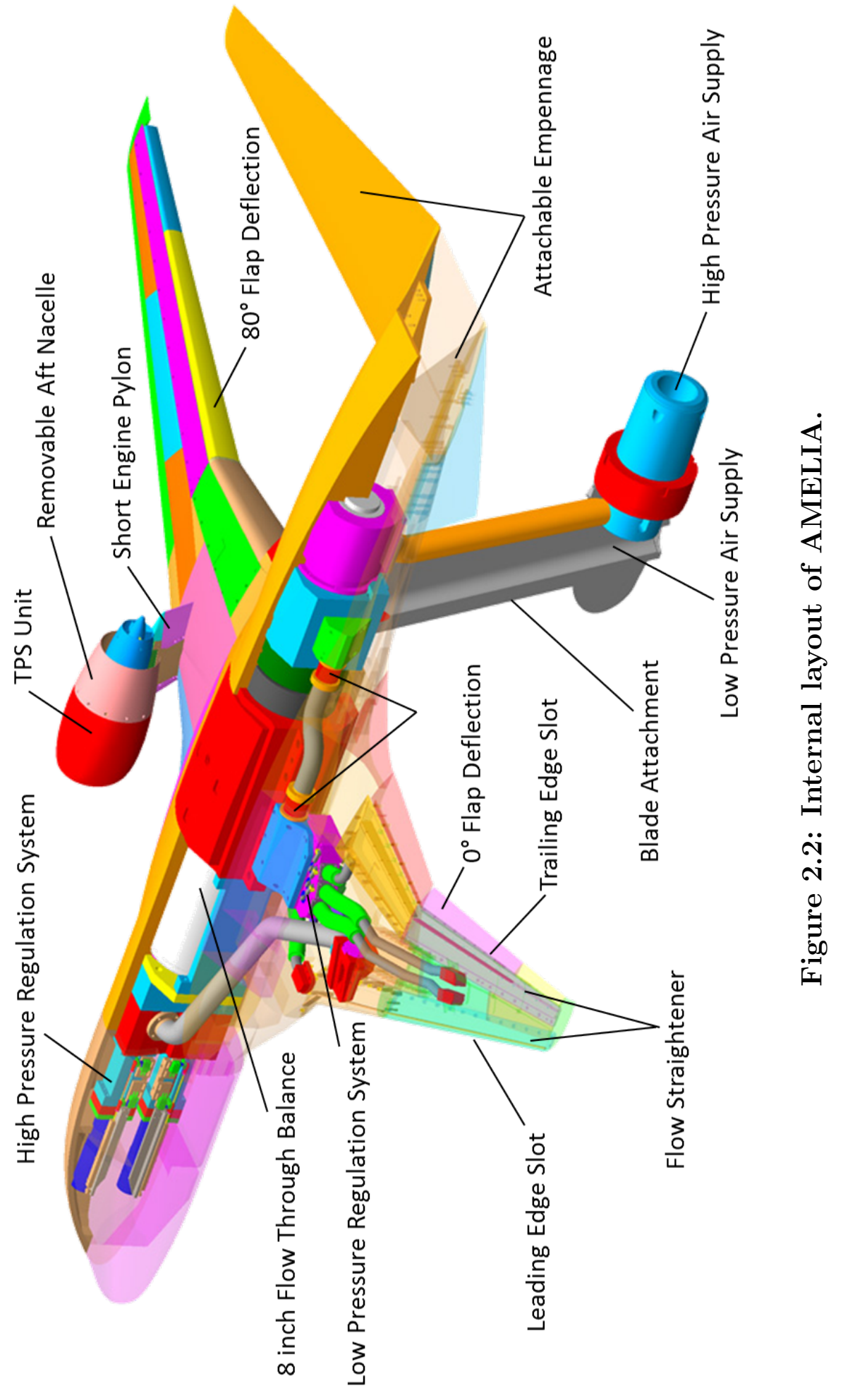




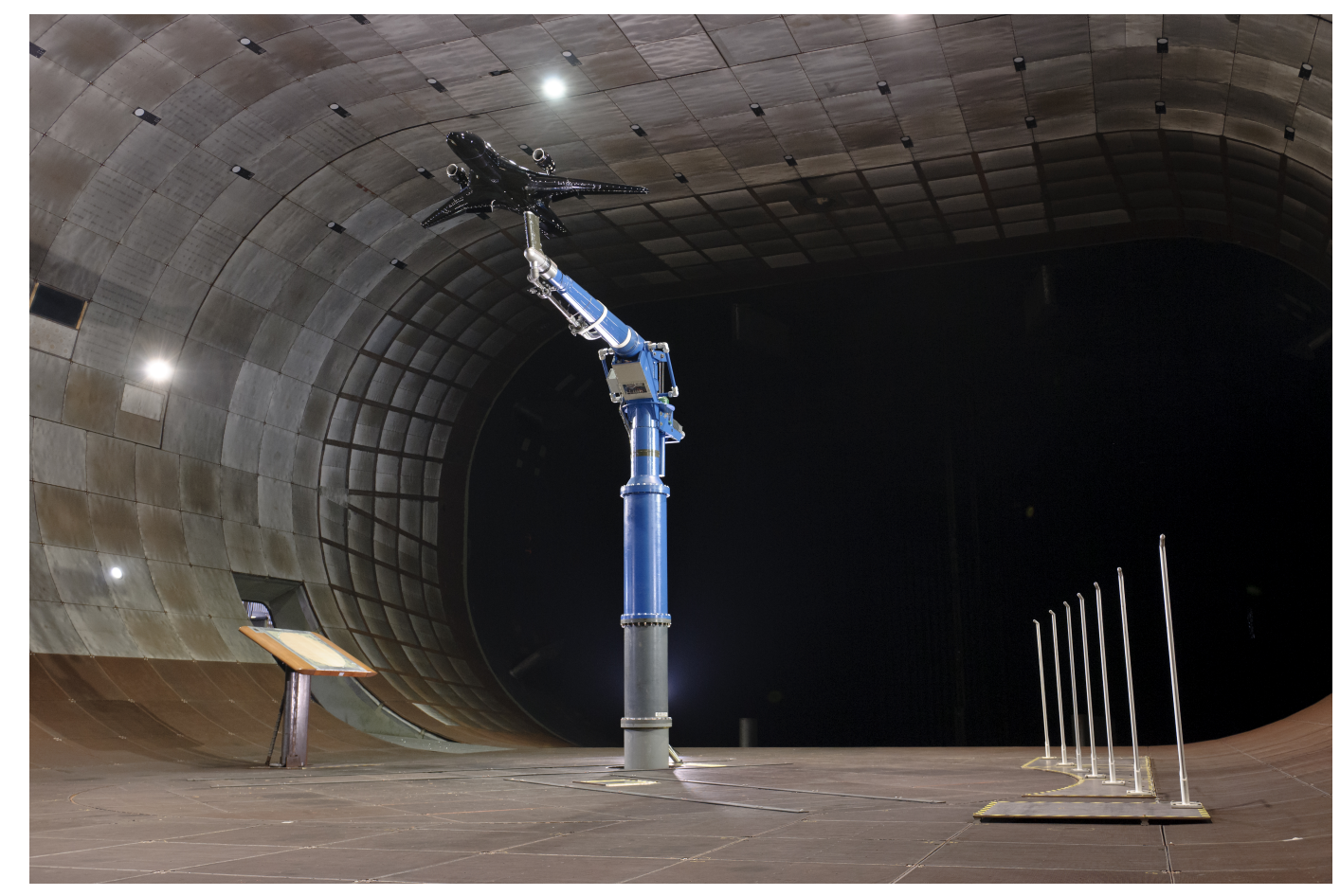

Figure 2.3: AMELIA mounted in the 40- by 80 -foot test section at the NFAC.

testing with the other surfaces attached would greatly supplement this already extensive data set. The model was manufactured by Patersonlabs, Inc., the larger fuselage sections are made primarily from aluminum and the wing is made primarily from stainless steel. Patersonlabs applied a black Imron paint coating, giving the model its black finish. The Imron coating is highly reflective, giving the surface a mirror-like finish which is required for the oil interferometry method employed.

The wing section is a NASA SC(2)-0414 supercritical airfoil, modified to accommodate the circulation control slots and dual-radius flaps, see Figure 2.6. There are four removable dual-radius flaps, with deflections of $0^{\circ}, 30^{\circ}, 60^{\circ}$ and $80^{\circ}$. The wing has a reference area of $15.8 \mathrm{ft}^{2}$, an aspect ratio of 6.33 , a taper ratio of 0.174 , and there is no dihedral. Figure 2.4 presents the wing planform and defines the wing reference area. The chord length at the start of the inboard 
slot is $32.7 \mathrm{in}$ and the mean aerodynamic chord is $22.4 \mathrm{in}$. The mean aerodynamic chord is calculated assuming the wing is linearly tapered from root to tip. The wing dimensions are summarized in Table 2.1.

Table 2.1: General wing dimensions.

\begin{tabular}{cc} 
Parameter & Value \\
\hline Wing span & $10 \mathrm{ft}$ \\
Wing area, $S_{\text {ref }}$ & $15.8 \mathrm{ft}^{2}$ \\
Aspect ratio & 6.33 \\
MAC & $22.4 \mathrm{in}$ \\
Taper ratio & 0.174 \\
Tip chord & $5.7 \mathrm{in}$ \\
Root chord & $32.7 \mathrm{in}$ \\
\hline
\end{tabular}

\subsubsection{Slot Blowing System - Low Pressure Supply}

The low pressure air supply, shown in Figure 2.5, provides the air for each of AMELIA's 8 circulation control plenums. Air is routed externally across the sting, up through the blade attachment where it splits into the left and right sides at the blade/model interface. Refer to Figure 2.11 for a picture of the external low pressure flow path. Upon entering the model, air is routed through the balance external flow path and into the low pressure distribution plenum. The low pressure distribution plenum is the manifold in which the air flow to each wing is controlled via 4 butterfly valves. Rotary potentiometers provide position feedback for the $24 \mathrm{VDC}$ gear motors that drive the butterfly valves. In Figure 2.5, the piping of the left wing is highlighted and the plenums are labeled as they are defined in Section 2.3, Test Measurements and Instrumentation. 


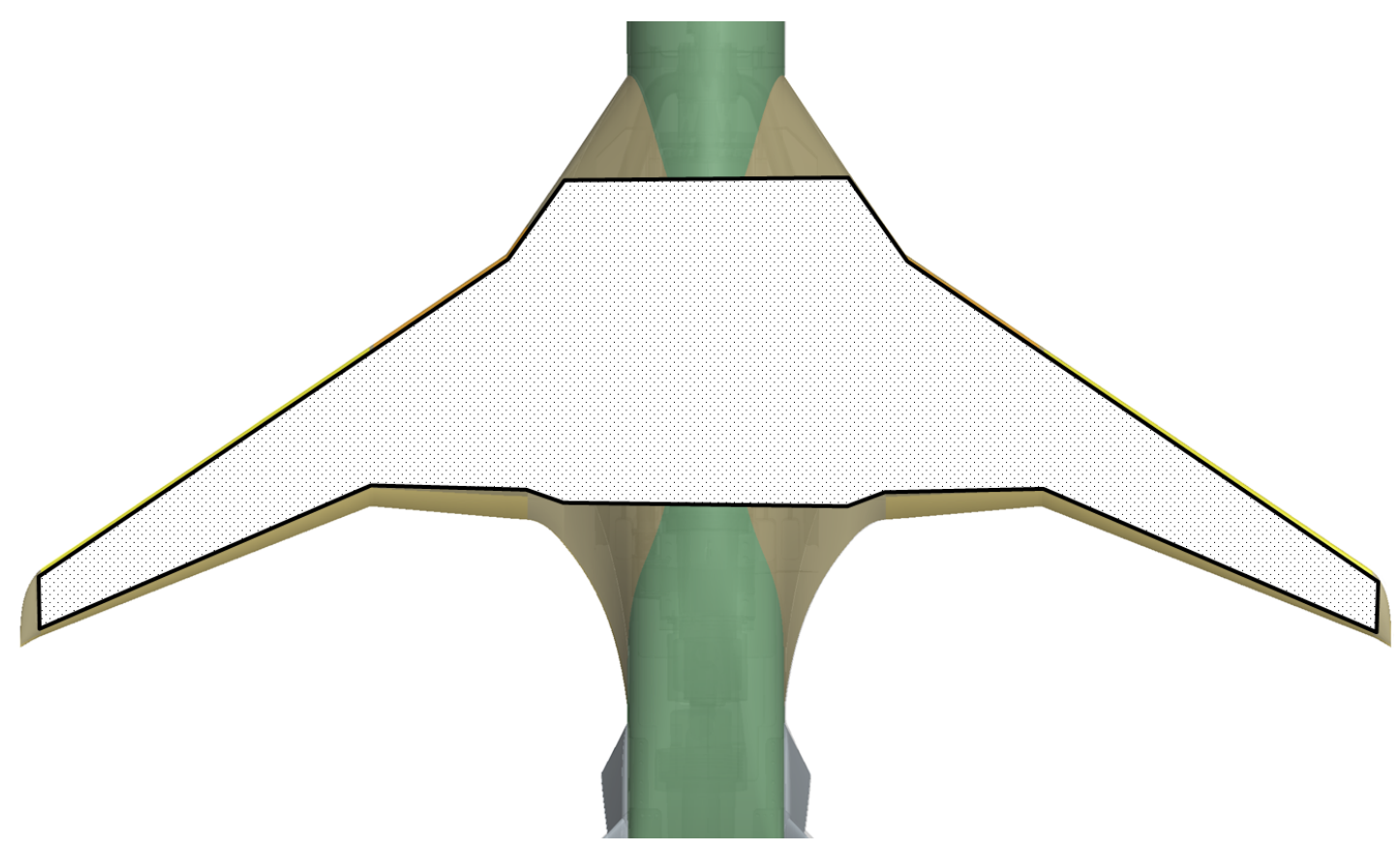

Figure 2.4: Wing planform and reference area definition.

The leading- and trailing-edge plenums have a contraction ratio of 15:1. The plenums span the majority of the wing, however there is a small unblown region at the break of the inboard and outboard plenums on the leading- and trailingedges. The design slot height to chord ratio is 0.00143 at the leading edge and 0.00238 at the trailing edge. The leading edge $h / c$ holds until the local slot height reaches $0.012 \mathrm{in}$, where it maintains this height until the end of the slot. A nominal cross-section view of the wing, with the $80^{\circ}$ flap deflection and plenum details highlighted, is shown in Figure 2.6.

As seen in the figure, the trailing edge slot height is set and secured using a push-pull system consisting of set-screws to hold the plenum under compression, and tie-downs to hold the slot height under pressurization. This system has seen past success in tests by Englar [14] and Cattafesta [9]. Static and pressurized measurements of the slot height were taken using a Capacitec Gapmaster3 and showed variations due to pressurization to be within the scatter of the uncertainty 


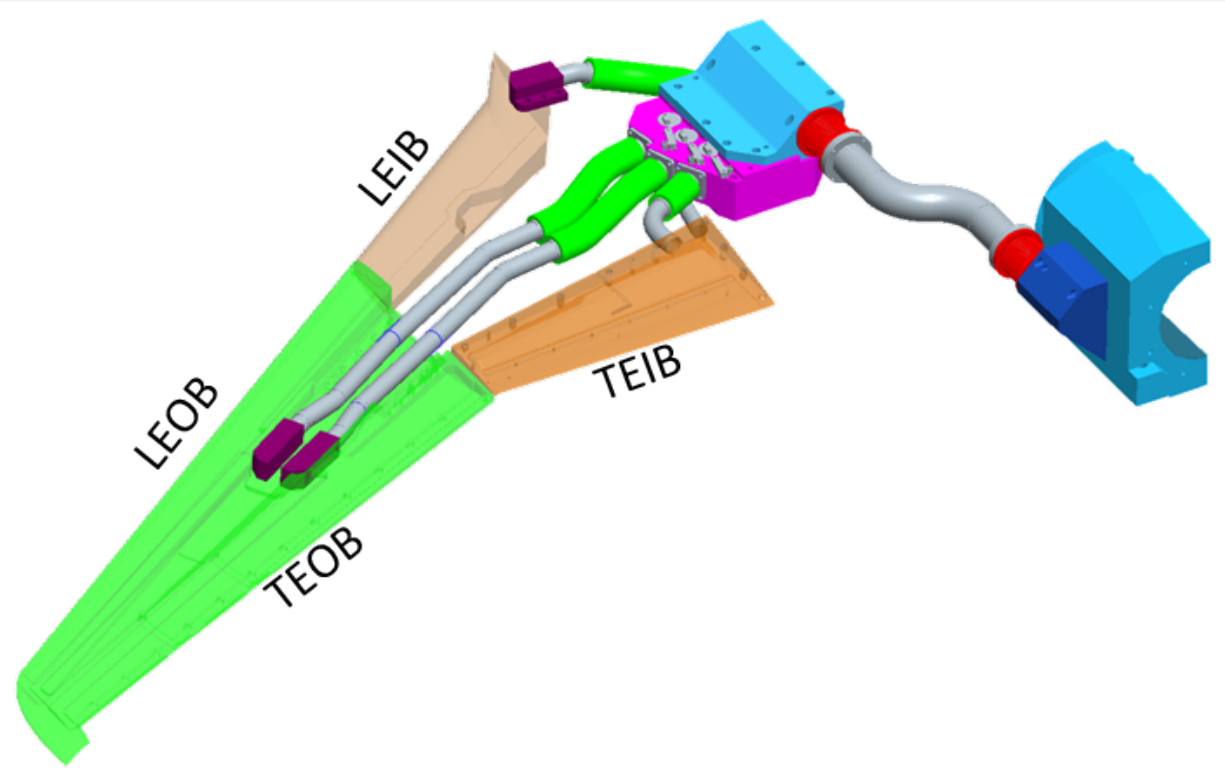

Figure 2.5: Low pressure air supply.

of the measurement, $\pm 0.00121 \mathrm{in}$. The leading edge slot does not have a similar push-pull system due to the required material thicknesses on the lower wing panel. As a result, the leading edge slot height is fixed once the panel has been fastened to the model.

The as-tested slot height to chord ratio is provided in Table 2.2. The data is generated by fitting a linear curve to the individual slot height measurements given by Paciano [15]. Trailing edge slot height symmetry between left and right wings falls within the overall $95 \%$ uncertainty interval of $\pm 0.00121 \mathrm{in}$. Overall, there is a $6 \%$ deviation between the design and as-tested slot height to chord ratio. It is worth noting that though it is important to match the parameters to which the model was designed, it should not be viewed as a metric of success or failure. It is not the goal of this project to validate a design, or test a model to a design. The design merely serves as a backdrop to the variety of data that has been generated in the hopes it can be used to test numerical codes. 

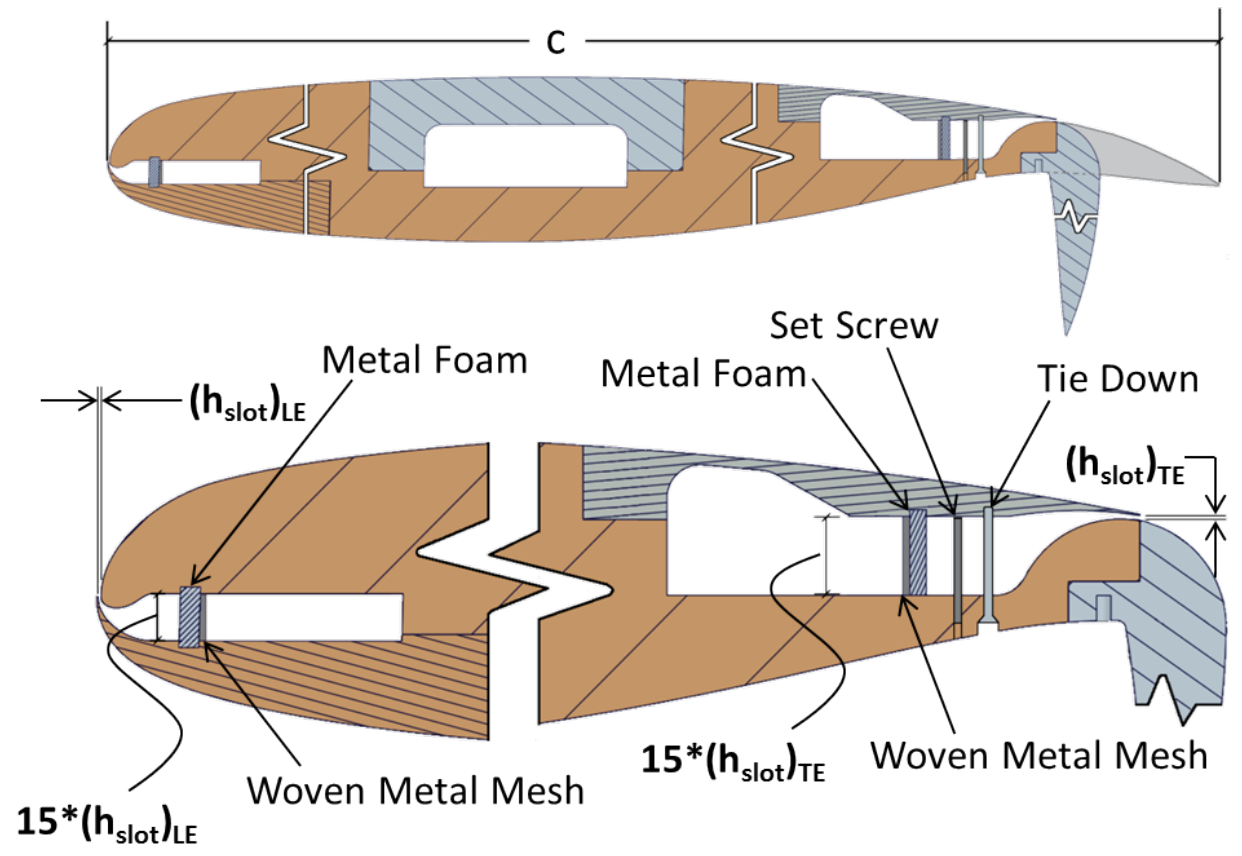

Figure 2.6: Nominal wing section and circulation control plenum details.

It should be noted that a portion of slot height measurements in the LEOB plenum were made with feeler gauges instead of the Gapmaster. The height and curvature in the slot, from about the half plenum span to the tip, prevent the Gapmaster wand from making a measurement. Human repeatability was assessed and values are averaged between two individual's measurements. Human repeatability was seen on the order of 1-2 thousandths of an inch with the feeler gauges.

A significant portion of pre-test resources were devoted to the characterization of the slot flow. The goal of the characterization was to achieve a level of familiarity with the air systems prior to wind tunnel testing and to make more detailed flow measurements, for the sake of CFD boundary conditions, than were going to be acquired during wind tunnel testing. The characterization is de- 
Table 2.2: Average slot height to chord ratio for the left and right wings.

\begin{tabular}{ccc}
\hline Plenum & Left Wing & Right Wing \\
\hline LEIB & 0.00133 & 0.00142 \\
LEOB & 0.00245 & 0.00233 \\
TEIB & 0.00244 & 0.00248 \\
TEOB & 0.00244 & 0.00249 \\
\hline
\end{tabular}

scribed elsewhere by Paciano [15] and is the primary subject of a soon to be published Masters Thesis. During the characterization, upon initial pressurization of the low pressure system, a significant flow quality issue stemming from the leading edge slots was realized. The shape and design of the inlet to the LEOB plenum created a highly vortical and 3-D flow through the slot and across the wing upper surface. The slot flow was nonuniform with respect to both the spanwise pressure distribution and the uniformity of the streamlines (which were visualized with pigmented gear oil). It took considerable effort to break up the three dimensionality of the flow and create an acceptable level of uniformity. In the end, the solution came through placing a combination of porous metal foam and a woven metal mesh in the plenum, as seen in Figure 2.6. This specific combination of treatments was able to sufficiently resist the oncoming flow and create the desired flow uniformity. The metal foam is a product manufactured by ERG Aerospace, and the woven metal mesh is a product called Rigimesh manufactured by Pall Corporation. A room temperature vulcanizing silicone was used to ensure the plenum was air tight near the fastener holes.

The successful application of the flow straightening treatment was verified during the wind-on oil flow visualization runs in the NFAC. Figure 2.7 shows a 


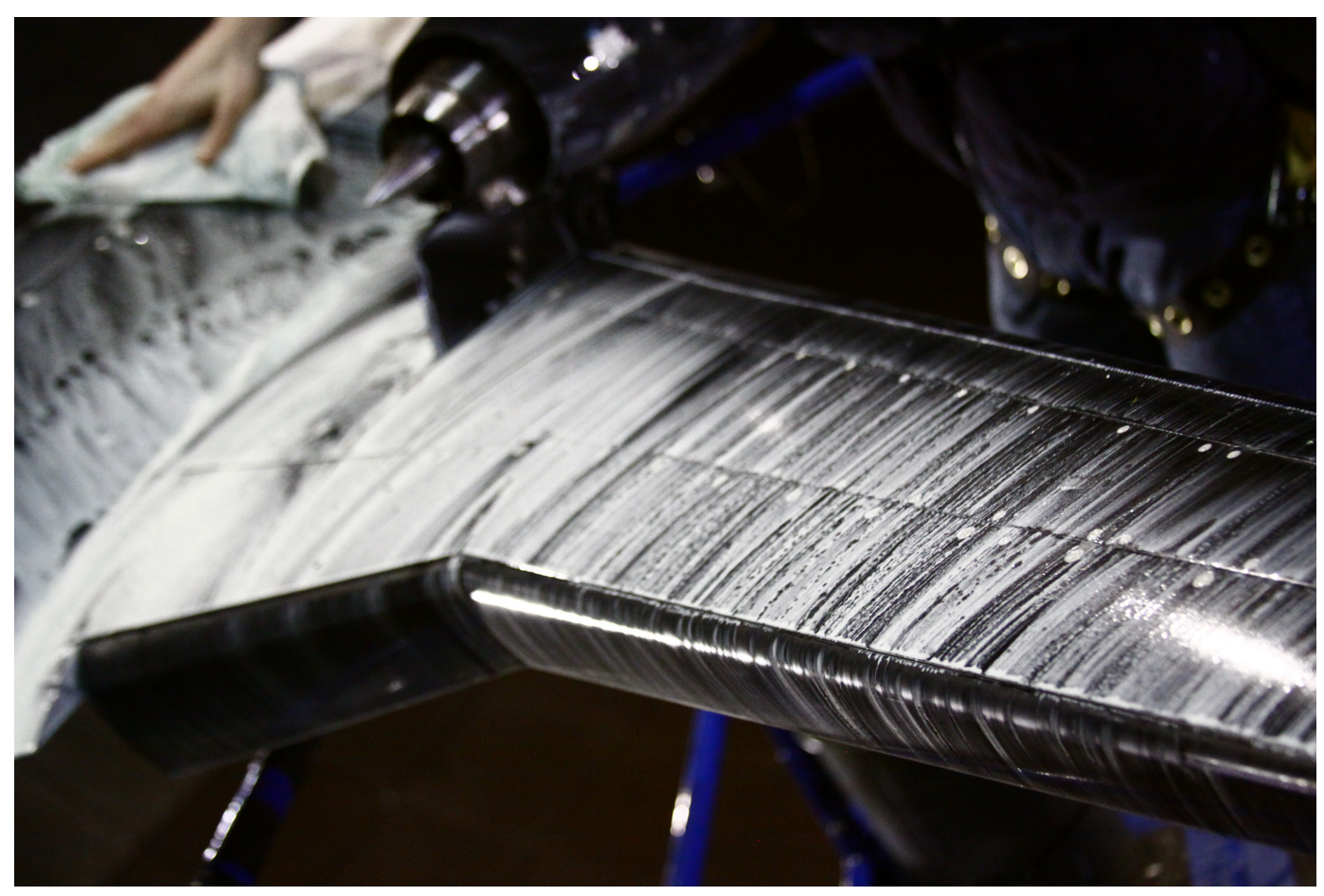

Figure 2.7: Oil flow visualization of spanwise flow uniformity.

picture taken during one of the oil runs, verifying the effectiveness during day to day operations.

The application of the metal foam and Rigimesh was able to break up the highly vortical flow and create uniform streamlines across the wing. The resulting spanwise variation in pressure is on the order of 1 psid to 2 psid for the inboard plenums and 3 psid to 4 psid for the outboard plenums. Whereas it would be ideal to have both uniform streamlines and a uniform pressure distribution across the plenums, it was not achievable in this case. The Cal Poly crew were under significant budget and time constraints during this calibration, which took upwards of 3 months to complete. The tunnel entry date was looming and the model build-up activities needed to proceed in order to maintain schedule. Once uniform streamlines were achieved, the decision was made to move on with the calibration, accepting the small pressure nonuniformities that exist across the 
span of a single plenum. The justification for this decision is simple. As this test is intended for CFD, it is significantly easier to prescribe a nonuniform pressure distribution across the span of a plenum - as, say, a boundary condition at the downstream side of the metal foam - than it is to prescribe a nonuniformity with respect to flow quality and streamlines. Measuring highly 3-D flows is not a trivial task and enforcing them numerically is not trivial. In other words, a nonuniform spanwise pressure distribution with uniform streamlines is quantifiable.

\subsubsection{TPS Units - High Pressure Supply}

The engine simulators are Tech Development, Inc. (TDI) model 441B turbine propulsion simulators. Three TPS units were loaned to Cal Poly from NASA Langley Research Center, serial numbers 1, 3 and 4. Serial number 3 was mounted in the right-hand nacelle and serial number 4 was mounted in the left-hand nacelle. The units were manufactured in the 1960's and have been used in numerous prior tests. The units were refurbished by TDI and functionally calibrated by Georgia Tech Research Institute in 2011 prior to wind tunnel testing. The units were calibrated in their fully installed configuration, i.e. assembled in the nacelle and pylon mounted. Calibration of serial number 1 was not completed due to a mechanical failure. Prior to model installation at the NFAC, the unit was repaired and on stand-by in the event of failure in one of the other units during testing.

The model 441 has a two stage fan that is driven by a three stage turbine. The turbine is powered by high pressure air delivered through one of the internal balance flow paths. Two independently operated needle valves located in the nose of the model control air flow to each TPS. The fan diameter is 5 in, the fan nozzle area is $9.53 \mathrm{in}^{2}$ and the turbine nozzle area is $4.21 \mathrm{in}^{2}$. The units have a 
maximum rating of $45,000 \mathrm{RPM}$ at $2.08 \mathrm{lb} / \mathrm{sec}$ and $425 \mathrm{psig}$. This corresponds to a fan pressure ratio of 1.55 . The nominal test RPM was $77 \%$ of maximum, or 34,500 RPM. Refer to Table 2.5 for the operating conditions at the nominal set-point.

The high pressure air system on AMELIA, shown in Figure 2.8, is fed through the internal sting air supply. Air passes from the sting, through the blade attachment and into the outermost of the balance's concentric internal air supplys. The maximum internal pressure of the balance is 600 psig. Downstream of the balance, air enters the high pressure air block where the flow split between left and right TPS is controlled by the needle valves. These mass flow plugs are driven by a linear potentiometer and can be positioned from fully open to fully closed. TPS control is described further in the next section, TPS Controls. The fully assembled high pressure air system from the sting attachment to the TPS is seen in Figure 2.8.

\section{TPS Controls}

Control to the TPS units came from two controllers being operated on separate systems. The two controllers provided the gross HPA (pressure, temperature, and mass flow) via the digital valves, and the individual TPS control via the needle valves internal to the model.

TPS control internal to the model was provided by a LabView controller operated by Cal Poly independent of the facility HPA controller. The controller operated the two independent flow paths: controlling the 8 butterfly valves on the low pressure side and the 2 needle valves on the high pressure side. The butterfly valves controlled the flow split between the individual slot blowing plenums and 


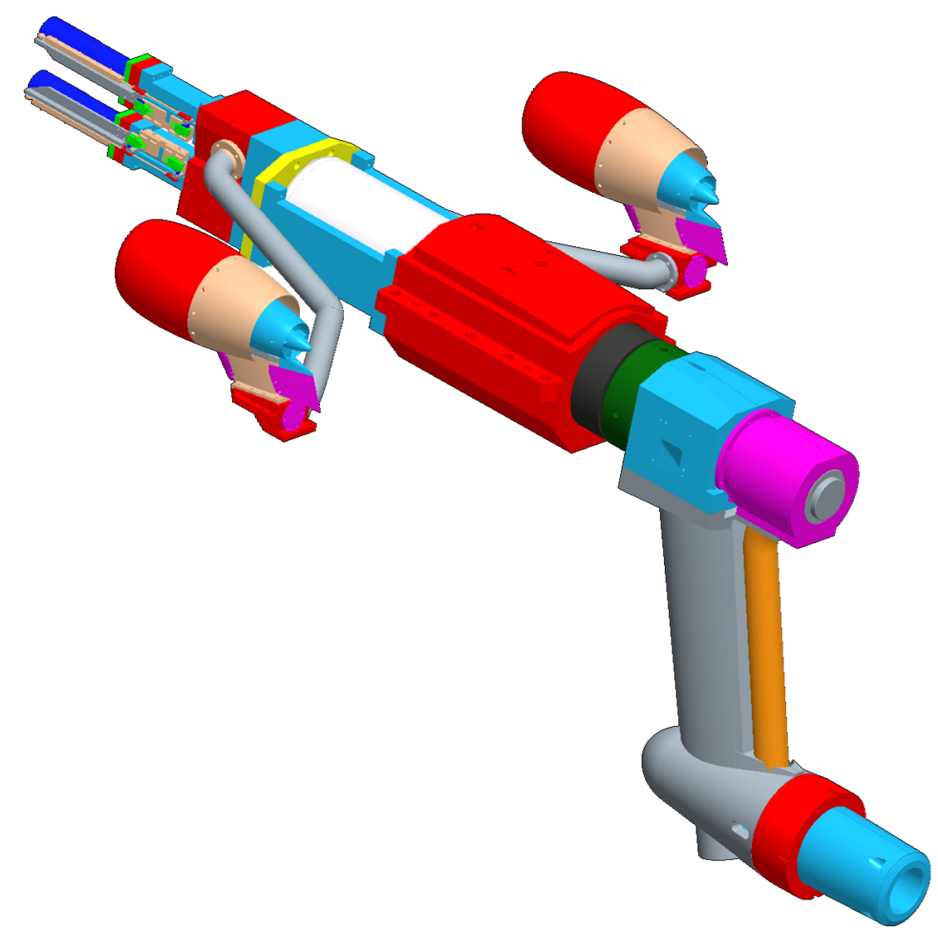

Figure 2.8: High pressure air supply.

the needle valves controlled the flow split between the left and right TPS units. The needle valves supplement the facility HPA controller. Facility HPA provided closed-loop "coarse" control of the air entering the model. Inside the model, the needle valves provided "fine" control to match left and right TPS performance. During testing, though, it was found that the facility HPA control was sufficient to match TPS performance within tolerance. As a result, the needle valves were left in the fully open configuration unless closed for safety or other reasons.

Facility HPA control has two modes of operation: flow control mode and pressure control mode. Flow control mode sets and maintains a constant mass flow rate, and pressure control mode holds a constant line pressure. RPM values hold truer in flow control mode because the turbine is driven by the mass flow rate being delivered, whereas the delivered pressure dictates the thrust produced. However in flow control mode, as line temperature increases, the pressure rises to 
maintain a constant mass flow rate thereby requiring more frequent adjustment during a run. In pressure control mode, as line temperature increases the mass flow rate does change, but operationally TPS performance is much less sensitive to the small mass flow rate changes. Accordingly, pressure control mode was used for the majority of TPS test points.

Traditionally, the drive air supplied to TPS units is heated to preclude exposure of the aft bearing to excessively low temperatures resulting from the expansion through the turbine, causing a failure. Upon operation of the model 441 units, however, an increase in drive air temperature resulted in increased aft bearing temperatures despite the nearly $-110^{\circ} \mathrm{F}$ flow temperature exiting the last turbine stage. Regulating the drive air temperature to $150^{\circ} \mathrm{F}$ resulted in aft bearing temperatures nearly reaching the safety-of-flight limit at $125^{\circ} \mathrm{F}$. This necessitated the change to lower the maximum operating condition from the intended $80 \%$ to $77 \%$, or $36,000 \mathrm{RPM}$ to $34,500 \mathrm{RPM}$, respectively. Drive air temperature was regulated at $110^{\circ} \mathrm{F}$. At $40 \mathrm{kts}$, this represents a reduction in thrust of $9.9 \mathrm{lb}_{\mathrm{f}}$, or $10 \%$. Other TPS instrumentation did not approach their safety-of-flight limits. The forward bearing temperature tracked the aft bearing and stayed below the limit of $225^{\circ} \mathrm{F}$. The maximum TPS set point for this test was well below the maximum rated RPM in order to preserve the lifetime of the units.

Due to the relative humidity in the tunnel circuit (as high as $80 \%$ ) and the line air temperature, small amounts of icing did occur on the back end of the TPS core. At points where appreciable ice accumulation was observed, ice was shed. Ice crystals extending 1-2 inches off the core are considered appreciable build up. Here, the TPS units were brought down to idle to let accumulated ice melt and then brought back up on-condition for a repeat point. This procedure 
could have been repeated as much as 4 times during a single polar. There were a small number of occurences where the repeat point was not taken, run sheets are annotated to reflect this. To avoid any non-linear aerodynamic interactions, deicing points were avoided whenever possible at higher angles of attack. There are no evident performance differences caused by the (de)icing of the TPS.

During model build-up, it was discovered that the thermal expansion of the brass needle valves restricted the 24 VDC motor's ability to actuate the valves in the internal HPA block. As the delivered HPA temperature was warmer than those experienced during build-up, the outer diameter of each needle valve was shaved 2-3 thousandths of an inch to provide relief. This had no operational effect on the TPS units during the test, unless testing in a one engine inoperative configuration. In this configuration, one needle valve is fully closed to simulate the lost engine; the point is repeated for the other side to get a full data set. Initial HPA checkout showed that a portion of flow was able to bypass the closed needle valve and spin the TPS to approximately 16,500 RPM. Maintaining operation of the valves at temperature allowed the needle position to be adjusted to compensate for the RPM differences between left and right sides that existed after the needle valves were machined down.

\subsection{Test Measurements and Instrumentation}

Aerodynamic forces and moments were measured using the Triumph Force Measurement Systems MC-130 8.0 inch, flow-through air balance. It is a 6component force balance with two concentric internal air flow paths and one external flow path. The propulsion simulators use one of the internal flow paths, and the slot blowing system uses the external flow path; the second internal 
flow path was not used. Forces are isolated on the external flow path through a system of bellows. The bellows system is designed to only excite the axial force gage when pressurized. This was observed during the characterization of the momentum flow effects through the balance and a tare was applied to the data. The balance calibration was performed by Triumph [16], and NASA Ames' Kevin James performed the calibration regression. The balance has a quoted accuracy of $\pm 0.5 \%$ full-scale, the as-calibrated capacity is provided in Table 4.2.

Angle of attack was measured using redundant clinometers mounted in the nose of the model. An analog Q-Flex model QA-2000 temperature compensated accelerometer and a Schaevitz gravity referenced tilt sensor were used. The Schaevitz sensor is the reference for the angle of attack measurement, it has a quoted accuracy of $\pm 0.05^{\circ}$.

The model is instrumented with 232 static pressure ports. The ports are arranged in one spanwise group and five chordwise groups, located at semi-span locations of: $\eta=0.179,0.364,0.758,0.967$ and 0.973 . The chordwise group at $\eta=0.364$ is on the engine centerline. The spanwise group is spaced along the semi-span on the upper and lower wing surfaces at approximately $30 \%$ chord. With the exception of 5 symmetric ports, the pressure taps are grouped on the left wing to keep the right wing clean for skin friction measurements. A cut-view of the model showing the chordwise groups is provided in Figure 2.9. The individual pressure taps are 0.020 in ID, and are connected to the pressure modules with 0.032 in urethane tubing. The pressure ports on a single buttline are clustered near the slots and on the flap surface. The model pressures were measured using the NFAC's PSI- Digital Temperature Compensated Initium system, with 2.5 psid and 15 psid electronically scanned pressure modules. Each module, which were stored in the nose, has 64 ports, with every $16^{\text {th }}$ port used as a reference 
pressure. The PSI-Initium system has a quoted accuracy of $\pm 0.05 \%$ of the fullscale reading. As applied to the two modules, the 2.5 psid module is accurate to \pm 0.001 psid and the 15 psid module is accurate to \pm 0.08 psid. Every model pressure was leak/plug and ID checked prior to testing. During testing, the leak/plug and ID checks were repeated any time a model component was changed or removed.

There are 8 unsteady surface pressure transducers, Kulite XCS-062 series, at locations near the TPS nacelle to measure engine noise and along the midfuselage at passenger level. The signals from these Kulites were acquired on the acoustic data system.

A thermocouple placed in the nose was used to monitor any excess temperatures that could cause thermal damage to pressure tubing and modules located in the vicinity of the TPS supply pipes. The supply pipes were wrapped in an insulating material and got only warm to the touch.

At the base of the model/blade interface, the low pressure line splits into two sides for the left and right wings. Two low pressure manifolds serve as the distribution point for each wing. Each low pressure manifold controls air flow to the plenums located on each wing through 4 independently operated butterfly valves. The manifold, or distribution plenum, is instrumented with an unsteady pressure transducer and a J-type thermocouple. The left and right side thermocouple measurements are averaged to provide the temperature measurement used in the calculation of the momentum coefficient, see Equation 2.4.10. Figure 2.10 presents a top view of the model showing the layout of the individual wing plenums and the low pressure distribution plenum. Note the plenum and TPS supply lines are visible in the figure. Each of the 8 plenums is instrumented with three total pressure probes, located at the middle and outside edges of the 


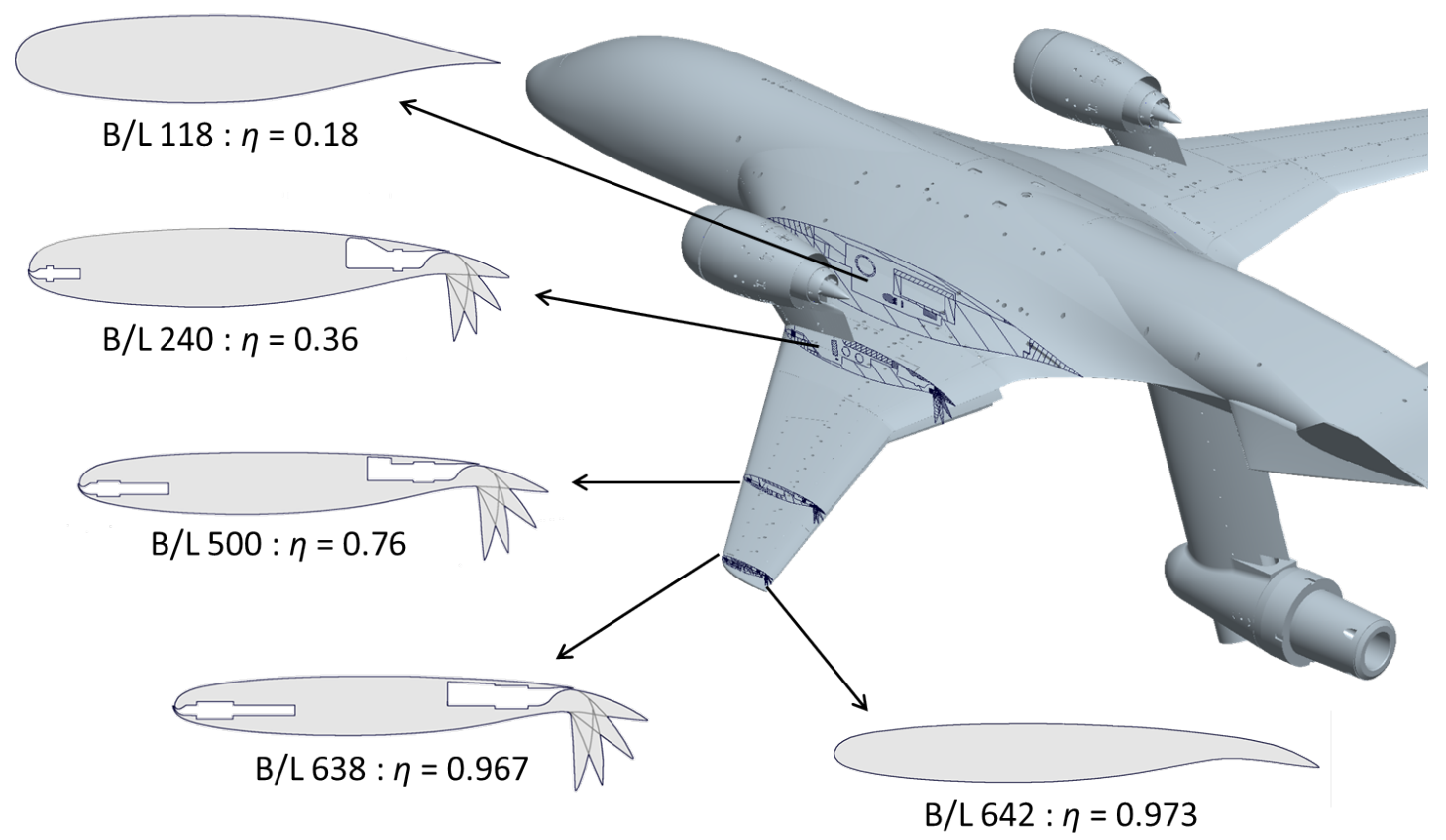

Figure 2.9: Chordwise groups of wing surface pressure ports.

plenum. The probe locations are shown in the figure as colored circles. As labeled in the figure, the plenums are designated:

1. LEIB Leading Edge Inboard

2. LEOB Leading Edge Outboard

3. TEIB Trailing Edge Inboard

\section{TEOB Trailing Edge Outboard}

Mass flow rate for the slot blowing system was measured using an orifice plate. The orifice plate was calibrated post-test and data presented herein reflect incorporation of the calibration data. The orifice plate was mounted externally on the sting assembly, just upstream of the blade attachment as seen in Figure 2.11. The calibrated uncertainty of the orifice plate measurement is $\pm 0.33 \mathrm{lb} / \mathrm{sec}$ at a $95 \%$ confidence level. 


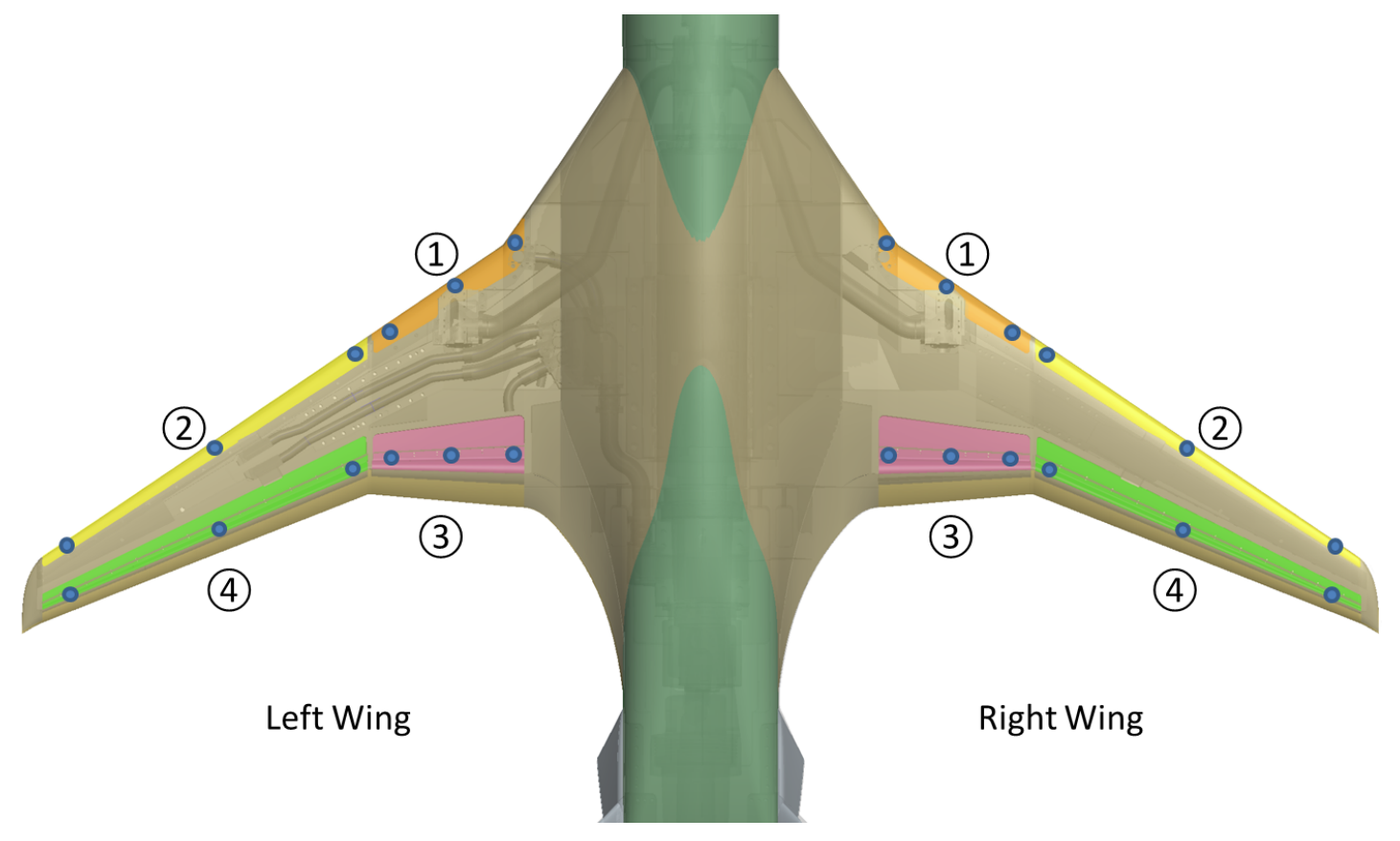

Figure 2.10: Planform view of AMELIA with plenums and total pressure probe locations highlighted.

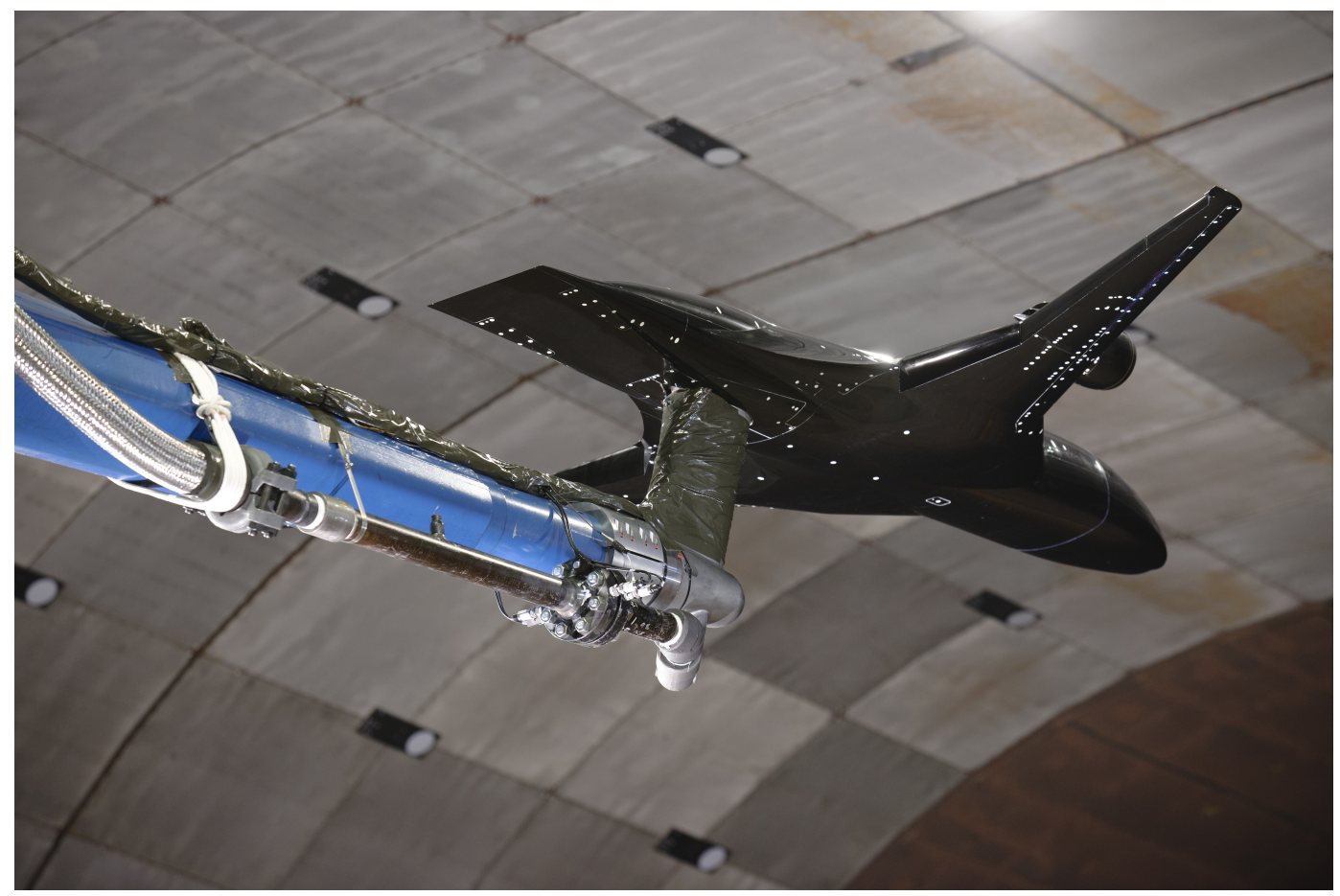

Figure 2.11: Aft view of AMELIA mounted in the NFAC, showing sting/blade attachment and orifice plate instrumentation. 
The TPS are instrumented with forward and aft bearings (with J-type thermocouples) and redundant magnetic speed pickup RPM sensors. The nacelle inlet is instrumented with 8 , radially spaced, static pressure taps. The taps are approximately $1.5 \mathrm{in}$ from the fan face. Core flow measurements were made with two each: total pressure probe, J-type thermocouple, and static pressure port. The instrumentation is spaced radially around the core, $180^{\circ}$ from its respective duplicate with respect to the unit's central axis. The fan flow is instrumented with 7 , radially spaced rakes. The rakes are spaced in the same manner as the inlet static taps, however the pylon blocks the bottom-most (would-be $8^{\text {th }}$ ) location. Each rake consists of: 4 total pressure probes, 1 J-type thermocouple, and 1 static pressure tap at the base of the rake. Figure 2.12 shows a cut-view of the TPS aft end, the instrumentation is highlighted in bright colors. The TPS pressures were routed using 0.032 in urethane tubing that was routed to a quick disconnect. 0.040 in tubing connected the downstream side of the quick disconnect to the pressure module. TPS vibrations were monitored using one BMA180 three-axis accelerometer per unit. The accelerometer was located at the base of the pylon.

In addition to the measurements listed above, direct measurement of skin friction using the Fringe Imaging Skin Friction technique (FISF) was obtained during each of the ten critical test points. The FISF technique is a non-intrusive method for the measurement of global skin friction direction and magnitude [17]. Twelve surface mounted J-type thermocouples on the right wing are used for surface temperature measurement needed for the determination of the correct oil viscosity. The temperatures are acquired on the NFAC LXI system. A summary of the results from the FISF testing can be found in Reference [18]. 


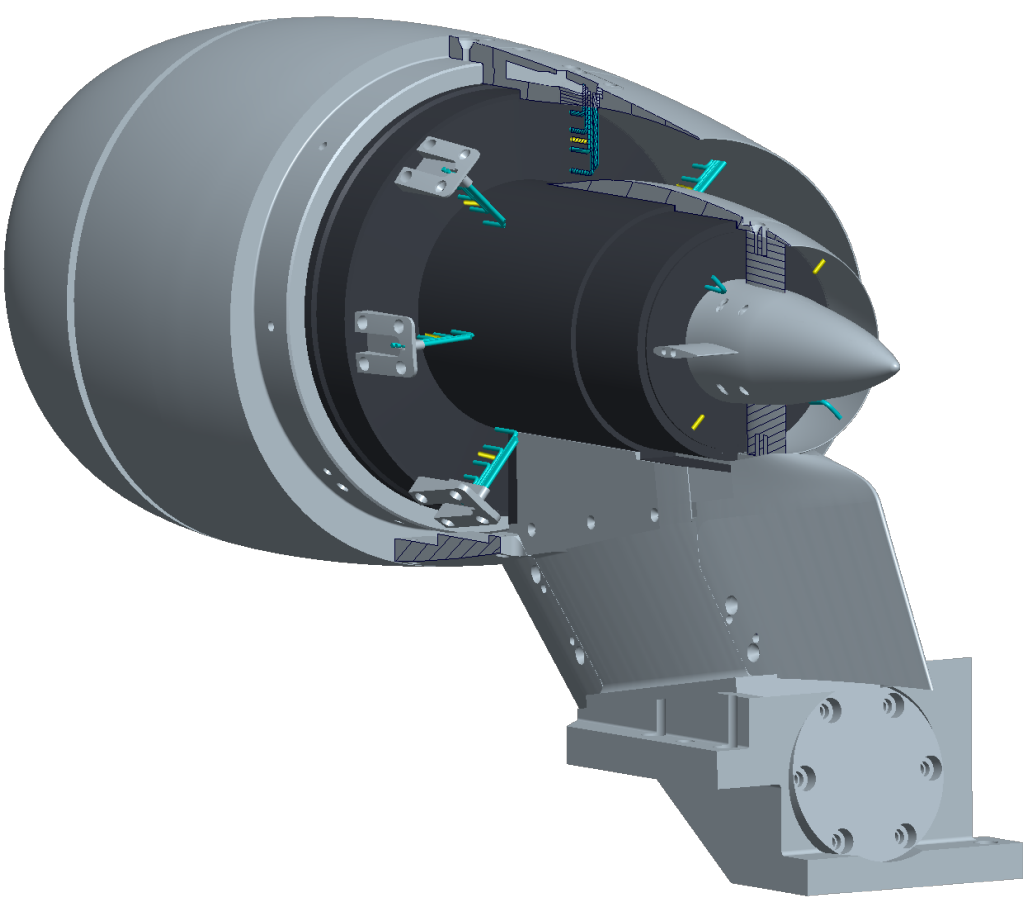

Figure 2.12: Isometric view of an installed and instrumented TPS unit.

\subsubsection{Data Acquisition}

The NFAC data acquisition system (DAS) as configured for the AMELIA test is summarized here. The result is a rather cursory overview of the overall system capabilities and the reader is encouraged to refer to van Aken [19] for more general information on the NFAC DAS. Acoustic measurements are acquired on a separate data system, and the reader can refer to Burnside [20] for details.

Data were acquired on four different data systems in place at the NFAC. Model pressures on the PSI-Initium system, thermocouples, and tunnel wall pressures, totalling 365 channels were acquired at $10 \mathrm{~Hz}$ on the steady DAS. The steady DAS interfaces with digital instruments. 143 channels, including the HPA system, were acquired at $1 \mathrm{kHz}$ on the $\mathrm{N} / \mathrm{rev}$-pulse based DAS. Wind tunnel and model health were monitored on 96 safety-of-flight channels acquired at $1 \mathrm{kHz}$. Wind-on data 
points were acquired for 32 seconds, and wind-off data points for 4 seconds. Data point duration was determined from the results of a data point duration study, not presented here; the results are contained in the Run 14 data file. Zero and resistor calibration points were acquired at the beginning and end of each run. After the initial points are acquired, a report is generated to ensure measured zero and resistor calibration voltages are within tolerance.

In addition to the data acquired from model and tunnel sensors, content from the 4 HD cameras mounted in the test section were recorded. The video feed, which is intended for incident recording, was used for flow visualization during both the smoke and oil flow runs. The videos have been made available along with the data sets.

Cal Poly required additional real-time computations for TPS thrust from a calibration look-up table, angle of attack measurement from two sensors, and mass flow rate from orifice plate instrumentation. The routines for reducing the additional computations into useful coefficients are provided in Section 2.4.3, Data Reduction.

\subsection{Test Procedure and Data Reduction}

\subsubsection{Test Conditions}

Testing was conducted at three tunnel velocities: $40 \mathrm{kts}, 60 \mathrm{kts}$ and $100 \mathrm{kts}$. Table 2.3 provides test average and variances on the velocity dependent parameters: dynamic pressure, Mach number, and Reynolds number based on mean aerodynamic chord. Set-point tolerance on velocity was $\pm 0.1 \mathrm{kts}$ and $\pm 0.1^{\circ}$ on angle of attack. Deviation in the remaining column values is primarily due to 
variation in tunnel atmosphere; intervals are presented with $95 \%$ confidence.

\section{Table 2.3: Summary of wind tunnel flow conditions.}

\begin{tabular}{rcrc} 
Velocity, kts & $M$ & \multicolumn{1}{c}{$q, \mathrm{psf}$} & $R e_{c}, 10^{6}$ \\
\hline $40.0 \pm 0.1$ & $0.061 \pm 0.001$ & $5.5 \pm 0.2$ & $0.82 \pm 0.05$ \\
$60.0 \pm 0.1$ & $0.091 \pm 0.004$ & $12.4 \pm 0.3$ & $1.23 \pm 0.23$ \\
$100.0 \pm 0.1$ & $0.151 \pm 0.002$ & $33.5 \pm 0.5$ & $1.99 \pm 0.05$ \\
\hline
\end{tabular}

Data acquired during an alpha sweep were generally obtained over a range from $-5^{\circ}$ to $+25^{\circ}$. Runs at high speed and high blowing conditions that saw considerable model vibrations were held to a smaller positive alpha limit; this angle of attack limit was subjective and dependent on the magnitude of the model vibrations. During an alpha sweep, the model is held at a single slot and TPS power setting and swept through the angle of attack range. Hysteresis effects between increasing and decreasing alpha sweeps were not observed. Momentum coefficient sweep data were acquired at a fixed angle of attack over a mass flow rate range from $0 \mathrm{lb} / \mathrm{sec}$ to $2.8 \mathrm{lb} / \mathrm{sec}$. The upper limit is $1.55 \mathrm{lb} / \mathrm{m} / \mathrm{sec}$ for the isolated trailing edge blowing configuration.

Several terms will be used to describe the power setting of the TPS and slot flow and are defined as follows. Full as it pertains to full slots or full TPS, corresponds to the maximum power setting of the respective system. Full slots corresponds to $2.8 \mathrm{lb} / \mathrm{m} / \mathrm{sec}$ total air supplied to the slots. Full TPS corresponds to each TPS spinning at 34,500 RPM. The TPS set-point is dependent on the mode of operation; $1.95 \pm 0.03 \mathrm{lb} / \mathrm{sec}$ total mass flow rate in flow control mode and $195 \pm 8$ psig in pressure control mode. Here, the variance in one parameter is due to the effect of holding the second parameter constant as the line temperature changes; i.e. the variance in pressure is the result of line temperature changes 
as the digital valve must compensate to hold mass flow rate constant, and vice versa. Again, these set-points reflect system totals; the flow split between left and right wings/TPS units occurs in the model, downstream of the regulating valves. A reference to full power indicates both the slots and TPS are operating at their full settings. Conditions referencing a fraction of full performance reflect that fraction of mass flow rate set for the slots, and that fraction of RPM for the TPS; i.e. a $2 / 3$ slots condition corresponds to $2 / 3$ of the full set-point, or $2 / 3 \times 2.8 \mathrm{lb} / \mathrm{sec}=1.87 \mathrm{lb} / \mathrm{sec}$.

The above mass flow numbers reference the digital valve set-point; the digital valve is the reference to set on-condition for both the TPS and slots (there is 1 digital valve per line). Note that this reference is not the true value per se, but it serves as a nominal value used for reference. Mass flow numbers listed elsewhere (e.g. those used in the calculation of $C_{\mu}$ ) are from the calibrated orifice plate and represent the true value.

Table 2.4 presents individual plenum nozzle pressure ratio (NPR) and total summed average nozzle pressure ratio as a function of the slot blowing configuration and set-point. Individual plenum NPRs use the average of the three internal total pressure probes, $\left(P_{0}\right)_{\text {plenum }} / P_{\infty}$. The values listed in the table represent testwide averages for the specified set-point. Run-to-run NPR will vary by a few percent due, primarily, to time-of-day and tunnel atmosphere. The NPR calculation uses the freestream static pressure instead of the jet exit pressure. Although using the jet exit would yield a higher value and truer estimate of the actual NPR, using the freestream pressure allows for meaningful comparison between data at different test conditions. Individual figures are labeled with the average momentum and thrust coefficient, as these values are more directly dependent on dynamic pressure. Note the total mass flow rate references the digital valve 
Table 2.4: Summary of individual plenum and average nozzle pressure ratios.

\begin{tabular}{|c|c|c|c|c|}
\hline Slot Configuration & $\dot{m}, \mathrm{lb}_{\mathrm{m}} / \mathrm{sec}$ & Average NPR & Plenum & NPR \\
\hline \multirow{8}{*}{ All Slots } & \multirow{4}{*}{$2.80($ full $)$} & \multirow{4}{*}{1.50} & LEIB & 1.63 \\
\hline & & & LEOB & 1.36 \\
\hline & & & TEIB & 1.67 \\
\hline & & & TEOB & 1.35 \\
\hline & \multirow{4}{*}{$1.87(2 / 3)$} & \multirow{4}{*}{1.22} & LEIB & 1.27 \\
\hline & & & LEOB & 1.14 \\
\hline & & & TEIB & 1.30 \\
\hline & & & TEOB & 1.15 \\
\hline \multirow{4}{*}{ TE-Only } & \multirow{2}{*}{1.55 (full) } & \multirow{2}{*}{1.57} & TEIB & 1.74 \\
\hline & & & TEOB & 1.39 \\
\hline & \multirow{2}{*}{$1.03(2 / 3)$} & \multirow{2}{*}{1.26} & TEIB & 1.34 \\
\hline & & & TEOB & 1.17 \\
\hline
\end{tabular}

set-point.

Table 2.5 presents TPS operating conditions at the nominal set-point. The values listed in the table represent test wide averages with uncertainties given at $95 \%$ confidence levels. The fan and core nozzle pressure ratio, FNPR and CNPR, is calculated by dividing the average of the total pressure probes in the respective stream (i.e. core or fan) by the freestream static pressure. Note the thrust is given as the combined static thrust and the mass flow is for the turbine flow only, it does not include the fan flow. 
Table 2.5: Nominal TPS set-point operating conditions.

\begin{tabular}{cccccc}
\hline $\mathrm{RPM}$ & $\dot{m}, \mathrm{lb}_{\mathrm{m}} / \mathrm{sec}$ & $P, \mathrm{psig}$ & Thrust, $\mathrm{lb}_{\mathrm{f}}$ & FNPR & CNPR \\
\hline $34,342 \pm 328$ & $1.95 \pm 0.03$ & $195 \pm 8$ & $187.6 \pm 4.4$ & $1.33 \pm 0.01$ & $1.12 \pm 0.01$ \\
\hline
\end{tabular}

\subsubsection{Coordinate Systems}

Balance data are reduced to coefficients using the standard practices outlined in Reference [21]. Reference [22] provides the definitions for the customary body, stability, and wind axis systems to which all data sets have been reduced. The model moment reference center is the balance center. The balance center is located 56.73 in from the nose. All data presented herein is with respect to the wind axis system, except where noted.

\subsubsection{Data Reduction}

Wind tunnel data are reduced to coefficients in the customary stability, body, and wind axis systems. Cal Poly required additional computations for the performance coefficients that define the TPS and slot blowing systems: $C_{T}$ and $C_{\mu}$, respectively. The Schaevitz and Q-Flex clinometers followed standard equation sets provided by the NASA Ames Unitary Plan Wind Tunnel.

The thrust coefficient, $C_{T}$, is calculated based on the combined thrust of the TPS.

$$
C_{T} \equiv \frac{\text { Thrust }}{q_{\infty} S_{r e f}}
$$

The isolated nacelle thrust calibration provided the balance-measured forces from which the thrust was calculated real-time in the tunnel. Corrected net thrust was bi-linearly interpolated from a $5 \times 8$ look-up table with inputs of freestream 
velocity and TPS RPM, as follows. Each TPS has a corresponding calibration matrix.

Differences in atmospheric conditions between the calibration and wind tunnel test environments required corrections of measurements to sea level standard conditions. It is because changes in atmospheric pressure create thrust differences that, for a constant flight speed, need to be corrected. Humidity is not corrected for as it is a second order effect. The raw TPS RPM is corrected to standard day as

$$
R P M_{\text {corrected }}=\frac{R P M}{\sqrt{\theta}}
$$

where $\theta$, the temperature ratio, is defined as

$$
\theta=\frac{T_{T, \infty}}{T_{S T D}}
$$

The standard temperature, $T_{S T D}$, for English units is $518.67^{\circ} \mathrm{R}$; it is a constant. Stagnation quantities are used for both the pressure and temperature corrections. In a similar manner the freestream velocity in knots, $V_{\infty}$, is corrected to standard day by

$$
V_{\text {corrected }}=\frac{V_{\infty}}{\sqrt{\sigma}}
$$

$\sigma$ is the density ratio, computed as

$$
\sigma=\frac{\delta}{\theta}
$$

where $\delta$ is the pressure ratio

$$
\delta=\frac{P_{T, \infty}}{P_{S T D}}
$$

For English units, the standard pressure is 14.6968 psia. The thrust is corrected as

$$
F_{\text {corrected }}=\frac{F}{\delta}
$$


$F$ is the net thrust. Net thrust is equal to the gross thrust minus ram drag; in other words, the ram drag component is in the measured thrust value. Ram drag is a function of the fan mass flow rate, it is temperature dependent, and is the primary reason for the shift in thrust lines at different wind speeds. It is for these reasons that the calibration matrix is a function of corrected tunnel speed and RPM instead of fan pressure ratio and RPM. A post-test nacelle calibration of mass flow rate would allow the calibration and full-scale data to be re-reduced to correct for ram drag. At present, there are no plans to do so. Once the net thrust has been obtained, the thrust coefficient is computed via Equation 2.4.1.

The momentum coefficient, $C_{\mu}$, characterizes the performance of a circulation control wing. It is also referred to as the blowing coefficient, discharge coefficient, or jet momentum coefficient. It is defined in the same way as the thrust coefficient.

$$
C_{\mu} \equiv \frac{\text { Jet Momentum }}{q_{\infty} S_{r e f}}=\frac{\int\left(\rho_{j} \vec{V}_{j} \cdot \vec{n}\right)\left(\vec{V}_{j} \cdot \vec{n}\right) \mathrm{d} A}{q_{\infty} S_{r e f}}
$$

The subscript $j$ denotes properties with respect to the jet flow, i.e. in the slot. The integral in the numerator of Equation 2.4.8 is approximated as

$$
C_{\mu}=\frac{\dot{m}_{j} u_{j}}{q_{\infty} S_{r e f}}
$$

Mass flow rate is measured from the calibrated orifice plate for which the reduction routine was provided by the manufacturer, Wyatt Engineering. The small slot height makes direct measurement of the jet velocity difficult, so it is standard to approximate using isentropic relations. Please note, total pressure surveys of the jet flow were made and are presented by Paciano [15]. For isentropic flow, the jet velocity is

$$
u_{j}=\left[\frac{2}{\gamma-1} \gamma R T_{T, j}\left(1-\left(\frac{P_{j}}{P_{T, j}}\right)^{\frac{\gamma-1}{\gamma}}\right)\right]^{1 / 2}
$$


where the specific heat ratio, $\gamma$, is 1.4 and the gas constant, $R$, for dry air is $1716.59 \mathrm{ft} \mathrm{lb}_{\mathrm{f}} /\left(\operatorname{slug}^{\circ} \mathrm{R}\right)$. It is also common practice to substitute the freestream static pressure in lieu of the jet static pressure, $P_{j}$. From a technical standpoint, this will yield a lower jet velocity than actual, and for CFD, should be calculated from expansion to the local static pressure using, say, the static pressure taps located at the leading edge and on the flaps. The reason $C_{\mu}$ is reported using expansion to the freestream static pressure is because the local static pressure will change with angle of attack or any geometry change in the CCW surface (e.g. changing flap deflection), thus making comparison between model configurations and alpha sweeps not meaningful.

As measuring the mass flow rate into each of the 8 individual plenums was not possible, the reflected $C_{\mu}$ is a combined momentum coefficient for the system. The total pressure term in Equation 2.4.10 is the average of all 24 plenum total pressure measurements. The total temperature is taken as the average of the left and right low pressure plenum thermocouple.

Here, the reader is encouraged to exercise caution and be aware of all implications when calculating and reporting values of (and relating to) $C_{\mu}$. The momentum coefficient is a relation for the ratio of jet flow momentum to freestream flow momentum; it is the fundamental metric for the performance of a $\mathrm{CCW}$. The higher the ratio of jet momentum, the greater the CCW benefit can be. Circulation control relies on the principle of the Coandă effect. The Coandă effect, as stated simply and applied to the AMELIA geometry, is the tendency of the high momentum jet flow to remain attached around the dual-radius flap or leading edge. The jet flow sticks to the highly curved flap (called the Coandă surface) because of the force that is exerted in the radial direction that is the result of the pressure gradient between the jet flow over the flap and the freestream flow. 
The determination of the true local pressure to which the slot flow alone is expanded in Equation 2.4.10 is not a trivial task. The implications, however, of not accurately reporting or predicting slot flow parameters are apparent. In the CFD model, it will likely require multiple iterations to match the appropriate boundary conditions to yield the correct flow properties at the jet exit.

\subsubsection{Data Corrections}

The data presented are not corrected for wind tunnel wall or model support interference effects. As the data set is intended for CFD validation, corrections to free-air conditions are not necessary. Wall pressure data was recorded, however, but are not presented. Flow angularity in the test section is not known and no data corrections have been applied; the most recent flow characterization was completed in 1989 [23]. Weight tares for each model configuration have been applied to the data sets. No additional corrections have been made to account for either the thrust effects from the TPS units or the pressure tares for the CCW. It is commonplace to correct for the propulsive effects of the TPS units, i.e. by subtracting the components of the thrust vector that are parallel and perpendicular to the freestream vector from lift and drag. Whereas this may be correct for pure jet flaps, where the true thrust value and its direction are known (or can be determined), it is not the case for powered-lift or a CCW-based powered-lift system like AMELIA. In a powered-lift flow field, the thrust value and direction changes with dynamic pressure, momentum coefficient, and local slot height. Subtracting the thrust coefficient component, $C_{T} \cdot \sin \left(\alpha+\delta_{j e t}\right)$ [from the lift coefficient], does not accurately account for the complex flow-field. Therefore, the data sets are left as total measured forces and coefficients. However, should it be determined that the thrust coefficient component is sufficient, wind-off TPS-on alpha sweeps 
can be used in an attempt to correct the data sets. Static alpha sweeps were also conducted for slot blowing-only, should any attempt at correcting slot pressure tares be made.

\section{Boundary Layer Transition}

Boundary layer transition was fixed using trip dots placed discretely on the model. The dots were sized to create fully turbulent flow over the entire model when the slots are not blowing. When the slots are blowing, the dots are enough to trip the flow if it is not already contaminated from the leading edge plenums. The trip dots were sized following a routine derived from Braslow [24]. Trip dots of two different heights were applied to the model. Dark blue dots, 0.0114 in high, were applied to the wing upper surface and nose at $12 \%$ of the local chord. Orange dots, 0.0065 in high, were applied to the pylon and nacelle at $12 \%$ of the local chord. The transition dots are CAD-cut disks that have an adhesive backing; the dots were painted with a layer of super glue to provide additional adhesion so not to shear-off when the slots are blowing. As the overall goal of the wind tunnel test was to produce data for advancing primarily RANS CFD, where the turbulent flow assumption is built-in, verifying turbulent flow over the model is important. Using the fact that there is higher shear in a turbulent boundary layer, as compared to a laminar boundary layer, oil fringes were used to visually verify transition at the nose and over the wing upper surface. More shearing creates a thinner oil film layer and thus larger fringe spacing. Photographs from the FISF database can verify this assessment, but none are presented here. 


\section{Chapter 3}

\section{Model Configurations}

The results that follow are discussed based on the four basic model configurations, they are: Low Pylon Height, High Pylon Height, Clean Wing, and Isolated Trailing Edge Blowing. Testing took place in the order listed. The low and high pylon heights were tested with combined leading- and trailing-edge blowing, but they will be referred to by their pylon heights. The clean wing and isolated trailing edge blowing configurations both have the TPS removed, however the clean wing configuration has combined leading- and trailing-edge blowing.

The purpose of this chapter is to provide background information on each of the tested model configurations as well as present select model aerodynamic performance results. These results will provide a general overview of isolated configuration performance. The following chapter, Aerodynamic Performance Results, expands on these results and focuses on comparing the performance of the different model configurations. 


\subsection{TPS Removed}

\subsubsection{Clean Wing}

Originally, testing was only planned for the low and high pylon heights. Clean wing runs were added late in the test planning phase by sacrificing low pylon runs at the $30^{\circ}$ flap deflection. The decision was justified because of the value the clean wing runs provide to the CFD community. The removal of the TPS units provides a much simpler validation case for $\mathrm{CFD}$; it is likely that a $\mathrm{CFD}$ validation will start with this configuration (or the isolated trailing edge blowing configuration) before attempting a simulation of the entire model. The addition of the TPS, and the coupling of the CCW and over-the-wing mounted engines, significantly complicates the flow physics. The TPS also add a significant burden to building the computational grid and implementing boundary conditions.

A Bondo product was used to fill the hole in the wing in the absence of the TPS unit. The Bondo was formed to match the wing mold lines and a FARO measuring arm was used to acquire geometric points, post-test, to confirm the mold lines of the wing in relation to the manufactured CAD model. Testing in the clean wing configuration took place over 5 wind-on days, wherein 64 useful data runs and one critical test point were acquired. Again, the data presented in this configuration has the combined leading- and trailing-edge blowing.

Figures 3.1 to 3.3 present data acquired during slot sweeps. Data are provided at a fixed tunnel speed and flap deflection, with curves for $\alpha=-5^{\circ}, 0^{\circ}$ and $10^{\circ}$. Here, with leading- and trailing-edge blowing, lift continues to increase as angle of

attack is increased. The region at low blowing where the increase in $C_{L}$ with each increment of blowing is the highest is referred to as the separation control region. 
The separation control region is where the separation point is quickly moved to the trailing edge of the flap as blowing is increased. A momentum coefficient of less than approximately 0.1 characterizes this region, seen in Figure 3.1. Beyond this region is the super circulation region. Here, lift continues to increase but it is not as efficient because the separation point has been fixed at the trailing edge of the flap. For the $60^{\circ}$ flap deflection, drag is positive and increases with blowing across the three angles of attack. Figure 3.3 shows decreasing pitching moment with angle of attack.

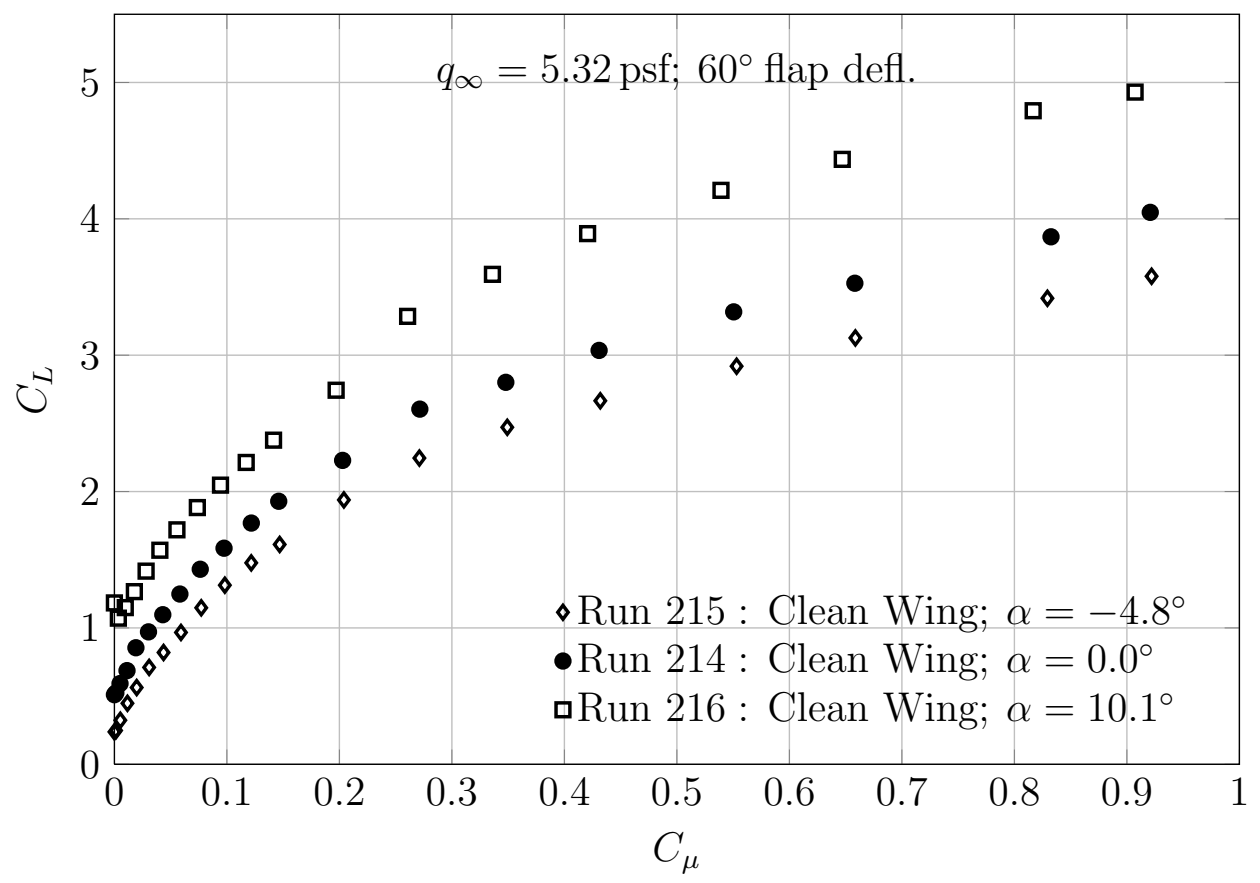

Figure 3.1: Representative lift coefficient performance in the clean wing configuration.

\subsubsection{Isolated Trailing Edge Blowing}

As this wind tunnel test is a first on many fronts, it is important to have a subset of data available to compare against historical data. However, as was discussed in the introduction, the majority of past circulation control testing 


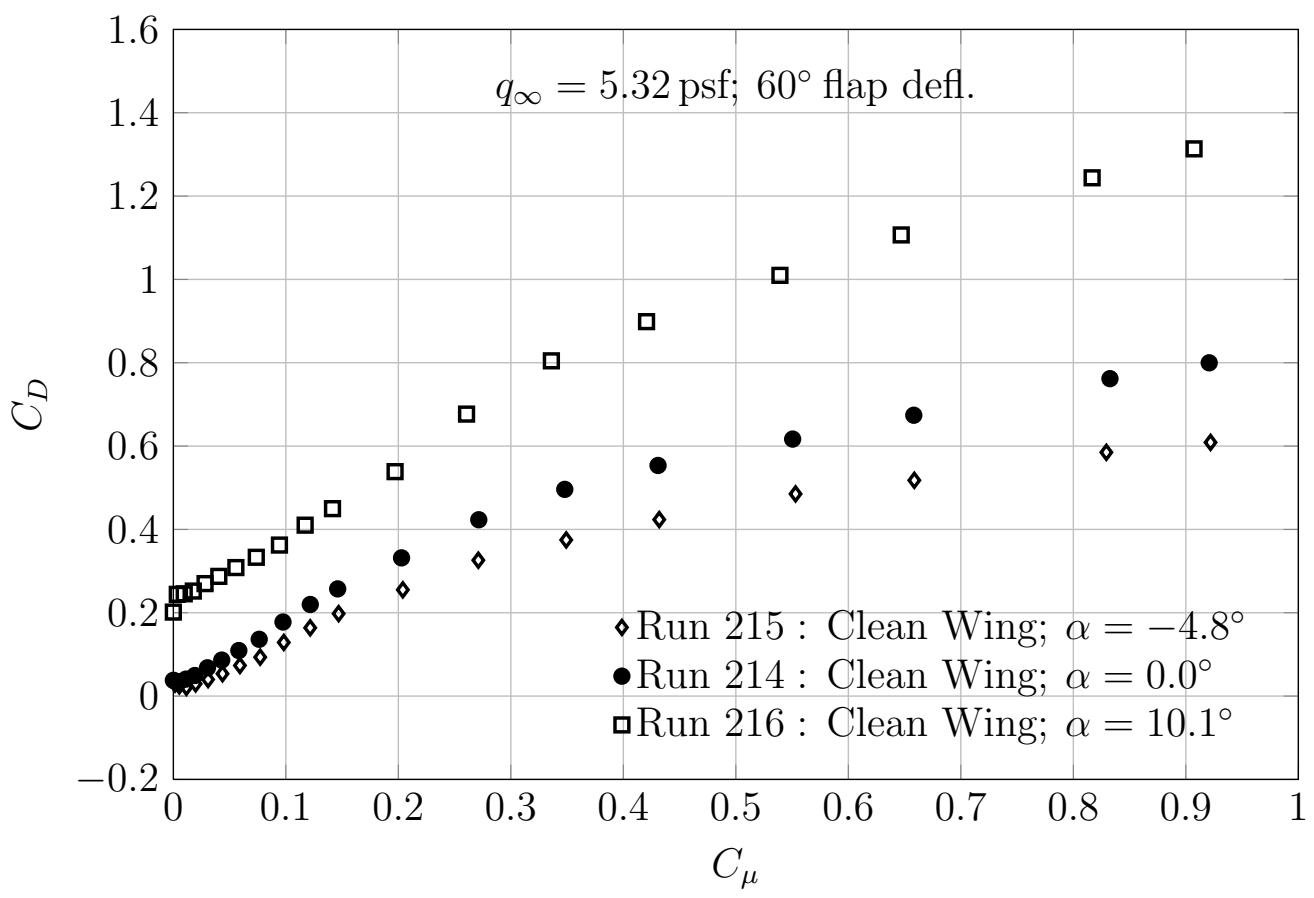

Figure 3.2: Representative drag polar for the clean wing configuration.

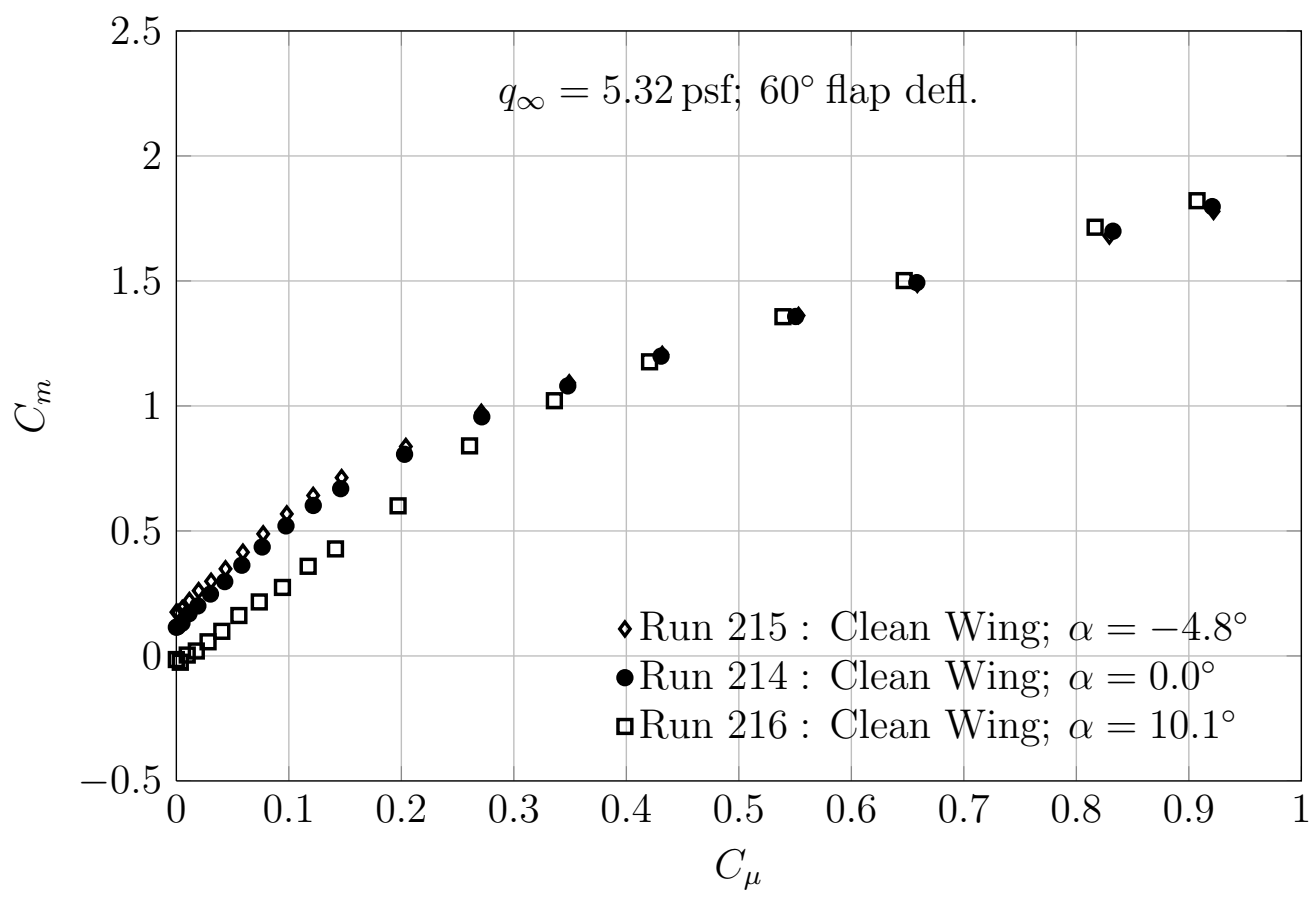

Figure 3.3: Representative pitching moment coefficient performance in the clean wing configuration. 
has focused on models that are limited to trailing edge blowing. To remedy this, the final two days of wind-on testing were used to acquire isolated trailing edge blowing runs; the remaining clean wing runs were sacrificed to do so. Only a small subset of data were acquired in this configuration at the $0^{\circ}$ and $60^{\circ}$ flap deflections, but it is arguably the most important of the entire data set. In this configuration, the TPS are removed and the leading edge plenums have been blocked at the downstream side of the butterfly valves in the low pressure distribution plenum. To set on-condition for this configuration, the trailing edge plenum pressures are matched to what was set for the combined blowing runs. The result is slightly more than half of the total mass flow rate as the split between the leading- and trailing-edges is not exactly half of the total air delivered to the low pressure side. See Table 2.4 for details.

Results from the prior CCW experiments have shown large lift augmentation can be achieved through TE blowing, however performance falls off at positive angles of attack - stall at the leading edge is the cause. Circulation control is best thought of as effective camber; as blowing coefficient is increased, the more effective camber the wing has. At high blowing rates the effect is manifested at the leading edge, where the stagnation point moves further downstream on the lower surface to a point where it cannot maintain attachment through the increased acceleration around the nose and the wing stalls. Previously, a leading edge device (such as a slat) has been employed in an attempt to delay stall at the leading edge. Although effective at delaying stall to higher angles of attack, the leading edge article is not entirely sufficient and leading edge blowing is necessary. The reader is encouraged to refer to Englar $[5,6]$ for more information on prior circulation control testing.

Figure 3.4 shows a typical lift curve for AMELIA with isolated trailing edge 
blowing at $40 \mathrm{kts}$ and $60^{\circ}$ flap deflection. For a fixed flap deflection, the addition of blowing decreases the stall angle due to the flow's inability to maintain attachment around the leading edge as the up-wash increases due to the blowing induced circulation. The figure shows that although blowing greatly augments the lift generation, the locus of stall points moves below $\alpha=12^{\circ}$ as $C_{\mu}$ is increased. At $C_{\mu}=0.38$, the model stalls at $0^{\circ}$ angle of attack - the need for leading edge blowing is evident. In general, lift and pitch moment are increased with blowing. The drag data, Figure 3.5, shows a slot thrust as momentum coefficient is increased; this is not seen with the positive flap deflections as the direction of the jet leaving the slot is no longer in line with the drag axis.

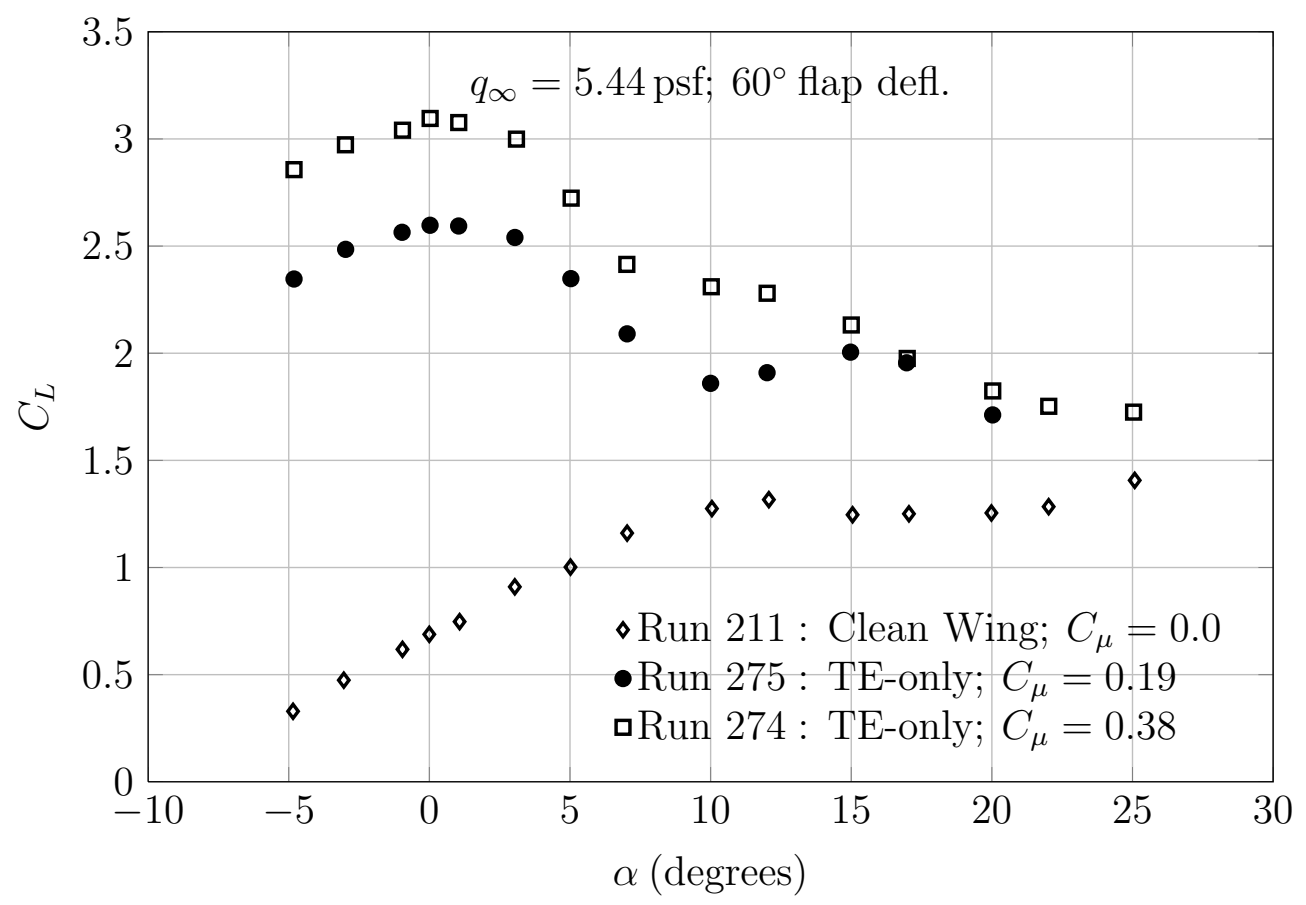

Figure 3.4: Representative isolated trailing edge blowing lift coefficient performance. 


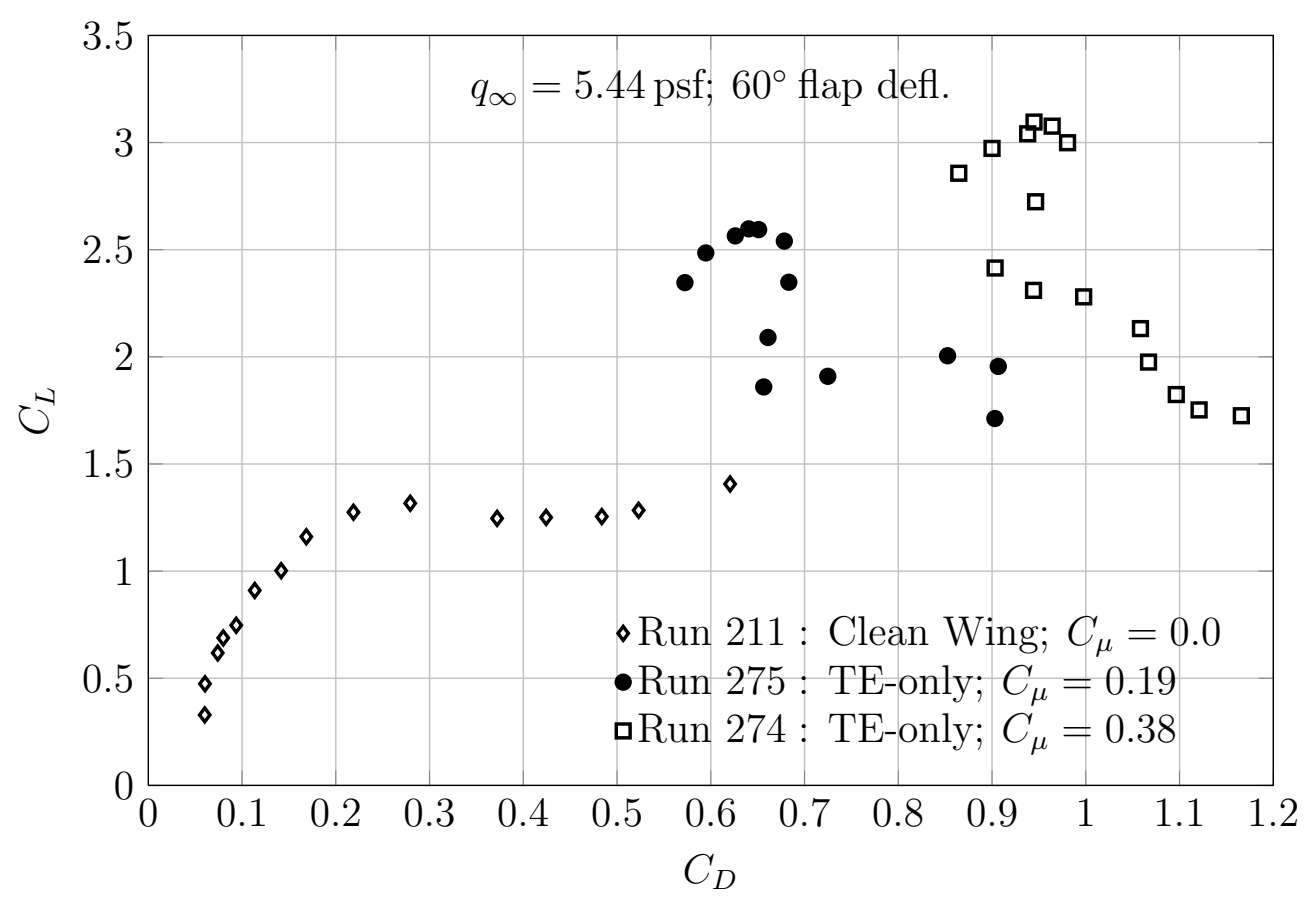

Figure 3.5: Representative isolated trailing edge blowing drag polar.

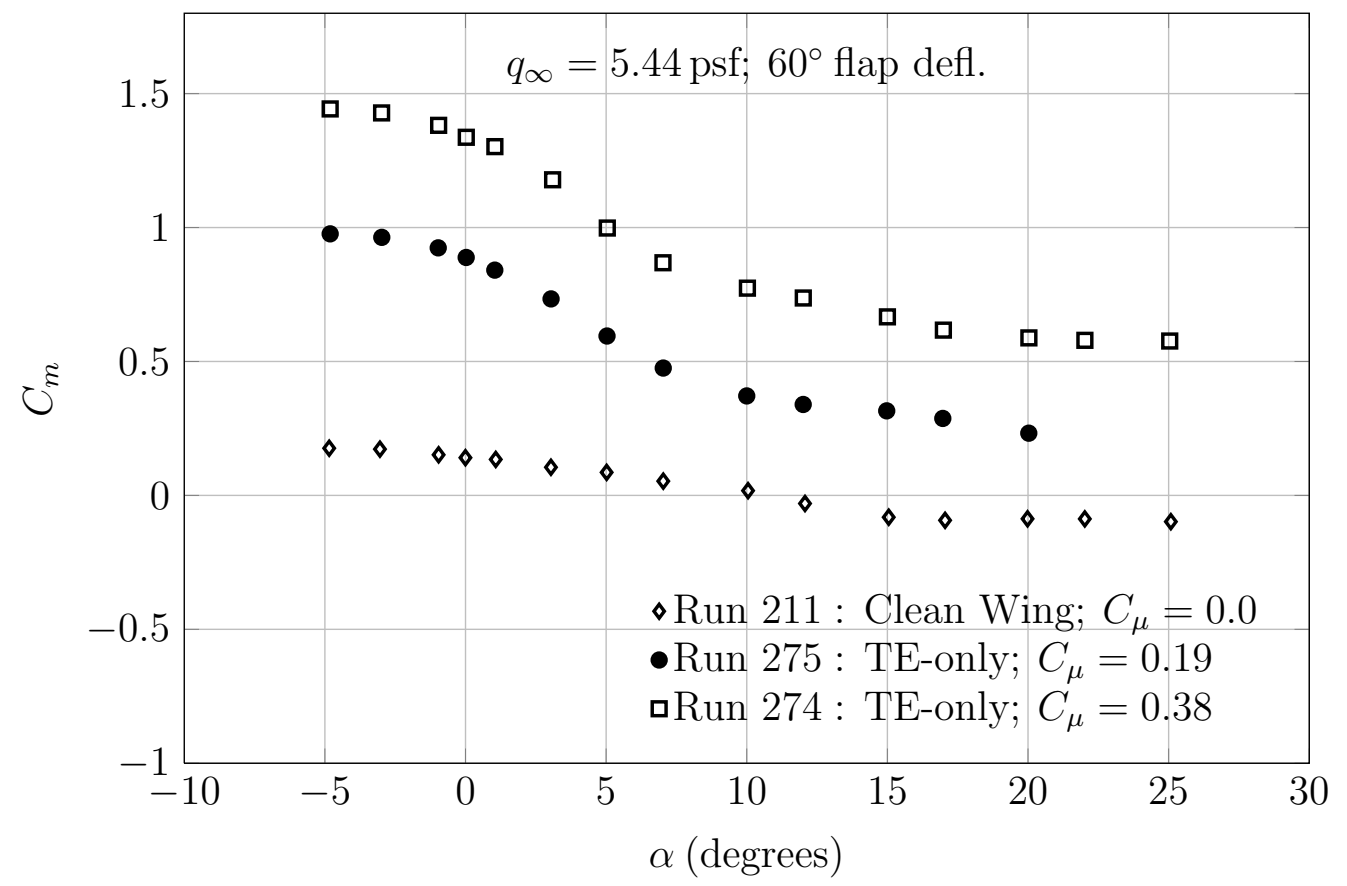

Figure 3.6: Representative isolated trailing edge blowing pitching moment performance. 


\subsection{TPS Mounted}

The high pylon measures 6.26 in from the wing upper surface to the TPS centerline; the low pylon measures 4.21 in along the same reference. Using the fan diameter $(D)$ of $5 \mathrm{in}$, the high and low pylon height is non-dimensionalized to a $z / D$ of 1.25 and 0.84 fan diameters above the wing upper surface, respectively. Figure 3.7 shows a close-up front view of the engine heights. Note: referring to the pylon heights as short and long is analogous to what is used here, low and high.
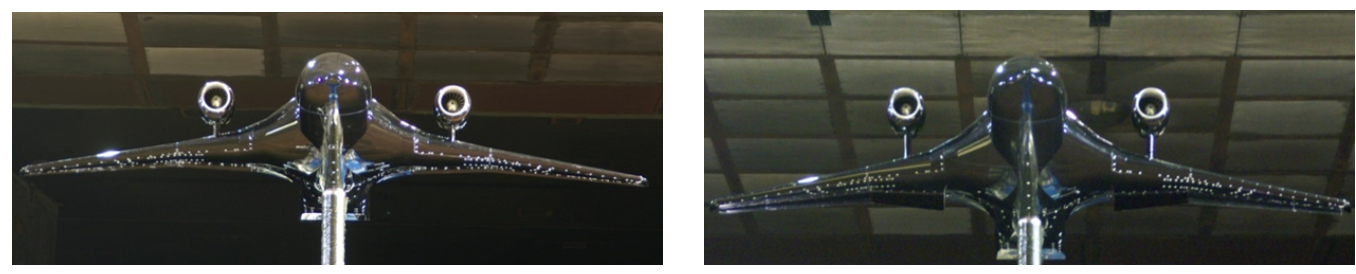

Figure 3.7: Front view of the engine heights. Left to right: low pylon height, high pylon height.

\subsubsection{Low Pylon Height}

The low engine pylon height was the first configuration tested. Testing in this configuration lasted for a period of 20 wind-on days, wherein 151 useful data runs were acquired. Six critical test points, five oil flow visualization, and two smoke flow visualization runs were also completed in this time. The results from the oil flow and smoke flow runs are not presented here, but are available with the wind tunnel data sets. For safety, the TPS were not in operation during the smoke flow runs.

The data presented with the TPS on is left uncorrected. As a result, the thrust component is present and results in a negative drag value due to the 
alignment of the drag axis with the local freestream vector. The addition of the engine thrust increases the lift curve slope because of the thrust component. It will be emphasized later, but the increase in lift when the engine simulators are on is not so much due to the thrust deflection angle, but more due to the increased wing upper surface velocities and resulting decreased static pressures. In general though, larger lift augmentation is achieved from increasing momentum coefficient rather than increasing thrust coefficient. The data will show that even at high angles of attack, the addition of leading edge blowing alone is not enough to prevent wing stall.

Figures 3.8 to 3.10 present aerodynamic data for varying flap deflections at $100 \mathrm{kts}$ and the full power condition. With the TPS-on at high blowing and angle of attack, the $80^{\circ}$ flap cannot maintain increased lift performance over the $60^{\circ}$ flap. As will be discussed further in the next chapter, the low pylon doesn't appear effective at deflecting engine exhaust at high flap deflections. This is predominately seen at this high speed where stall occurs between $10^{\circ}$ to $12^{\circ}$. The addition of TPS thrust delays stall from $7^{\circ}$ to $13^{\circ}$, compared to the clean wing. As was seen in the other configurations, drag and pitching moment increase as the flap deflection increases. Figure 3.9 shows increasing drag as flap deflection is increased, with slot thrust from the $0^{\circ}$ flap.

\subsubsection{High Pylon Height}

The model change from the low pylon to the high pylon took place over a single day and testing was able to proceed with no unexpected down time incurred. Testing at the two pylon heights allowed for the highly coupled CCW and over-the-wing mounted design to be characterized, both aerodynamically and 


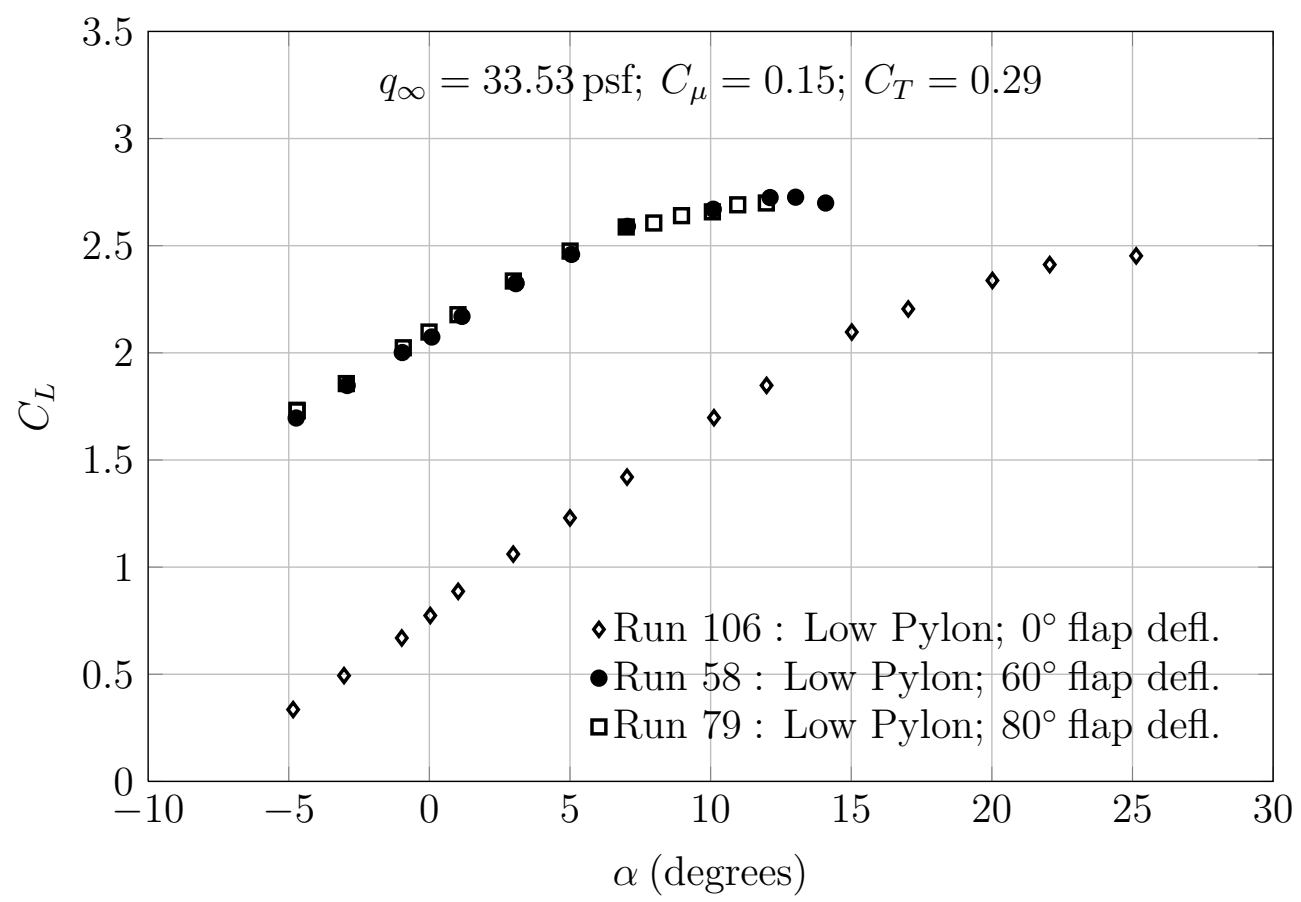

Figure 3.8: Representative model lift coefficient performance at the low pylon height.

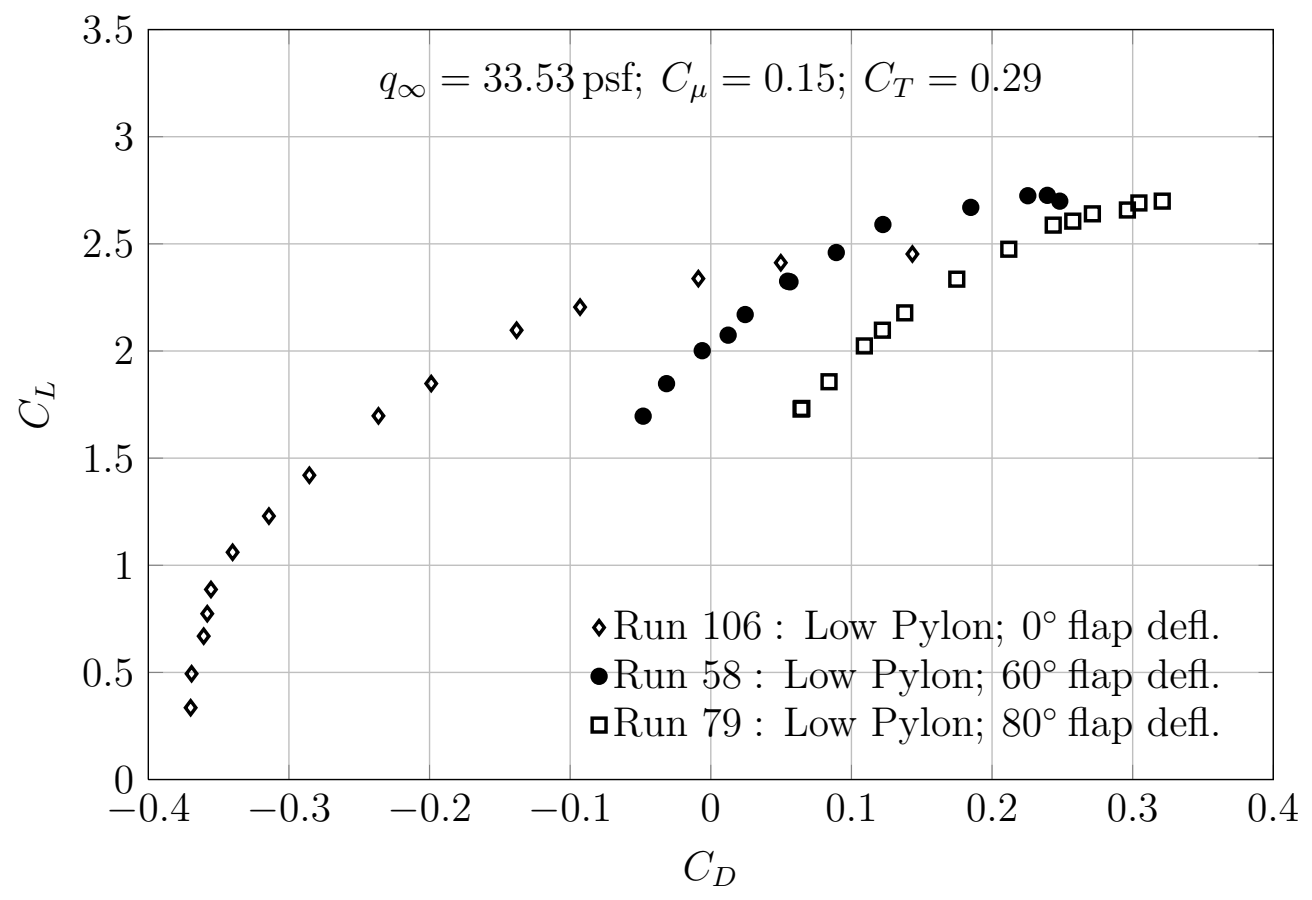

Figure 3.9: Representative model drag polar at the low pylon height. 


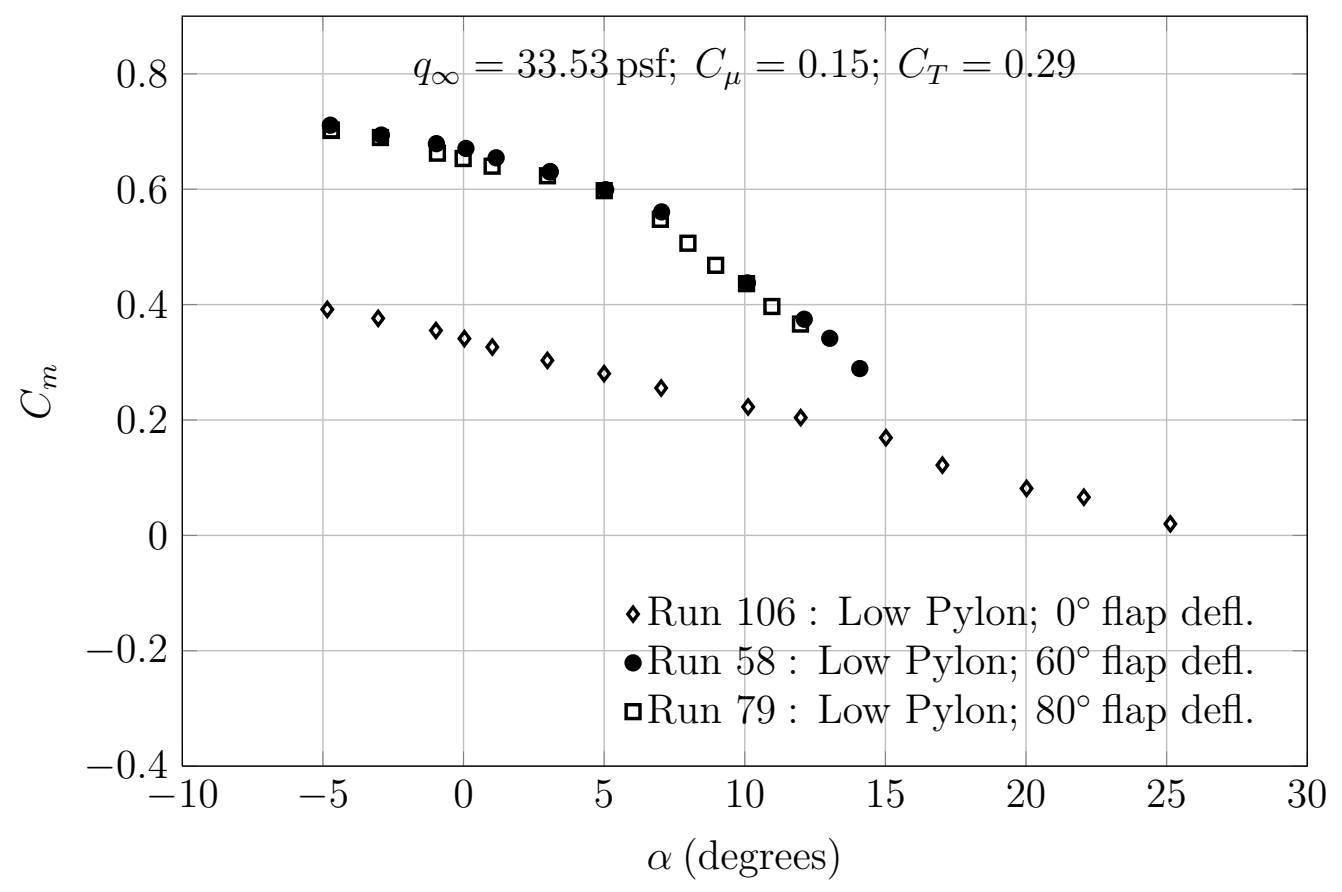

Figure 3.10: Representative model pitching moment coefficient performance at the low pylon height.

acoustically.

Figures 3.11 to 3.13 present alpha sweeps for each point in the poweredlift matrix (see Results Section 5 for an explanation) at $40 \mathrm{kts}$ in the $80^{\circ}$ flap deflection. Figure 3.11 shows the performance benefits from deflecting engine exhaust are seen predominately at higher angles of attack. The increase in lift is not so much due to the thrust deflection angle, but more so the increased upper surface velocities that result. As expected, each point in the powered-lift matrix is additive with respect to increasing the full powered lift coefficient. At $25^{\circ}$ angle of attack, the maximum lift coefficient is increased by just over 1 to 6.5 with the engine simulators at the nominal set-point. Again, the lift curve is increased because of the thrust component being present in the data. In Figure 3.12, the positive flap deflection does not provide slot thrust, hence the larger (positive) drag when the slots are blowing. The thrust recovery from the thrust coefficient 
component is also seen in the figure. Figure 3.13 shows that the application of both TPS thrust and slot flow are additive components to the total pitching moment.

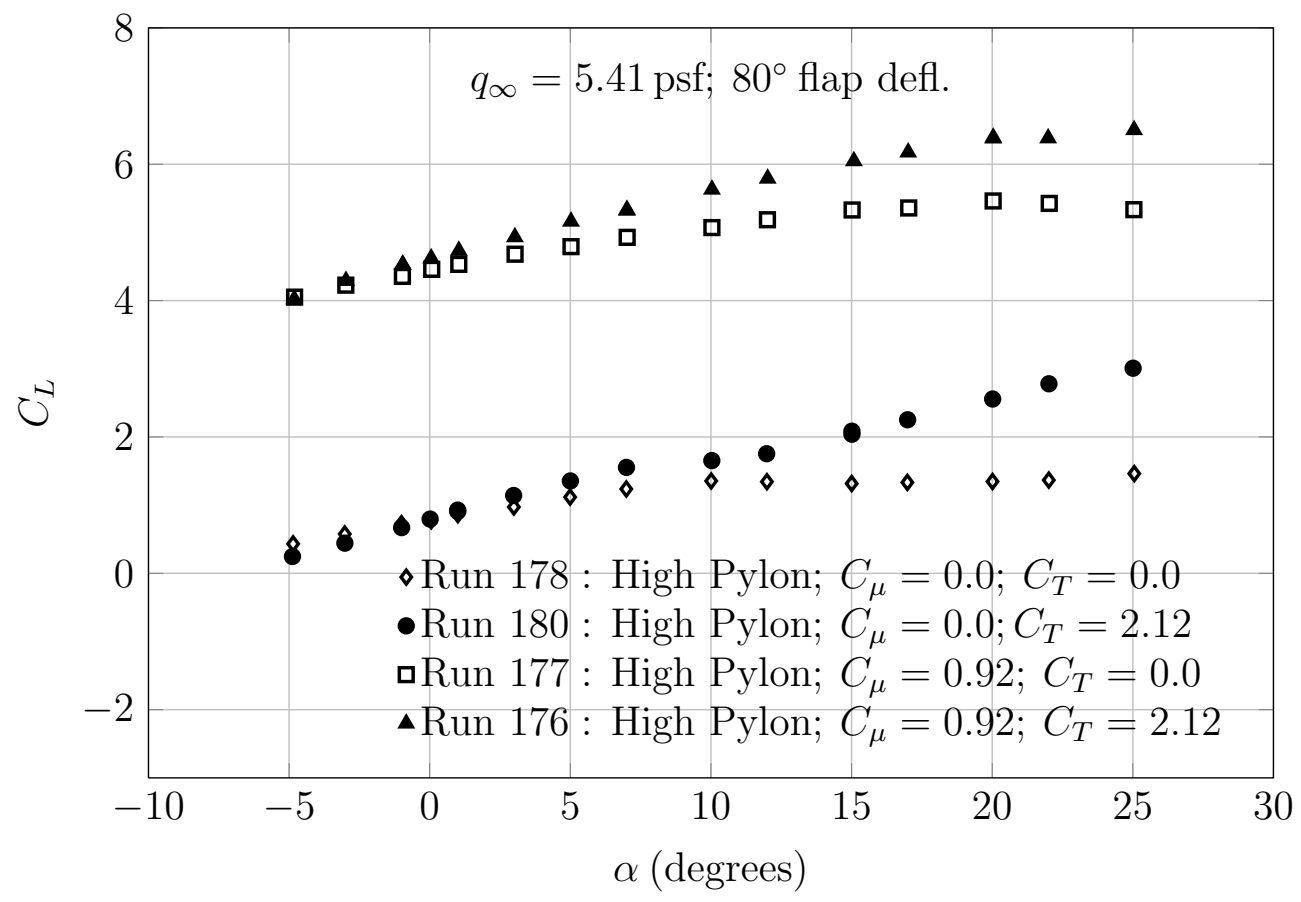

Figure 3.11: Representative model lift coefficient performance at the high pylon height. 


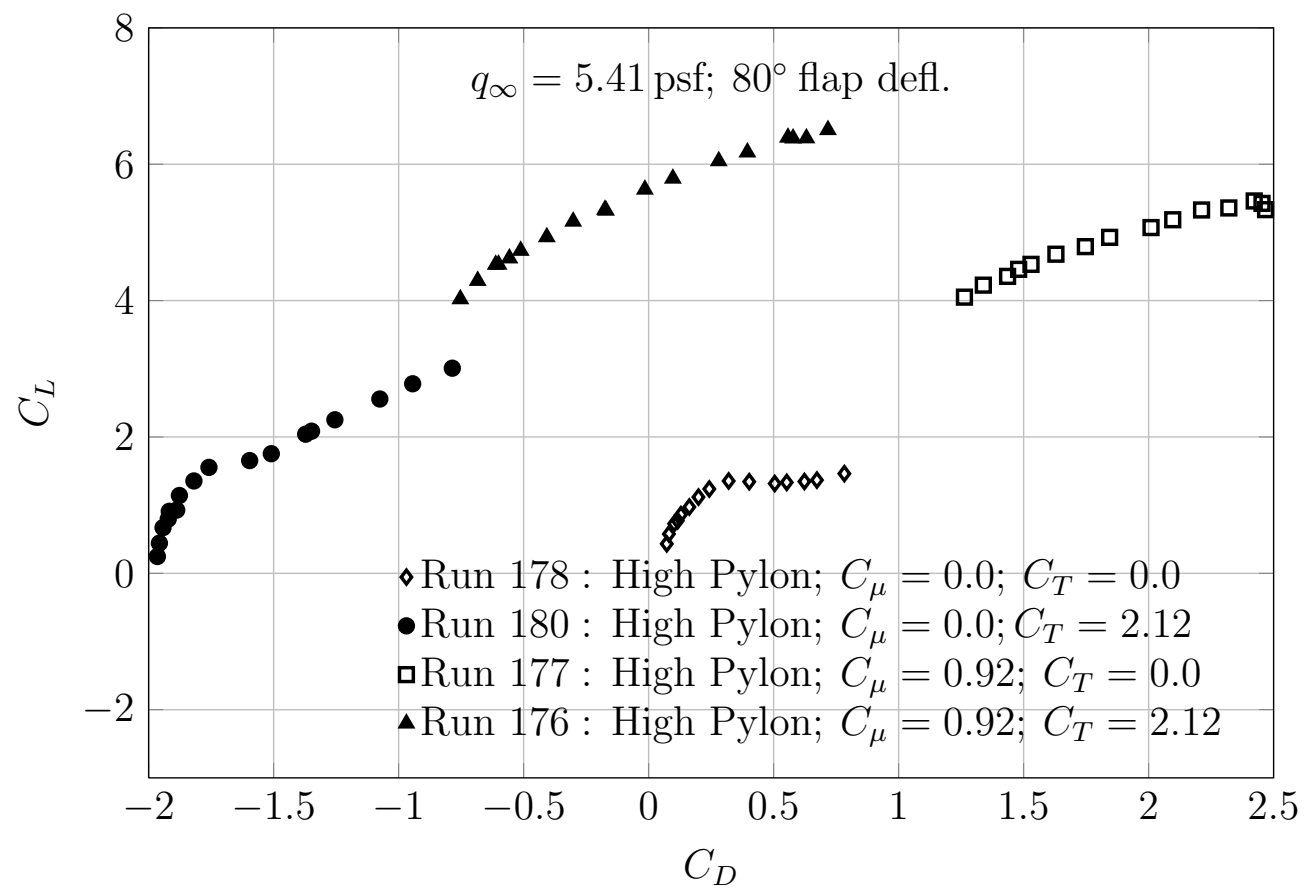

Figure 3.12: Representative model drag polar at the high pylon height.

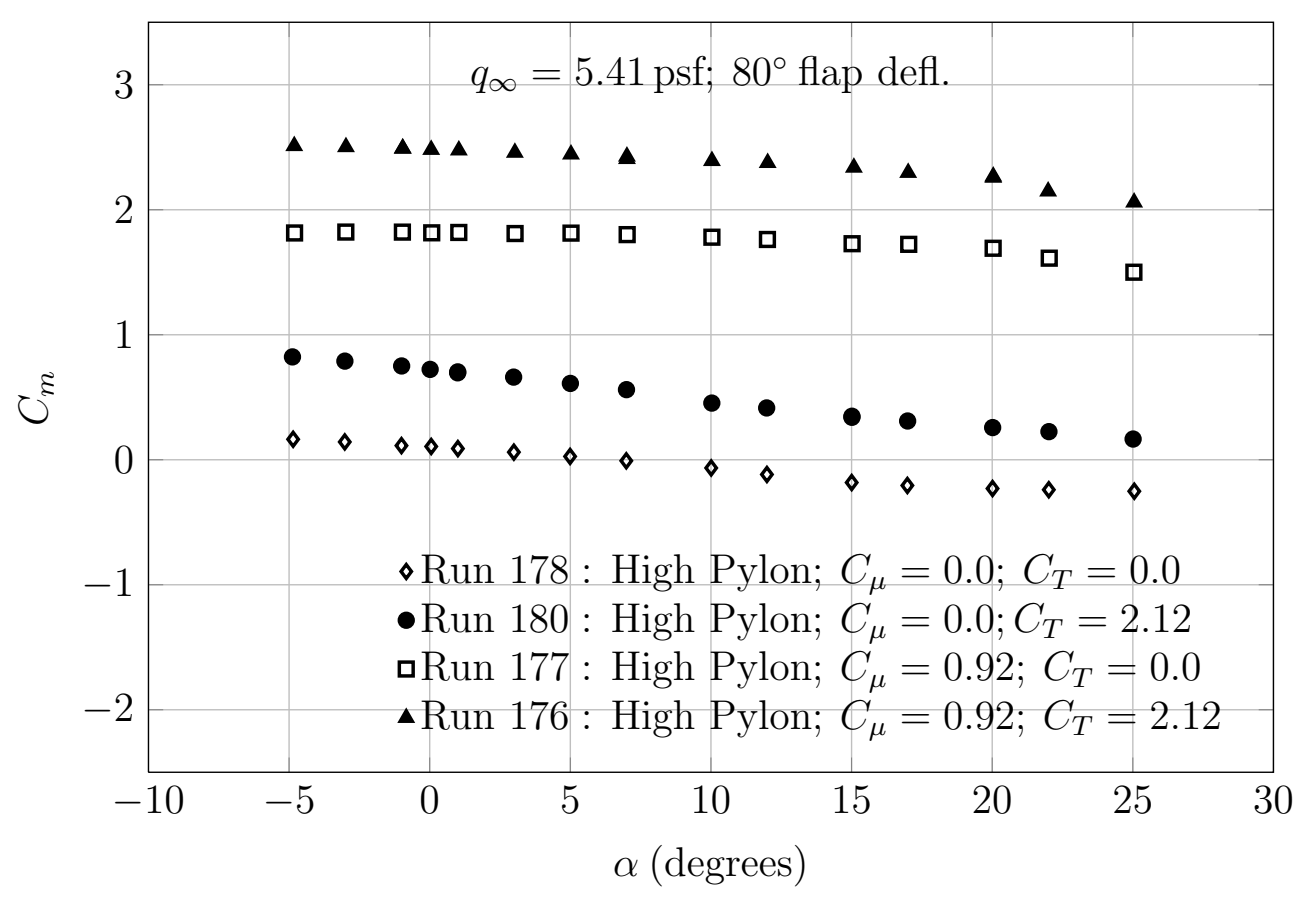

Figure 3.13: Representative model pitching moment coefficient performance at the high pylon height. 


\section{Chapter 4}

\section{Data Repeatability and Uncertainty Analysis}

This chapter focuses on the estimation of the errors and uncertainties associated with the test data. The goal of uncertainty analysis is to state, to a specified level of confidence, the bounds within which the true measurement value lies [25].

In general, measurements have two sources of error: bias error and precision error. The two error sources form the total error through a root-sum-sqaure addition. Bias error is generally considered a fixed quantity, it can be large or small, and vary in both sign and magnitude (though zero-centered); the determination of the bias error relies on the knowledge of the true measurement value. Hysteresis is an example of a bias error, where the value of the output depends on whether the input is increasing or decreasing. Large biases are believed to be eliminated through a well controlled experiment - this is generally done through means of instrument calibration and using established test techniques - small biases, however, typically still remain. Precision errors, on the other hand, are 
random. As a result, their quantification through analysis techniques is easier (in this case statistical analysis is used). For example, precision errors typically result from fluctuating experimental conditions, i.e. they cause data scatter.

As alluded to thus far, the estimation of the absolute uncertainty with biases is difficult and outside the scope of this work. The remainder of this chapter focuses on the estimation of the repeatability error. The preceding information forms the background for the detailed statistical analysis of the force and moment coefficient repeatability that follows. Factors that contribute to non-repeatability in the test data will be discussed and a summary of uncertainties will be presented at the end of this chapter.

In order to make an assessment of the precision error, multiple sets of identical runs at different model configurations and tunnel conditions were obtained; the runs were distributed as widely as possible throughout the test matrix in order to make the most reliable assessment of such uncertainty. Out of a total of 292 data runs, 14 different repeat run configurations were obtained. A list of the repeat runs is given in Table 4.1. Note the table only has 13 entries as the wind-off repeat sweep is not included; there will be no analysis figures provided, but the run statistics will be presented. No repeat runs were acquired in the high pylon configuration.

\subsection{Repeatability Analysis Method}

Precision error is the random component of the total error that has to do with the difference between a measured value and the population mean of measured values (i.e. the data scatter). Because precision error is the random component of the true error, statistical analysis is used to estimate the data mean and express 
Table 4.1: Listing of repeated runs.

\begin{tabular}{|c|c|c|}
\hline Model Configuration & Run Numbers & Group \\
\hline \multirow{9}{*}{ Low Pylon } & 19 and 95 & 1 \\
\hline & 21 and 105 & 2 \\
\hline & 26 and 60 & 3 \\
\hline & 36,92 and 102 & 4 \\
\hline & 46, 56 and 133 & 5 \\
\hline & 56 and 66 & 6 \\
\hline & $69,81,82$ and 128 & 7 \\
\hline & 78 and 79 & 8 \\
\hline & 152 and 153 & 9 \\
\hline \multirow{2}{*}{ Clean Wing } & 213 and 218 & 10 \\
\hline & 246 and 255 & 11 \\
\hline \multirow{2}{*}{ TE-Only Blowing } & 274 and 290 & 12 \\
\hline & 294 and 311 & 13 \\
\hline
\end{tabular}


the data scatter about the estimated mean with a specified level of confidence. The method employed here is referred to as multivariable regression statistical analysis (MRSA); the method is used by Wahls [25] and is consistent with the AIAA standard [26]. In the MRSA method, the data sample mean is estimated by a single least-squares curve fit based on all data from a set of identical runs. This method assumes that the data scatter is random and can be represented by a normal distribution, and that the dependent variable can be represented as a single function of the independent variable using a polynomial regression equation. For this analysis, the independent variable is angle of attack. The dependent variables are $C_{L}, C_{D}$, and $C_{m}$. The data scatter about the mean is quantified with confidence and prediction intervals on the bounds. Herein, the confidence interval is interpreted as the bounds about which the estimated mean encompasses the true mean, and the prediction interval is interpreted as the bounds about which the estimated mean will contain any single future observation. The bound widths are equivalent to the level of confidence in the statistical analysis; here $95 \%$ confidence and prediction levels are reported.

The polynomial least-squares regression equation of order $K$ takes the general form

$$
\hat{Y}(X)=C_{0}+C_{1} X+C_{2} X^{2}+C_{3} X^{3}+\cdots+C_{K} X^{K}
$$

where $X$ is the independent variable, $\hat{Y}$ is the best estimate of the dependent variable, and $C_{i}$ are the least-squares constant coefficients. The selection of the order of the curve fit, $K$, can be subjective; an algorithm was written to constrain and select the appropriate order of each polynomial regression. The algorithm evaluates the least-squares regression for multiple orders and selects the order that minimizes the standard error while constraining with the following criterion:

$$
K \leq \sqrt{N}-1
$$


This criterion provides a useful limit for the order of the polynomial regression, see Reference [27]. $N$ is the total data sample size.

The standard error is a measure of the data scatter about the estimated mean; it is an extension of the sample standard deviation accounting for multiple single regression lines in one fit. The standard error is defined as

$$
S E=\left[\frac{\sum_{i=1}^{N}\left(Y_{i}-\hat{Y}_{i}\right)^{2}}{N-K-1}\right]^{1 / 2}
$$

where $\hat{Y}_{i}$ is the least-squares estimate of $Y_{i}$ corresponding to $X_{i}$ at the $i^{\text {th }}$ data point (i.e. at a single angle of attack). The confidence and prediction intervals are defined in terms of the standard error. The confidence interval, $C I$, is defined as

$$
C I\left(X_{0}\right)= \pm t_{95} \cdot S E \cdot Q\left(X_{0}\right)
$$

The prediction interval, $P I$, is defined as

$$
P I\left(X_{0}\right)= \pm t_{95} \cdot S E \cdot \sqrt{1+Q\left(X_{0}\right)^{2}}
$$

where $t_{95}$ is the value of the t-distribution for $95 \%$ confidence. $Q\left(X_{0}\right)$ is a measure of the data density in the area of the independent variable, $X_{0}$. The term accounts for the data density such that more populated regions have narrower intervals than those that are sparser. This effect can be seen in the widening of both prediction and confidence intervals at the ends of the data range, where the mean value is known with less confidence because the data is less concentrated in these regions. As defined, the confidence interval is the range in which the true mean value lies and the prediction interval is the range in which any single future observation will fall.

The results of the repeatability analysis are presented in Figures 4.1 to 4.11. Plots are provided for each of the repeat runs and repeatability is represented in 
terms of the dependent variables previously mentioned. The regression analyses were based on data acquired over the entire angle of attack range within a given set of repeat runs. Each figure presents the original polar and the residuals resulting from each curve fit. The residuals, or delta coefficients, are defined as the difference between the least-squares estimation of the data sample mean and the measured value at a given angle of attack.

$$
\Delta Y=Y_{i}-\hat{Y}_{i}
$$

The statistical quantities in the lower subplot of each dependent variable plot set provide a summary of relevant statistics for each regression. The quantities represented are: the order of the least-squares curve fit, $K$, the goodness of fit, $R^{2}$ (coefficient of determination), and the standard error, $S E$, for each regression.

Repeatability for slot sweeps, and wind-off sweeps was assessed. The wind-on slot sweep, group 11, is near term time scale (discussed in Section 4.3). The model was in the clean wing configuration, 60 kts test section velocity, $60^{\circ}$ flap deflection, and $0^{\circ}$ angle of attack. The slot sweep statistics are not included in the summary averages listed at the end of this chapter; the repeatability is: $\Delta C_{L}= \pm 0.0156$, $\Delta C_{D}= \pm 0.0019, \Delta C_{m}= \pm 0.0027$. The plots for this group of repeat runs are not provided. Note the independent variable for slot sweep regression analysis is $C_{\mu}$ instead of $\alpha$. Static alpha and slot sweep repeat runs are short term time scale, repeatable to: $\Delta L= \pm 0.237 \mathrm{lb}_{\mathrm{f}}, \Delta D= \pm 0.785 \mathrm{lb}_{\mathrm{f}}, \Delta P M= \pm 1.155 \mathrm{ft} \mathrm{lb}_{\mathrm{f}}$. Repeatability plots for the wind-off polars are not provided. 
Low Pylon; $0^{\circ}$ flap defl.
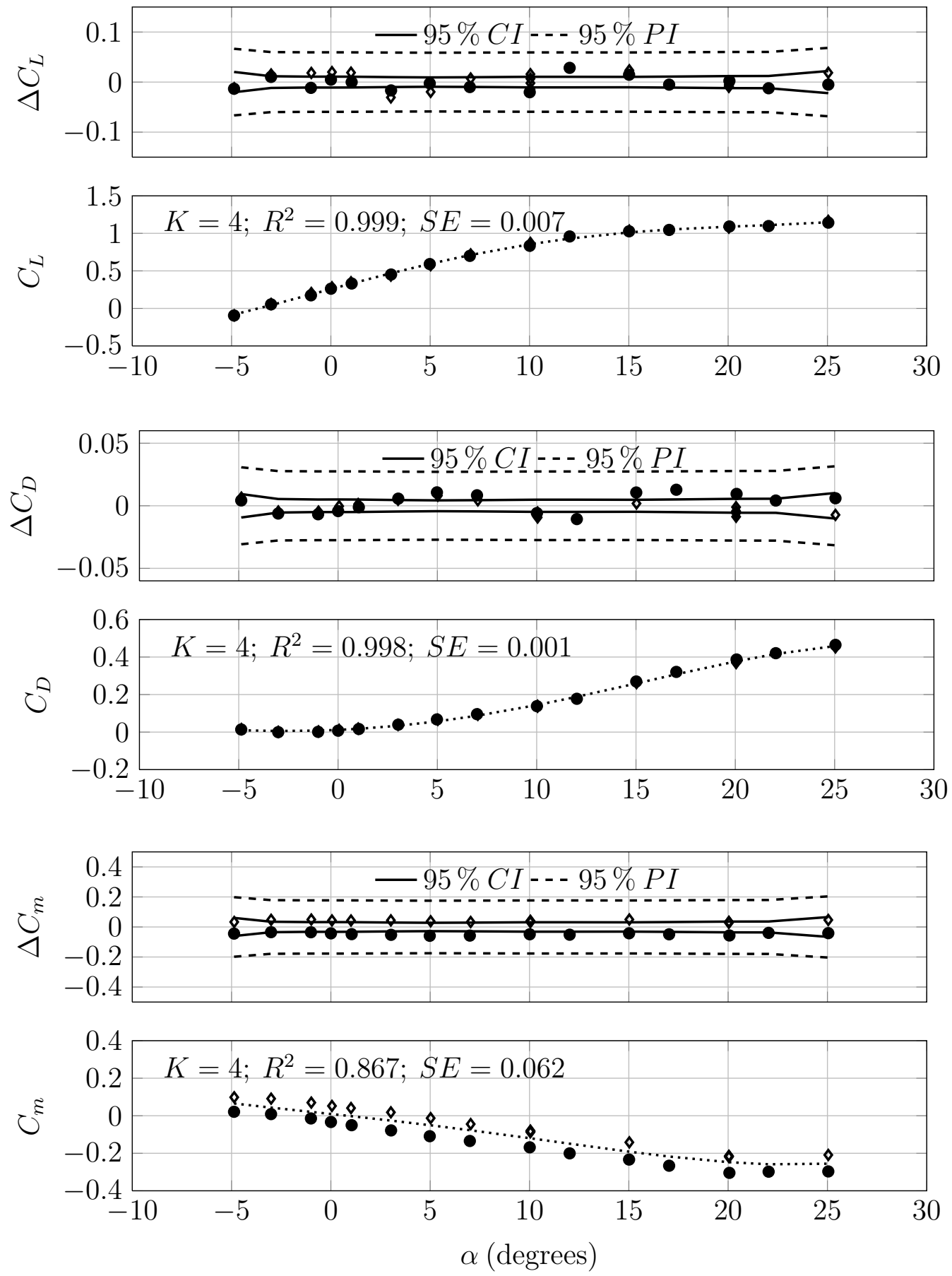

ه Run 19: $q_{\infty}=5.52 \mathrm{psf} ; C_{\mu}=0.0 ; C_{T}=0.0$

- Run 95: $q_{\infty}=5.58 \mathrm{psf} ; C_{\mu}=0.0 ; C_{T}=0.0$

..... Data Sample Mean

Figure 4.1: Group 1: repeatability statistical regression results for $C_{L}$, $C_{D}$, and $C_{m}$. 
Low Pylon; $0^{\circ}$ flap defl.
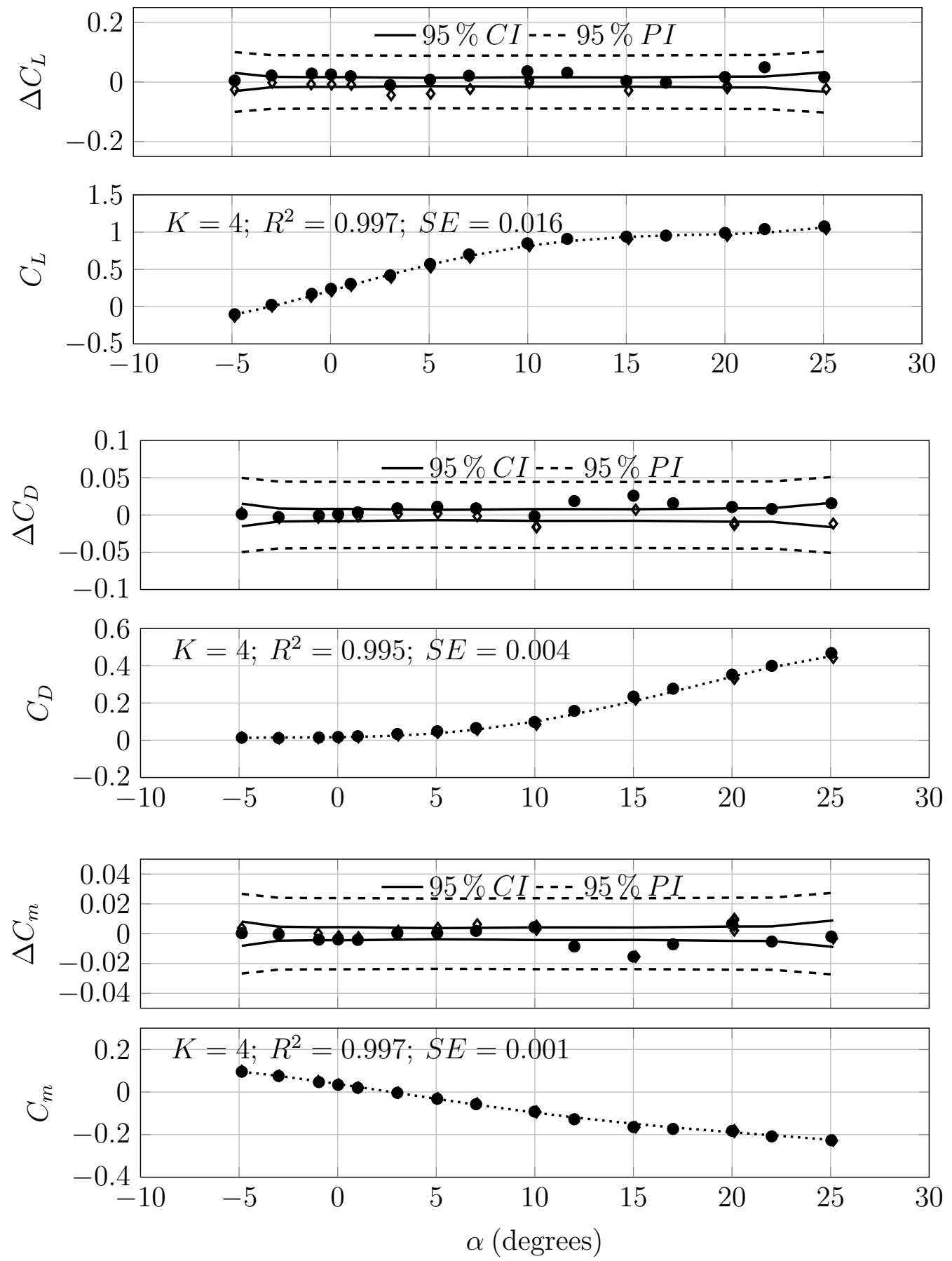

$\diamond$ Run 21: $q_{\infty}=33.94 \mathrm{psf} ; C_{\mu}=0.0 ; C_{T}=0.0$

- Run 105: $q_{\infty}=34.30$ psf; $C_{\mu}=0.0 ; C_{T}=0.0$ ..... Data Sample Mean

Figure 4.2: Group 2: repeatability statistical regression results for $C_{L}$, $C_{D}$, and $C_{m}$. 
Low Pylon; $60^{\circ}$ flap defl.
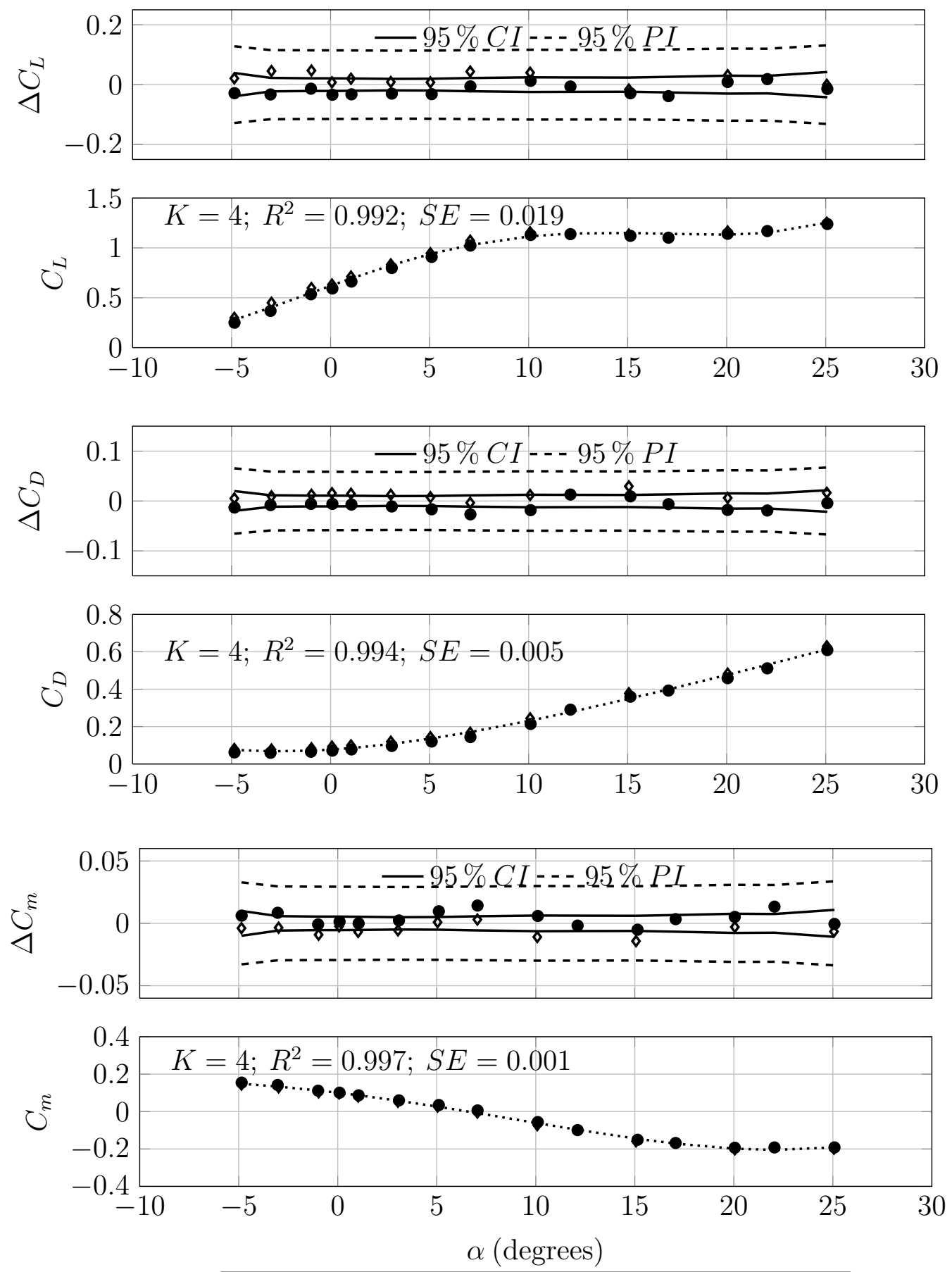

จ Run 26: $q_{\infty}=12.76 \mathrm{psf} ; C_{\mu}=0.0 ; C_{T}=0.0$

- Run 60 : $q_{\infty}=12.08$ psf; $C_{\mu}=0.0 ; C_{T}=0.0$

..... Data Sample Mean

Figure 4.3: Group 3: repeatability statistical regression results for $C_{L}$, $C_{D}$, and $C_{m}$. 
Low Pylon; $0^{\circ}$ flap defl.
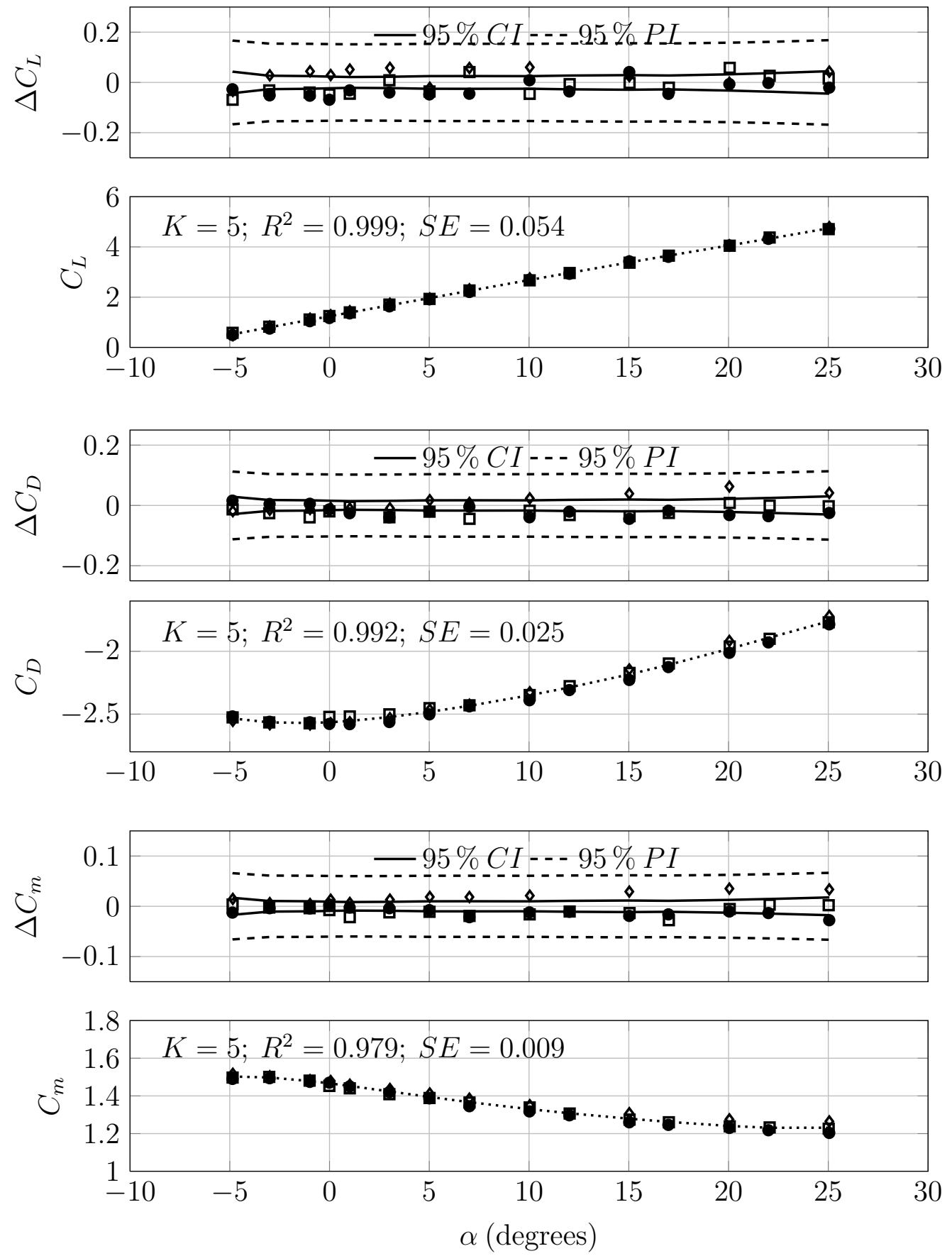

هun 36: $q_{\infty}=5.55 \mathrm{psf} ; C_{\mu}=0.91 ; C_{T}=2.09$

- Run 92: $q_{\infty}=5.63 \mathrm{psf} ; C_{\mu}=0.87 ; C_{T}=2.13$

口 Run 102: $q_{\infty}=5.60 \mathrm{psf} ; C_{\mu}=0.88 ; C_{T}=2.13$

..... Data Sample Mean

Figure 4.4: Group 4: repeatability statistical regression results for $C_{L}$, $C_{D}$, and $C_{m}$. 
Low Pylon; $60^{\circ}$ flap defl.
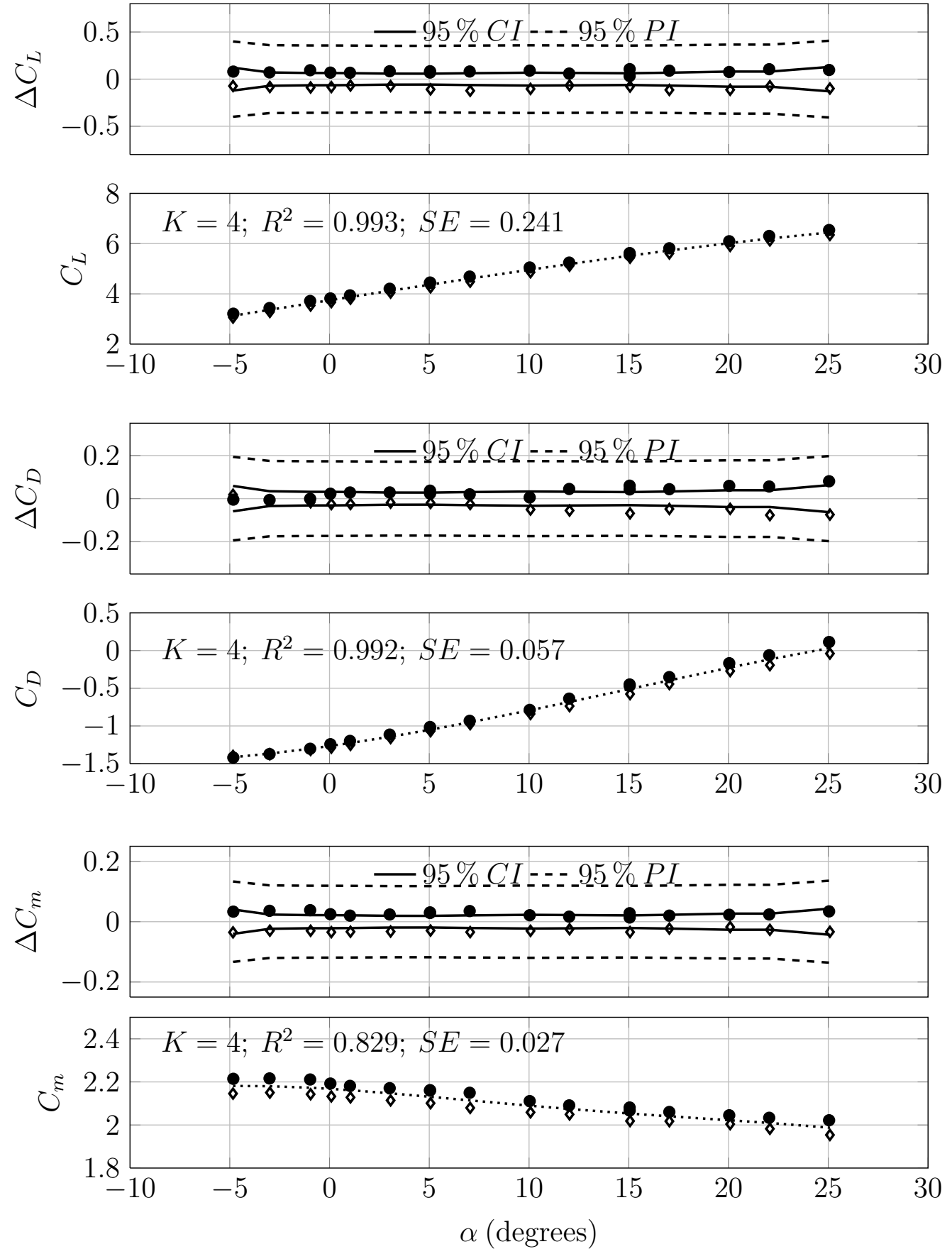

ه Run 46: $q_{\infty}=5.58$ psf; $C_{\mu}=0.82 ; C_{T}=2.12$

- Run 133: $q_{\infty}=5.46 \mathrm{psf} ; C_{\mu}=0.89 ; C_{T}=2.13$

... Data Sample Mean

Figure 4.5: Group 5: repeatability statistical regression results for $C_{L}$, $C_{D}$, and $C_{m}$. 
Low Pylon; $80^{\circ}$ flap defl.
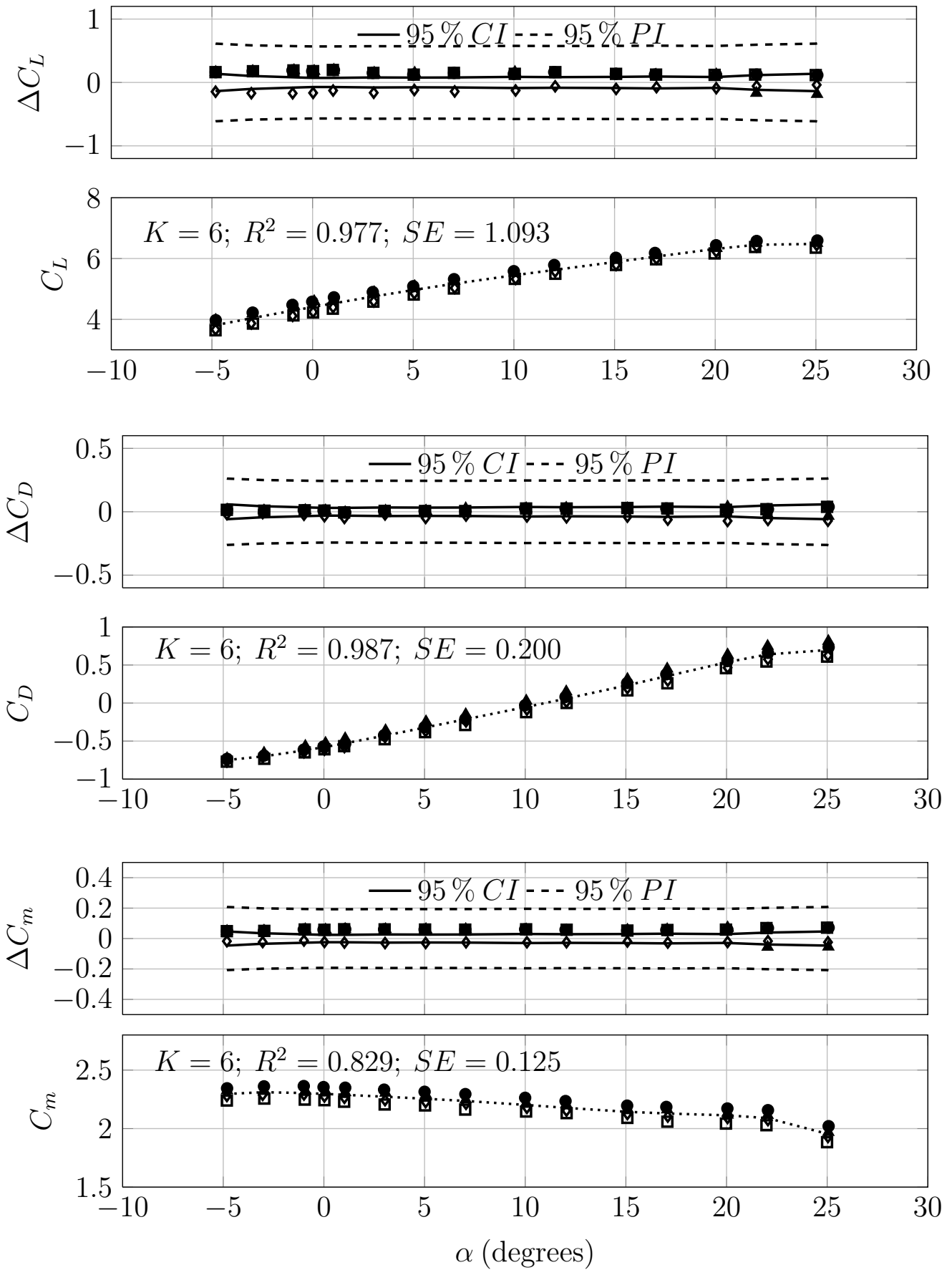

$\diamond$ Run 69: $q_{\infty}=5.56$ psf; $C_{\mu}=0.90 ; C_{T}=2.12$

- Run 81: $q_{\infty}=5.33$ psf; $C_{\mu}=0.95 ; C_{T}=2.12$

口 Run 82: $q_{\infty}=5.68$ psf; $C_{\mu}=0.86 ; C_{T}=2.12$

\ Run 128: $q_{\infty}=5.36$ psf; $C_{\mu}=0.93 ; C_{T}=2.13$ Data Sample Mean

Figure 4.6: Group 7: repeatability statistical regression results for $C_{L}$, $C_{D}$, and $C_{m}$. 
Low Pylon; $80^{\circ}$ flap defl.
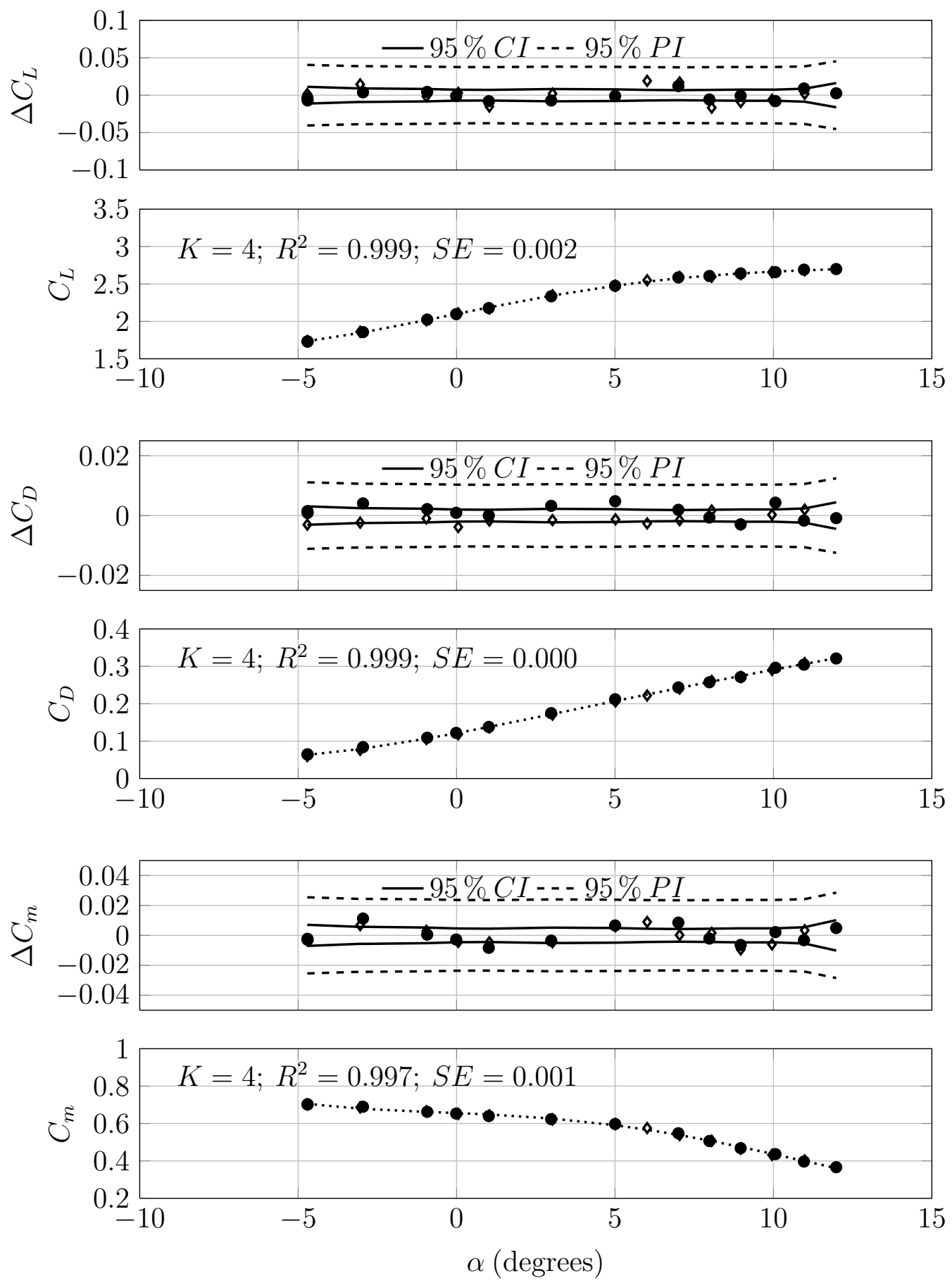

هun 78: $q_{\infty}=33.22 \mathrm{psf} ; C_{\mu}=0.15 ; C_{T}=0.29$

- Run 79: $q_{\infty}=33.09 \mathrm{psf} ; C_{\mu}=0.15 ; C_{T}=0.29$ Data Sample Mean

Figure 4.7: Group 8: repeatability statistical regression results for $C_{L}$, $C_{D}$, and $C_{m}$. 
Low Pylon; $30^{\circ}$ flap defl.
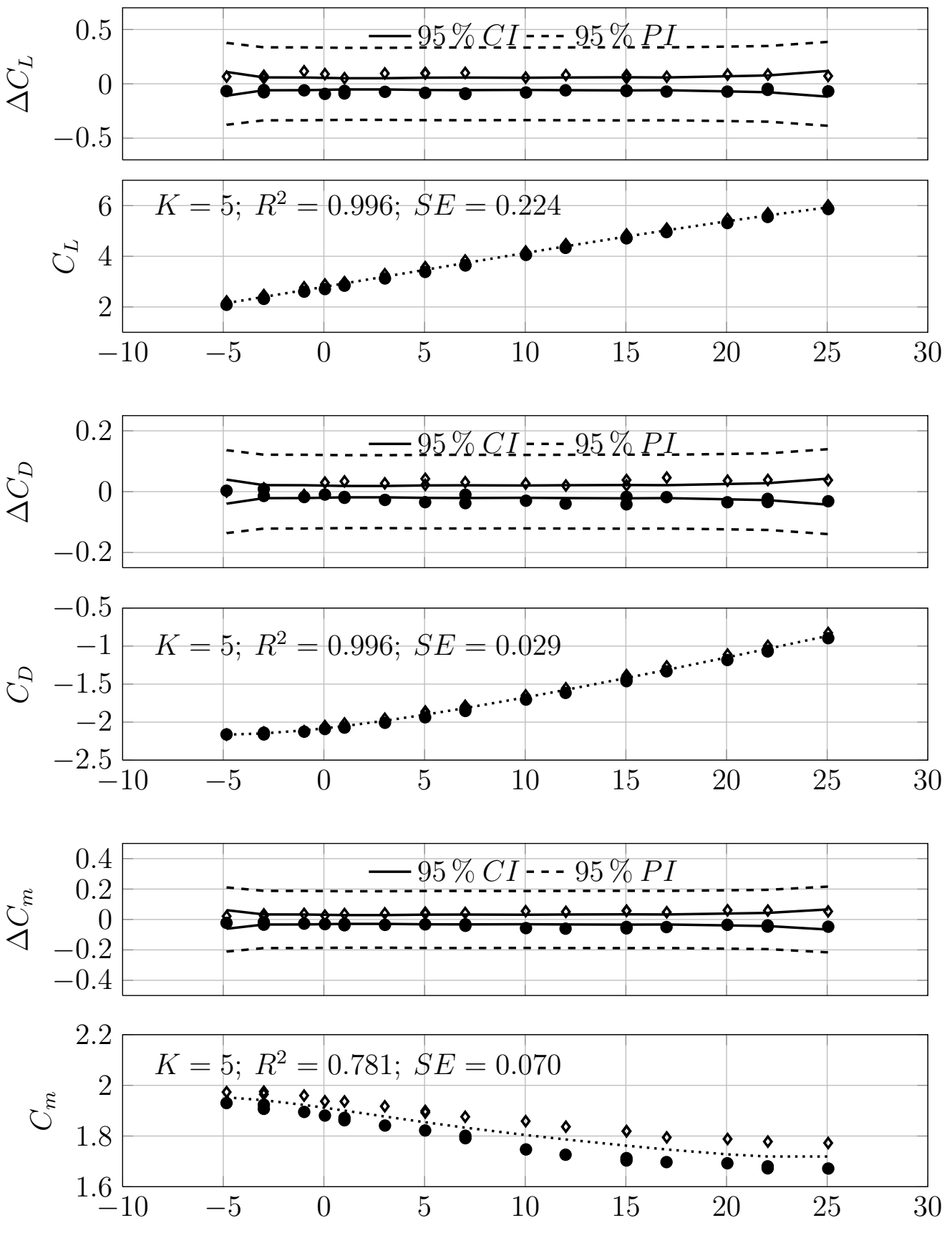

$$
\alpha \text { (degrees) }
$$

$\diamond$ Run 152: $q_{\infty}=5.37 \mathrm{psf} ; C_{\mu}=0.92 ; C_{T}=2.13$

- Run 153: $q_{\infty}=5.44$ psf; $C_{\mu}=0.91 ; C_{T}=2.12$ Data Sample Mean

Figure 4.8: Group 9: repeatability statistical regression results for $C_{L}$, $C_{D}$, and $C_{m}$. 
Clean Wing; $60^{\circ}$ flap defl.
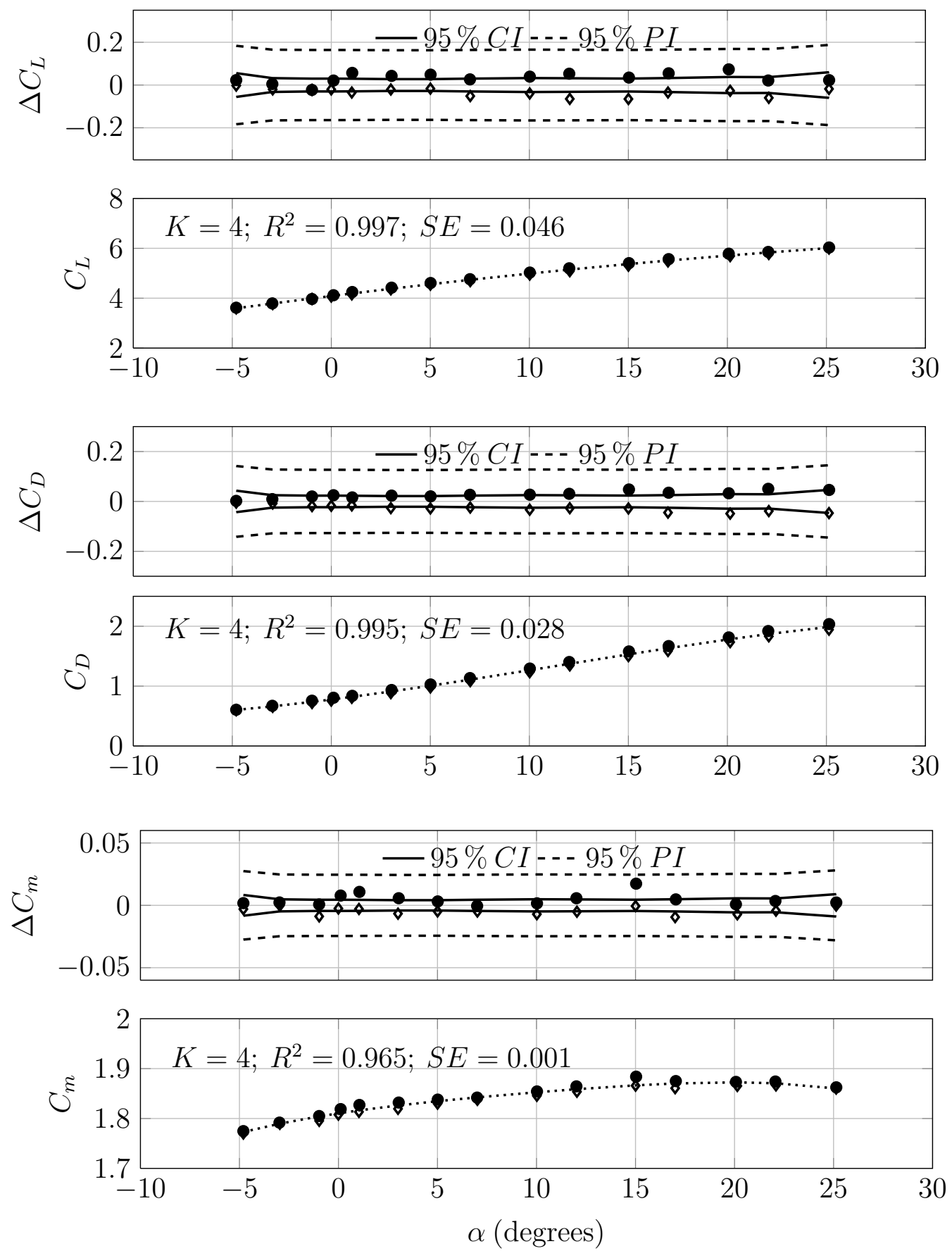

$\diamond$ Run 213: $q_{\infty}=5.32$ psf; $C_{\mu}=0.93$

- Run 218: $q_{\infty}=5.36$ psf; $C_{\mu}=0.92$

..... Data Sample Mean

Figure 4.9: Group 10: repeatability statistical regression results for $C_{L}, C_{D}$, and $C_{m}$. 
TE-only; $60^{\circ}$ flap defl.
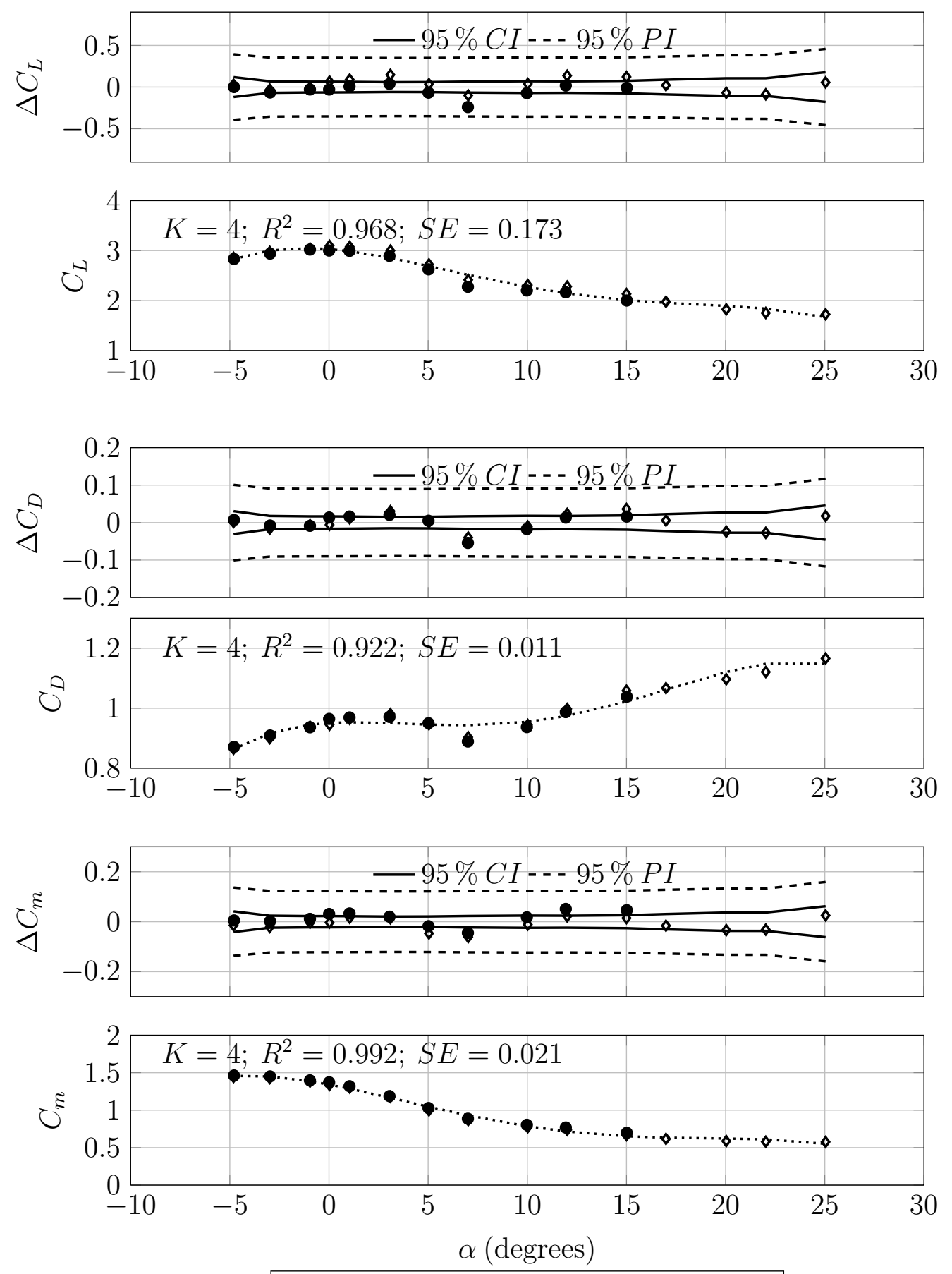

$\diamond$ Run 274: $q_{\infty}=5.48$ psf; $C_{\mu}=0.38$

- Run 290: $q_{\infty}=5.38$ psf; $C_{\mu}=0.40$

... Data Sample Mean

Figure 4.10: Group 12: repeatability statistical regression results for $C_{L}, C_{D}$, and $C_{m}$. 
TE-only; $0^{\circ}$ flap defl.
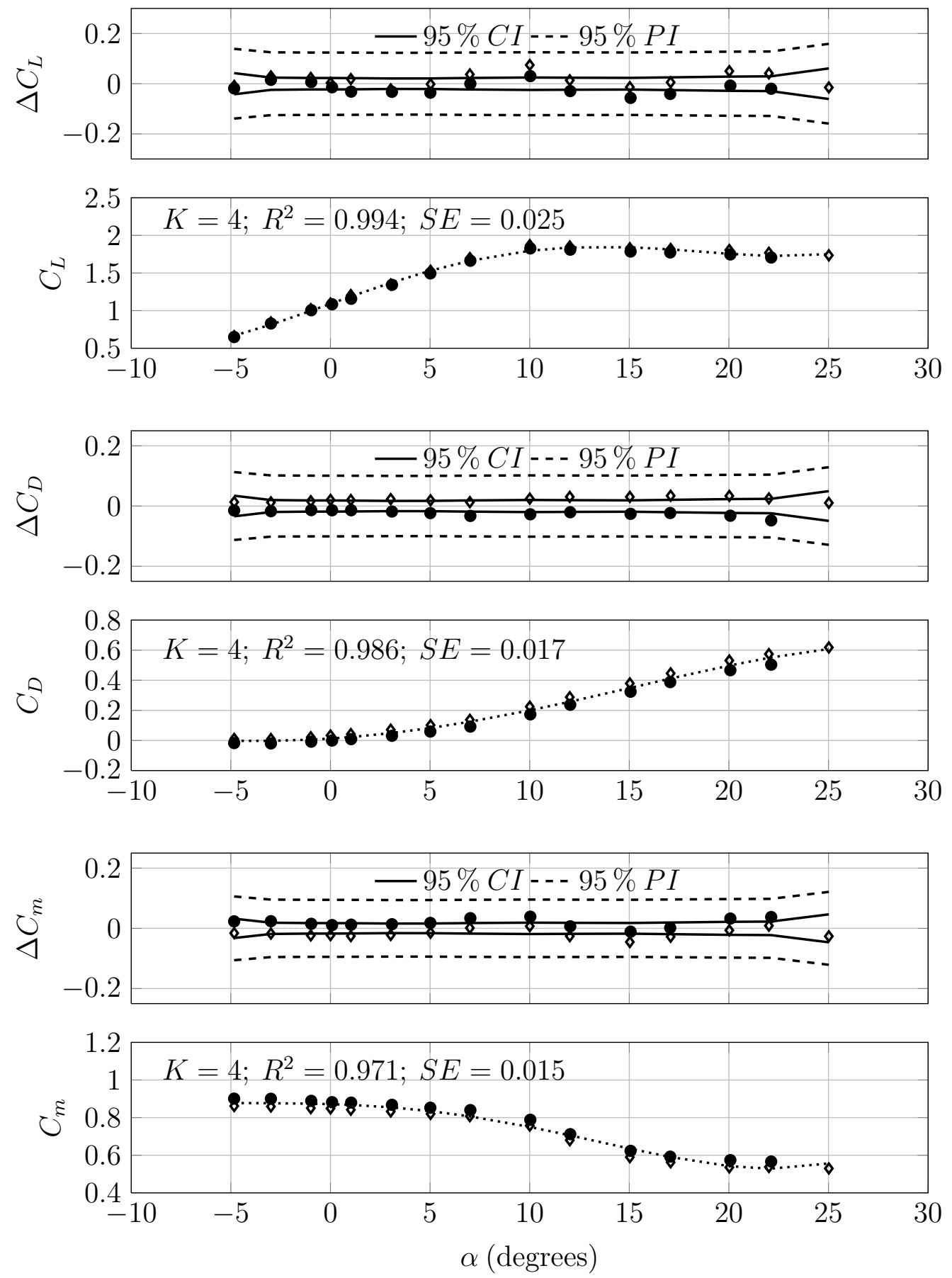

- Run 294: $q_{\infty}=5.52 \mathrm{psf} ; C_{\mu}=0.38$

- Run 311: $q_{\infty}=5.42 \mathrm{psf} ; C_{\mu}=0.41$ Data Sample Mean

Figure 4.11: Group 13: repeatability statistical regression results for $C_{L}, C_{D}$, and $C_{m}$. 


\subsection{Factors Contributing to Non-Repeatability}

There are a large number of possible sources of error that may contribute to non-repeatability in test data, the likely sources are discussed here. They include (but are not limited to): balance accuracy, balance temperature effects, angle of attack measurement, repeatability of wind tunnel flow conditions, and HPA properties. All of these sources will be addressed and/or quantified in the following sections. A potentially significant, but un-quantified, source of data non-repeatability has to do with pressure tubes and other cables shifting or changing in size due to temperature fluctuations within the model, that, when bridging the metric and non-metric sides of the balance causes fouling to occur. Extreme care was taken to ensure there was no fouling and it is believed to not have occurred.

\subsubsection{Balance Calibration Accuracy}

The balance calibration accuracy is presented in Table 4.2. The statistics listed are given at a $95 \%$ confidence level and pertain to how well the calibration matrix fits the calibration, not the overall uncertainty of the balance measurements. In the table, load residuals are defined as the difference between the load that was used for the regression analysis of the calibration data and the corresponding fitted value. Statistical quantities are computed using arithmetic mean as population mean. Note this differs from the MRSA approach which uses a least-squares curve fit to estimate the mean. The full-scale (FS) accuracy is stated in terms of the largest outlying load residual during calibration. Please note the capacity listed in the table is the calibrated capacity, it represents the operational capacity and not the overall capacity of the balance. 
Table 4.2: Summary of Balance Calibration Accuracies.

\begin{tabular}{crrrrr}
\hline Component & Capacity & Load Residuals & \multicolumn{2}{c}{ FS Accuracy } \\
\hline Normal Force, lb $\mathrm{b}_{\mathrm{f}}$ & \pm 5000 & \pm 3.87 & $0.077 \%$ & \pm 13.31 & $0.266 \%$ \\
Side Force, $\mathrm{lb}_{\mathrm{f}}$ & \pm 2500 & \pm 4.67 & $0.187 \%$ & \pm 10.49 & $0.420 \%$ \\
Axial Force, lb $\mathrm{f}$ & \pm 1200 & \pm 2.71 & $0.226 \%$ & \pm 8.25 & $0.687 \%$ \\
Rolling Moment, in $\mathrm{lb}_{\mathrm{f}}$ & $\pm 27,300$ & \pm 107.33 & $0.393 \%$ & \pm 431.89 & $1.582 \%$ \\
Pitching Moment, in lb $\mathrm{b}_{\mathrm{f}}$ & $\pm 29,000$ & \pm 34.41 & $0.119 \%$ & \pm 82.27 & $0.284 \%$ \\
Yawing Moment, in $\mathrm{lb}_{\mathrm{f}}$ & $\pm 10,500$ & \pm 48.77 & $0.464 \%$ & \pm 147.78 & $1.407 \%$ \\
\hline
\end{tabular}

The balance calibration accuracies are plotted in coefficient form and presented as a function of dynamic pressure in Figure 4.12. As seen, the balance yields more accurate coefficients at higher dynamic pressures. The tested dynamic pressure ranges from 5.5 psf at $40 \mathrm{kts}$ to $33.4 \mathrm{psf}$ at $100 \mathrm{kts}$. Figures 4.13 to 4.23 show the $95 \%$ balance accuracies plotted against $95 \%$ data scatter intervals. As seen in the plots, the data scatter falls outside the bounds of $95 \%$ confidence in the balance calibration accuracy for the majority of the groups. This would seem to suggest that confidence in the accuracy of repeatable measurements is due more to the repeatability of the measurement than, say, an unknown measurement bias; a satisfactory result.

\subsubsection{Angle of Attack}

The determination of the angle of attack is affected by several parameters including the measurement itself and the test section flow angularity. It is important to quantify, or attempt to quantify thse factors because the angle of 

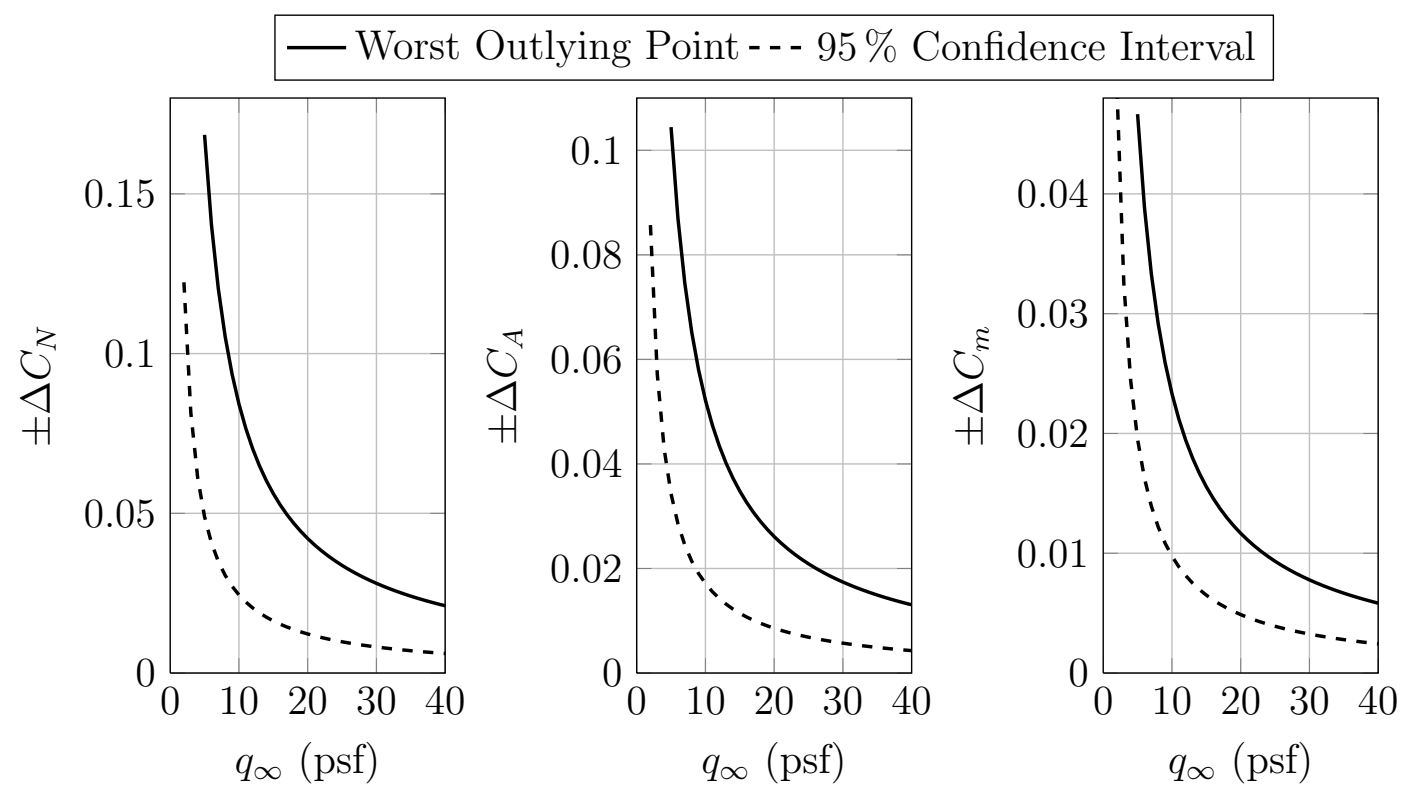

Figure 4.12: Balance accuracy bands in coefficient form, based on the values listed in Table 4.2.

attack has a direct impact on the calculation of the lift and drag coefficients.

$$
\begin{aligned}
& C_{L}=C_{N} \cos \alpha-C_{A} \sin \alpha \\
& C_{D}=C_{N} \sin \alpha+C_{A} \cos \alpha
\end{aligned}
$$

Using a root-mean-squared estimation of the error, the contribution of angle of attack errors to the lift and drag coefficients is

$$
\begin{gathered}
\Delta C_{L}=-C_{D} \Delta \alpha(\pi / 180) \\
\Delta C_{D}=C_{L} \Delta \alpha(\pi / 180)
\end{gathered}
$$

The primary measurement of angle of attack came from the onboard Schaevitz and QA-2000 sensors. These sensors were mounted in the nose of the model and 

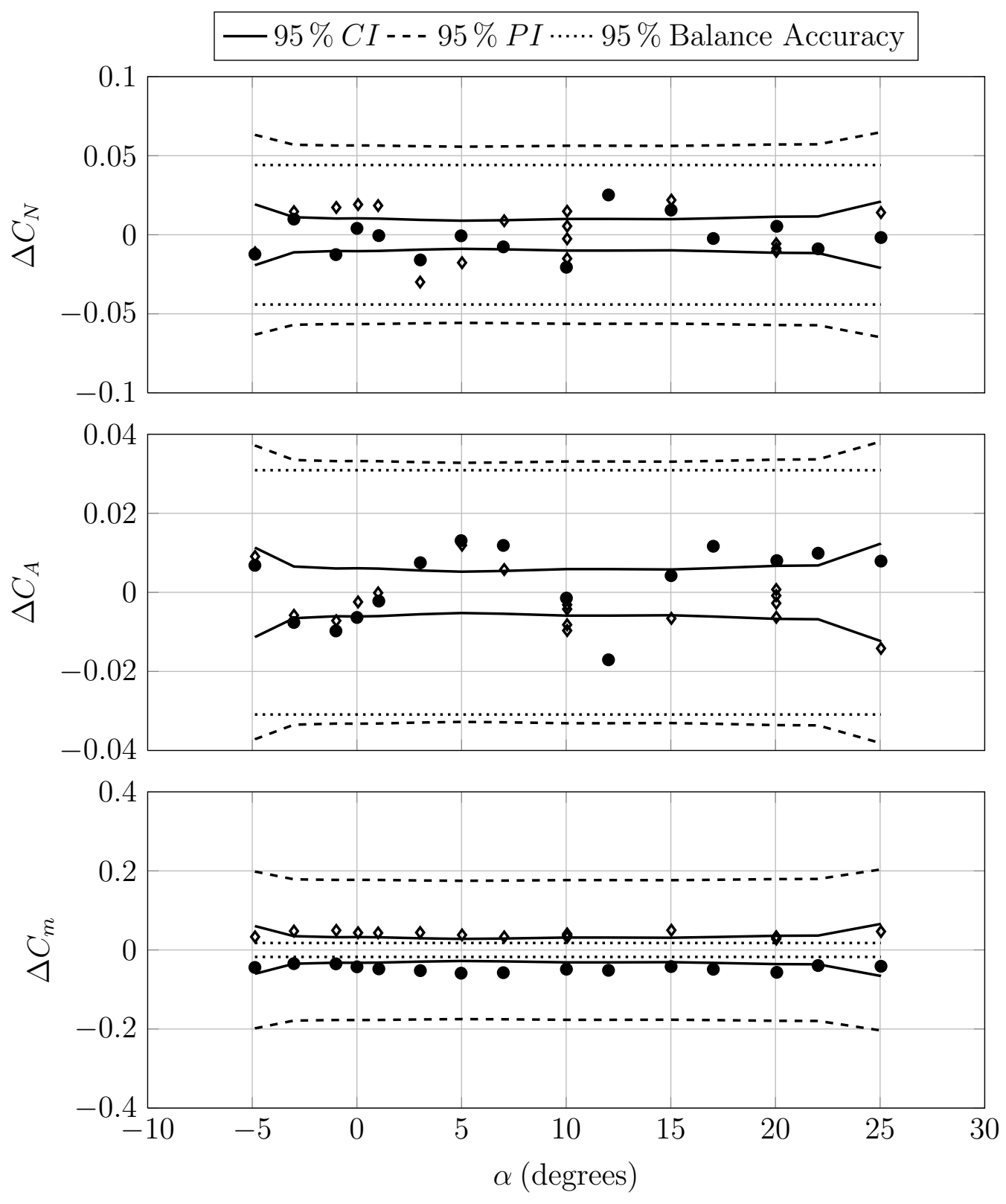

$\diamond$ Run 19: $q_{\infty}=5.52 \mathrm{psf} ; C_{\mu}=0.0 ; C_{T}=0.0$

$\bullet$ Run 95: $q_{\infty}=5.58$ psf; $C_{\mu}=0.0 ; C_{T}=0.0$

Figure 4.13: Group 1: Balance calibration accuracy statistical results of $C_{N}, C_{A}$, and $C_{m}$. 

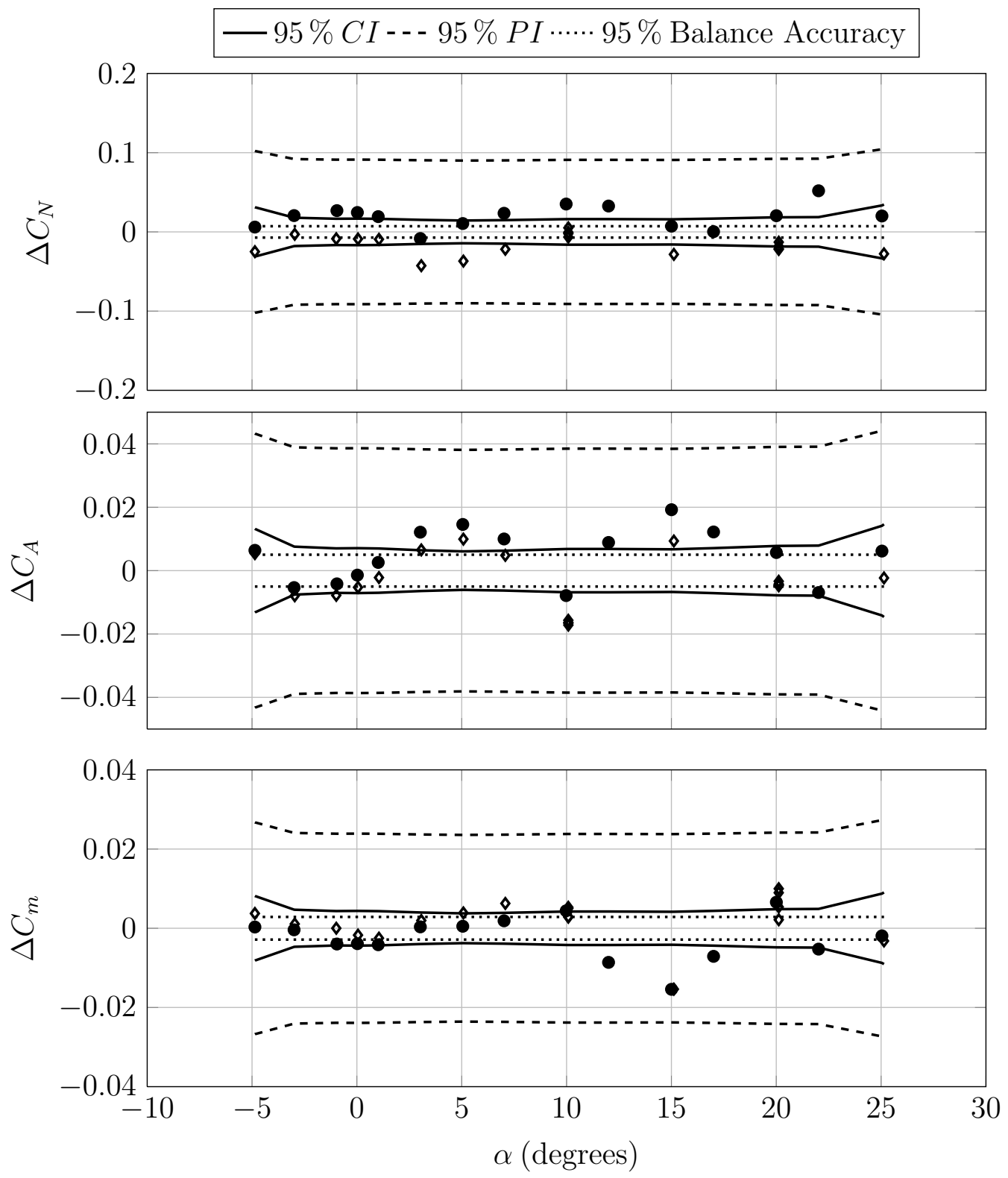

$\diamond$ Run 21: $q_{\infty}=33.94$ psf; $C_{\mu}=0.0 ; C_{T}=0.0$

$\bullet$ Run $105: q_{\infty}=34.30$ psf; $C_{\mu}=0.0 ; C_{T}=0.0$

Figure 4.14: Group 2: Balance calibration accuracy statistical results of $C_{N}, C_{A}$, and $C_{m}$. 

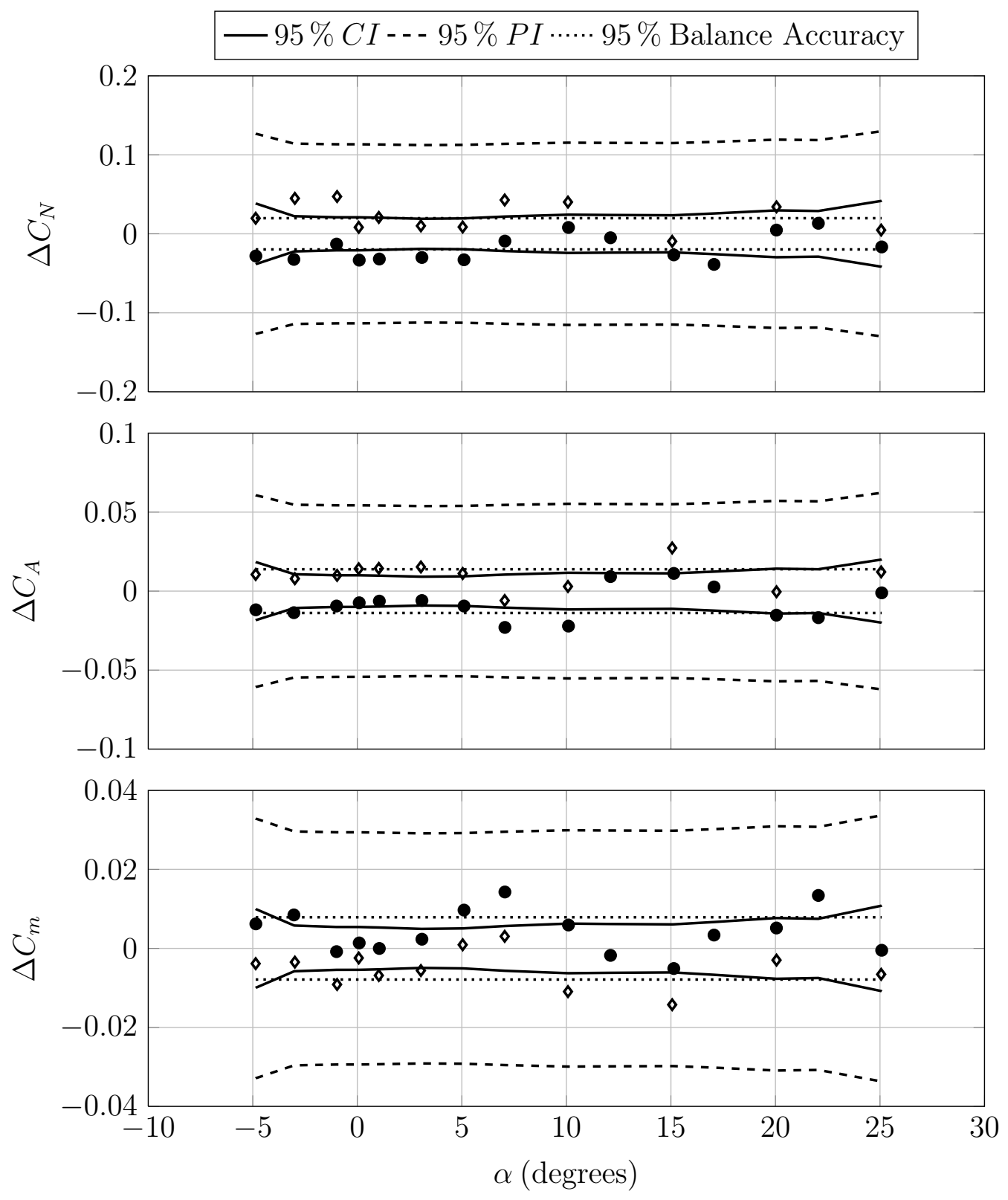

$\diamond$ Run $26: q_{\infty}=12.76 \mathrm{psf} ; C_{\mu}=0.0 ; C_{T}=0.0$ -Run 60 : $q_{\infty}=12.08 \mathrm{psf} ; C_{\mu}=0.0 ; C_{T}=0.0$

Figure 4.15: Group 3: Balance calibration accuracy statistical results of $C_{N}, C_{A}$, and $C_{m}$. 

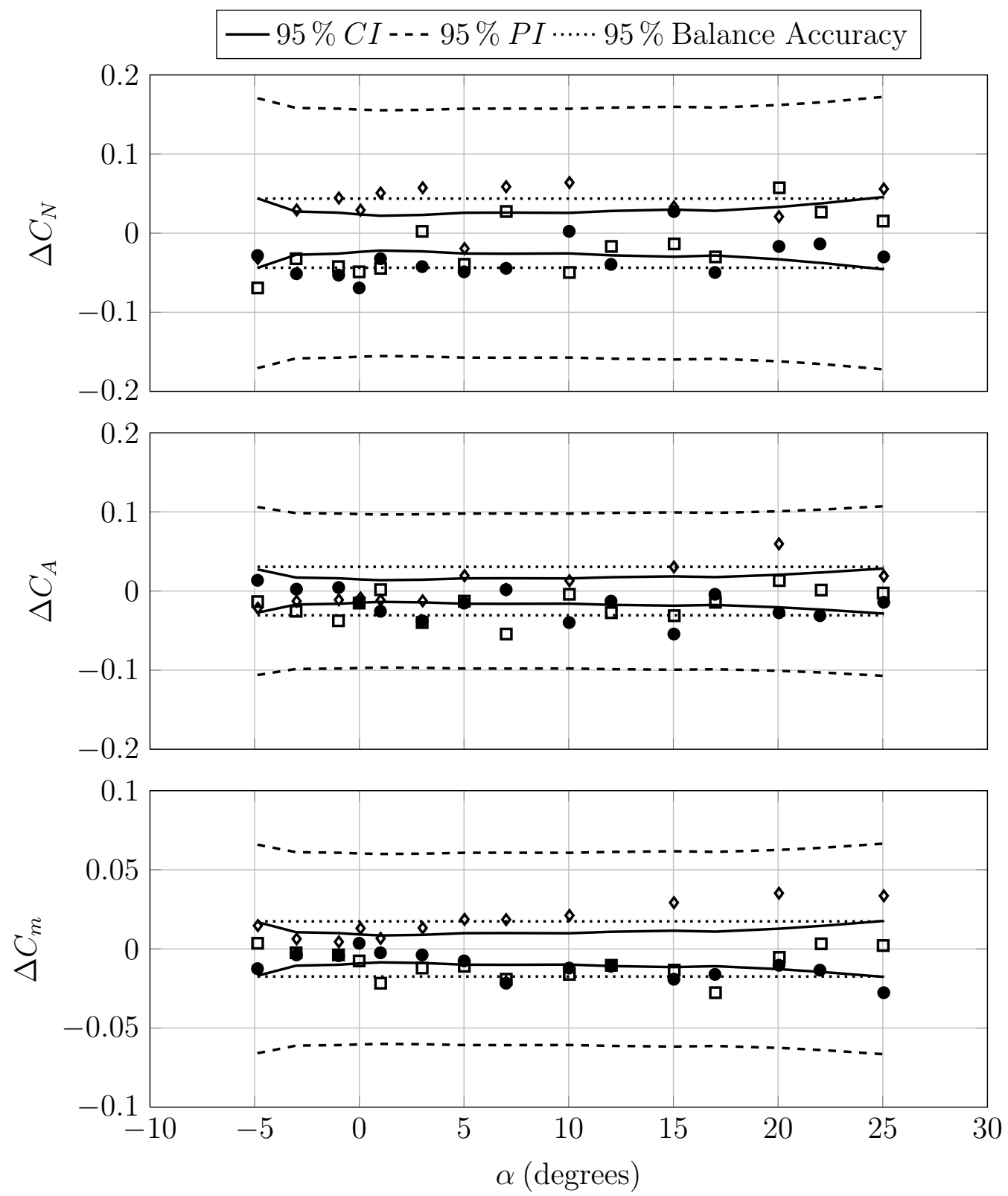

$\diamond$ Run $36: q_{\infty}=5.55$ psf; $C_{\mu}=0.91 ; C_{T}=2.09$

$\bullet$ Run 92: $q_{\infty}=5.63$ psf; $C_{\mu}=0.87 ; C_{T}=2.13$

ฉRun $102: q_{\infty}=5.60 \mathrm{psf} ; C_{\mu}=0.88 ; C_{T}=2.13$

Figure 4.16: Group 4: Balance calibration accuracy statistical results of $C_{N}, C_{A}$, and $C_{m}$. 

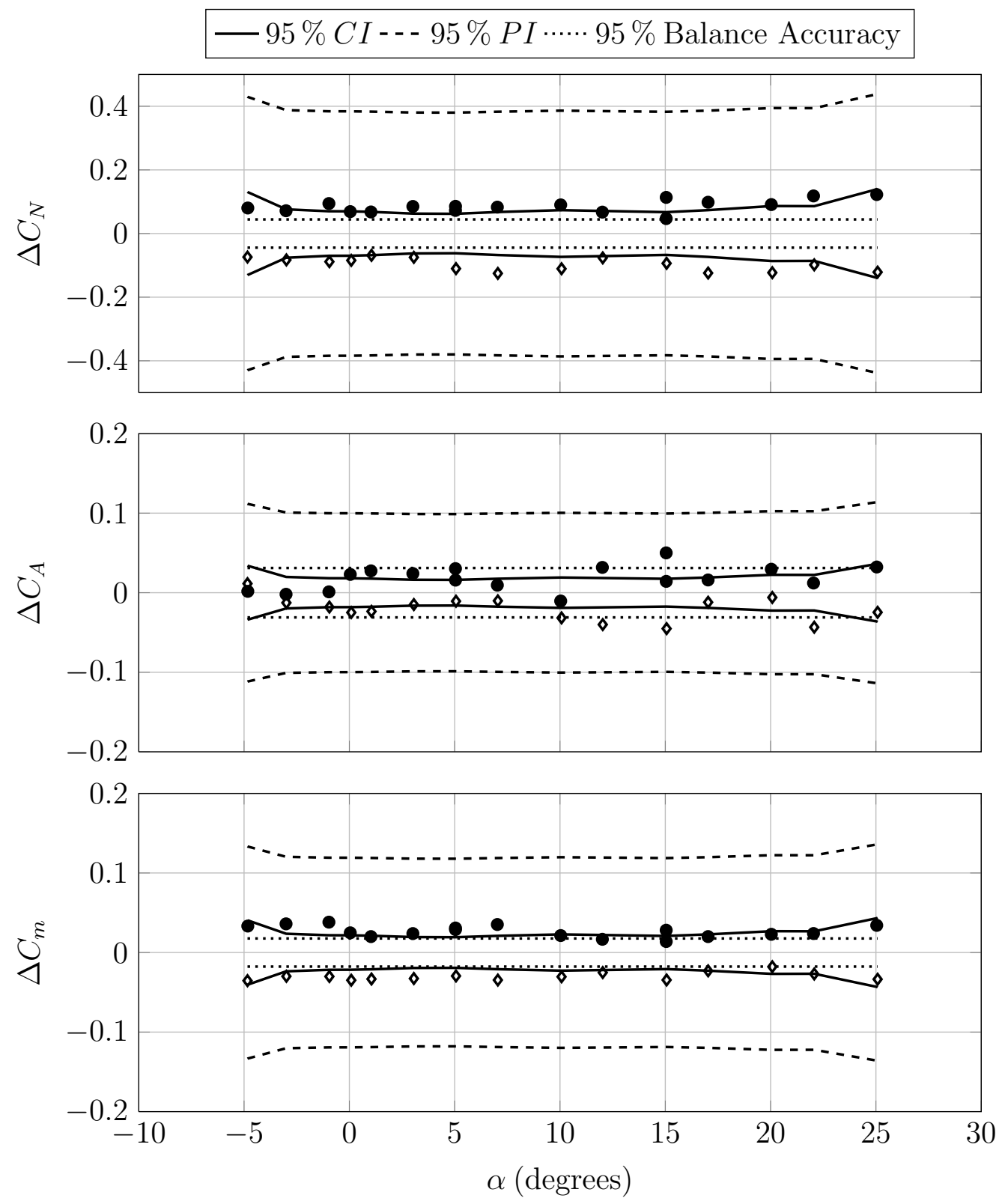

$\diamond$ Run $46: q_{\infty}=5.58 \mathrm{psf} ; C_{\mu}=0.82 ; C_{T}=2.12$

$\bullet$ Run $133: q_{\infty}=5.46 \mathrm{psf} ; C_{\mu}=0.89 ; C_{T}=2.13$

Figure 4.17: Group 5: Balance calibration accuracy statistical results of $C_{N}, C_{A}$, and $C_{m}$. 

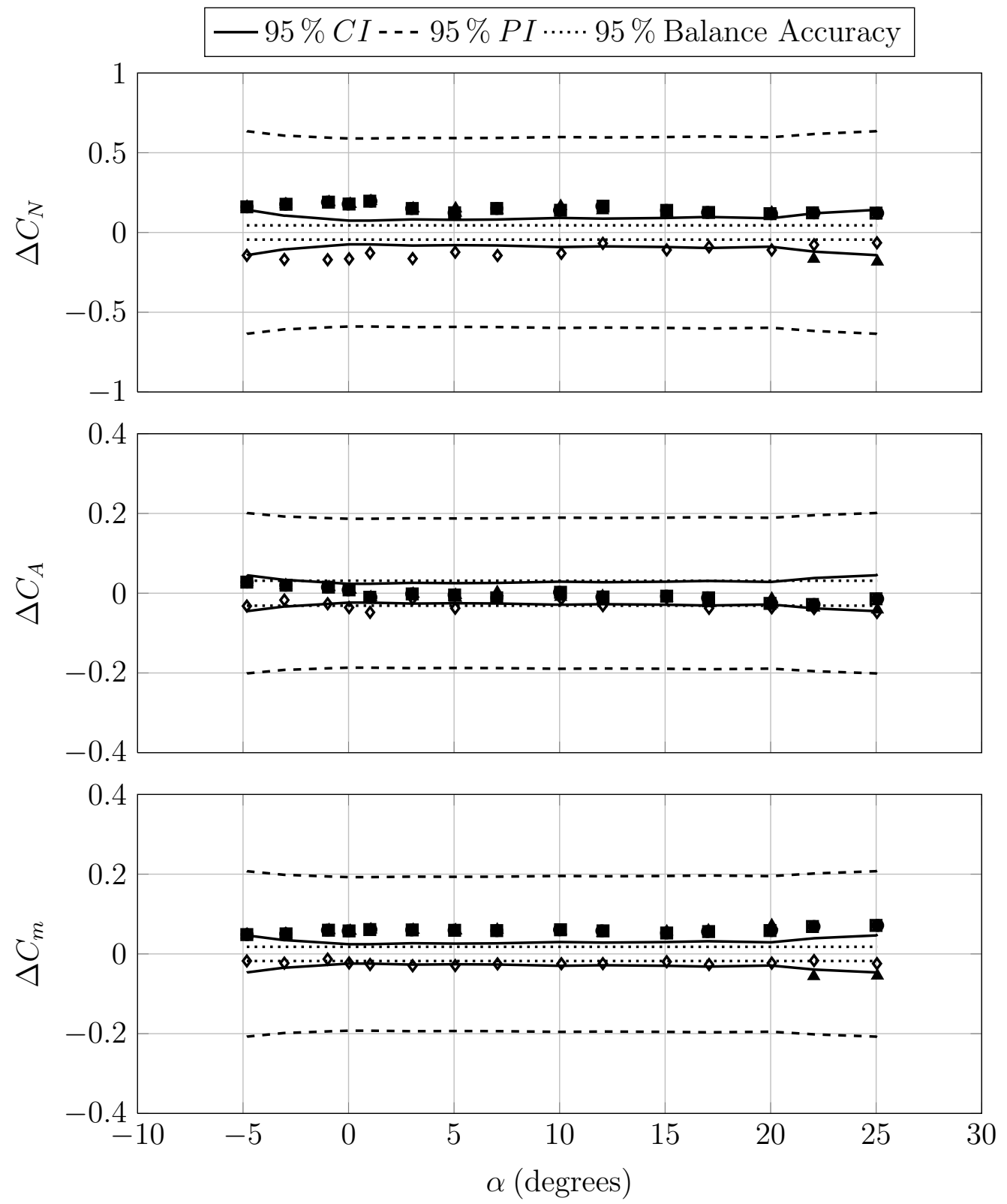

$\diamond$ Run 69: $q_{\infty}=5.56 \mathrm{psf} ; C_{\mu}=0.90 ; C_{T}=2.12$

$\bullet$ Run 81: $q_{\infty}=5.33$ psf; $C_{\mu}=0.95 ; C_{T}=2.12$

aRun 82: $q_{\infty}=5.68 \mathrm{psf} ; C_{\mu}=0.86 ; C_{T}=2.12$

৯Run $128: q_{\infty}=5.36$ psf; $C_{\mu}=0.93 ; C_{T}=2.13$

Figure 4.18: Group 7: Balance calibration accuracy statistical results of $C_{N}, C_{A}$, and $C_{m}$. 

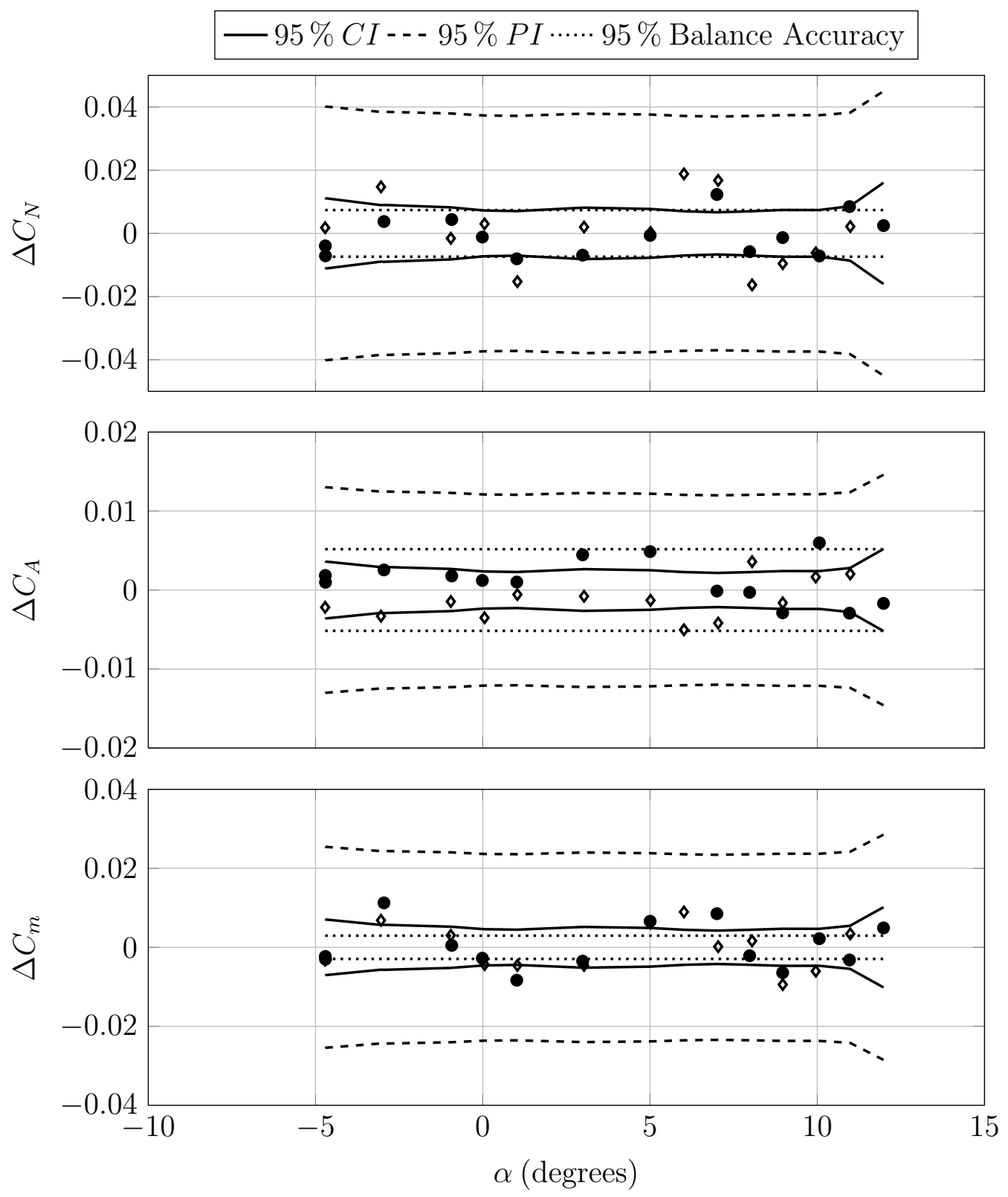

$\diamond$ Run 78: $q_{\infty}=33.22$ psf; $C_{\mu}=0.15 ; C_{T}=0.29$

-Run $79: q_{\infty}=33.09 \mathrm{psf} ; C_{\mu}=0.15 ; C_{T}=0.29$

Figure 4.19: Group 8: Balance calibration accuracy statistical results of $C_{N}, C_{A}$, and $C_{m}$. 

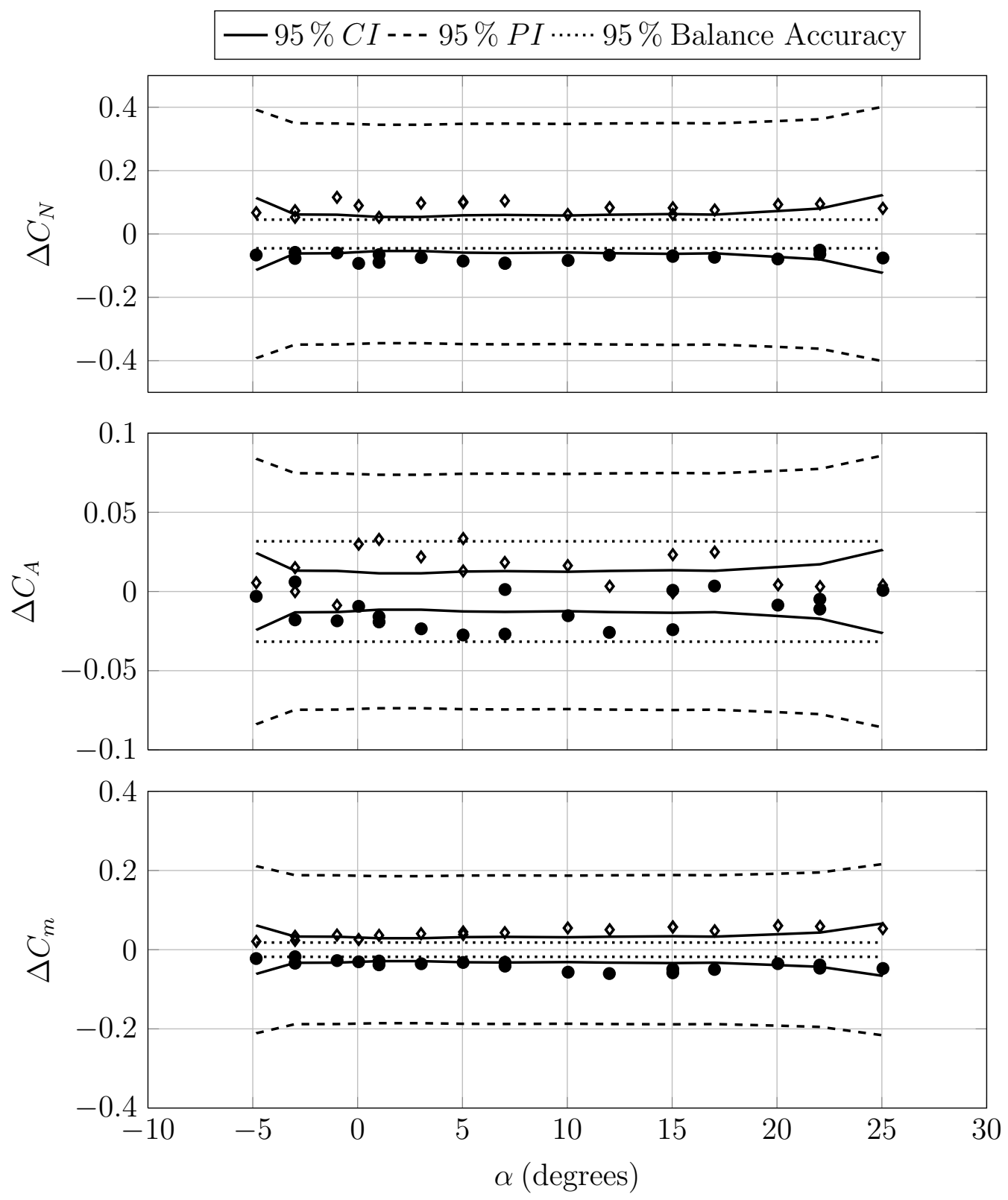

$\diamond$ Run $152: q_{\infty}=5.37$ psf; $C_{\mu}=0.92 ; C_{T}=2.13$ -Run 153: $q_{\infty}=5.44$ psf; $C_{\mu}=0.91 ; C_{T}=2.12$

Figure 4.20: Group 9: Balance calibration accuracy statistical results of $C_{N}, C_{A}$, and $C_{m}$. 

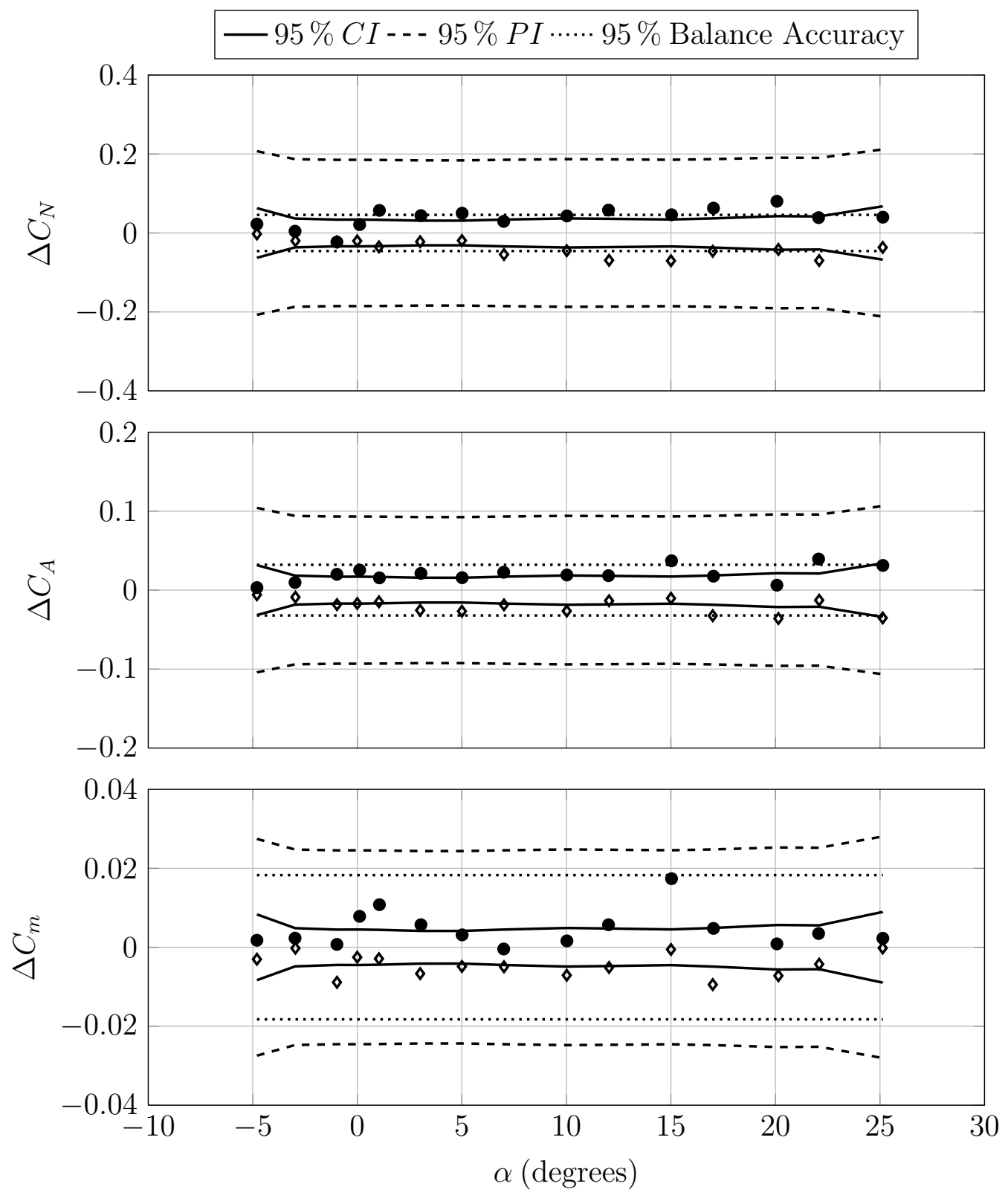

$\diamond$ Run 213: $q_{\infty}=5.32 \mathrm{psf} ; C_{\mu}=0.93$

$\bullet$ Run 218: $q_{\infty}=5.36 \mathrm{psf} ; C_{\mu}=0.92$

Figure 4.21: Group 10: Balance calibration accuracy statistical results of $C_{N}, C_{A}$, and $C_{m}$. 

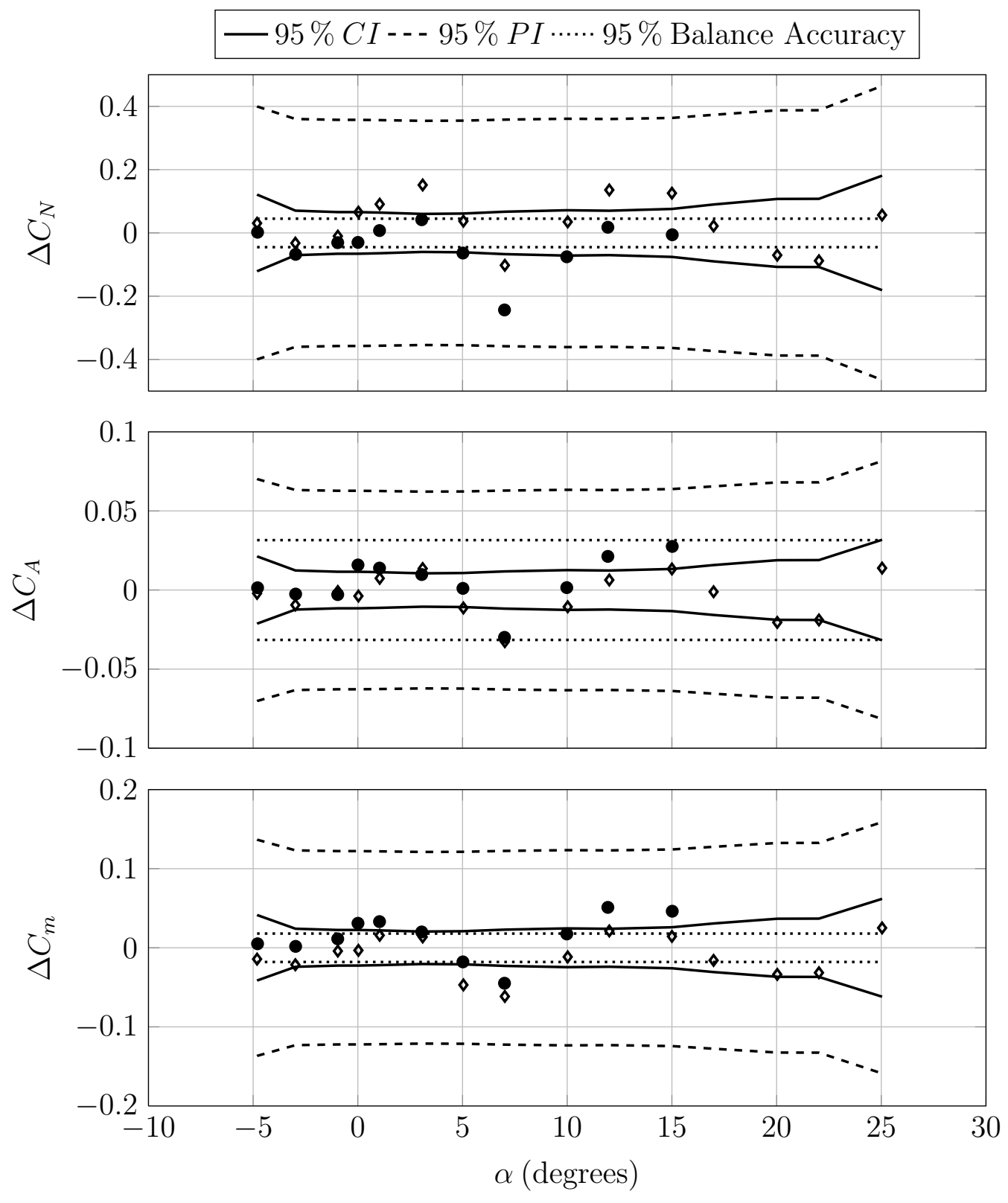

$\diamond$ Run 274: $q_{\infty}=5.48$ psf; $C_{\mu}=0.38$

$\bullet$ Run $290: q_{\infty}=5.38$ psf; $C_{\mu}=0.40$

Figure 4.22: Group 12: Balance calibration accuracy statistical results of $C_{N}, C_{A}$, and $C_{m}$. 

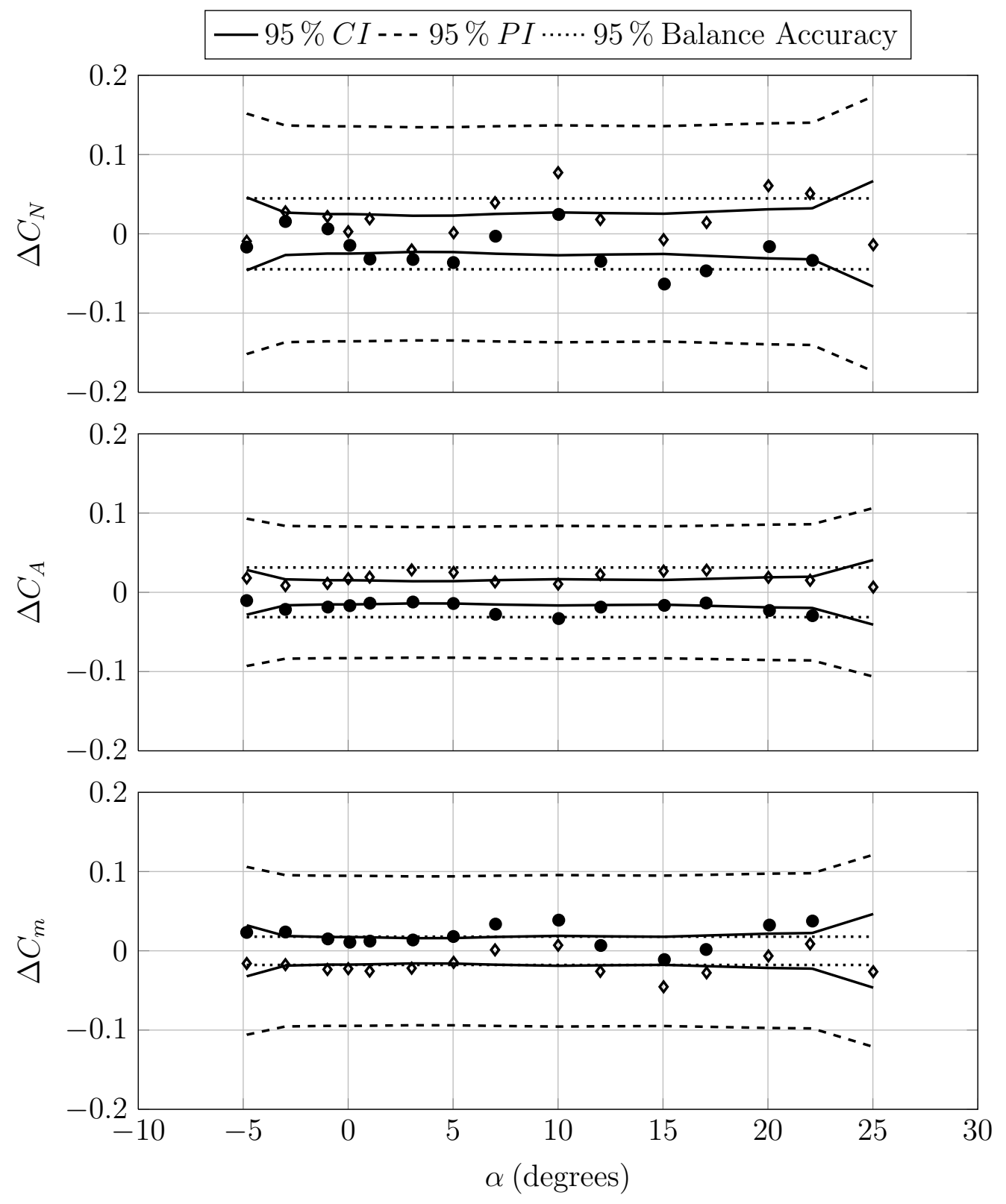

$\diamond$ Run 294: $q_{\infty}=5.52$ psf; $C_{\mu}=0.38$

$\bullet$ Run 311 : $q_{\infty}=5.42$ psf; $C_{\mu}=0.41$

Figure 4.23: Group 13: Balance calibration accuracy statistical results of $C_{N}, C_{A}$, and $C_{m}$. 
were subject to model vibrations. For high-speed high-lift test points, the model vibrations were sufficiently large to result in variation in the angle of attack sensors as high as $\pm 0.3^{\circ}$. For a lift coefficient of 3 (higher than what was seen at the highest dynamic pressure), the contribution to the drag coefficient error is 0.016 .

Two other factors may contribute to non-repeatability with respect to the model angle of attack. First is the test section flow angularity. As described earlier, the most recent tunnel characterization was completed in 1989 by Zell \& Flack [23] and flow angularity is not considered to be known at this time. Secondly, applying the MRSA over the entire angle of attack range (i.e. from $-5^{\circ}$ to $+25^{\circ}$ ) could affect the repeatability analysis; at high angles of attack, unsteady aerodynamic effects resulting from stall could bias the statistical regression.

\subsubsection{Flow Conditions}

Repeatability in the wind tunnel flow conditions has a direct impact on the aerodynamic data. Table 4.3 lists the repeatability for relevant flow measurements and calculated quantities. The table lists the mean value and average $95 \%$ confidence and prediction intervals across all repeat run groups. As the wind tunnel is un-pressurized, velocity is the only directly controlled flow property. As such, the repeatability of velocity is the best of all quantities shown; the largest $95 \%$ prediction interval is $\pm 0.57 \mathrm{kts}$. Measurements such as total and static pressures/temperatures are sensitive to the conditions outside the tunnel walls; these measurements affect the calculated quantities of $R e, M$, and $q$. The variation in total and static pressures are generally small, the largest prediction interval is \pm 0.487 psia in tunnel total pressure and \pm 0.477 psia in tunnel cen- 
terline static pressure. $95 \%$ confidence interval in the total temperature is as high as $\pm 9.31^{\circ} \mathrm{F}$. Overall, large scatter in the tunnel temperature and pressures should not be as significant to repeatability for this model because the flow field is dominated by the CCW. Non-repeatability with respect to flow conditions is likely to be driven by the slot flow.

Table 4.4 presents mean value and average $95 \%$ confidence and prediction intervals for the low pressure line temperature measurements. The instruments are located on the orifice plate assembly, and in the left and right low pressure plenum. Here, time-of-day plays a significant role in the repeatability of the temperature measurements. Runs in the morning have HPA temperatures that are significantly colder than those later in the day as the air is continuously heated. The potential effect on repeatability has to do with the mode of operation on the low pressure side and the effect of the temperature gradients on the slot flow. The low pressure side was operated in flow control mode; in which, the digital valve sets and holds a constant mass flow rate. The implication of operating in this mode is that as the line temperature increases, the pressure rises to maintain a constant mass flow rate. The effect of this is seen in the repeatability of the plenum pressures for runs with higher temperature variations. When comparing between groups 12 and 13, for example, freestream values are repeatable to approximately the same magnitude. The confidence and prediction intervals in temperature are larger for group 13, however, resulting in pressure intervals that are nearly three times as large. Looking further at these two groups, it would appear that force and moment coefficients for group 12 are less repeatable, see Figure 4.10. Here, however, a flaw in extending the regression over the entire angle of attack range is evident. Including the region beyond $\alpha=1^{\circ}$ where the flow physics are highly non-linear results in a poor correlation and fit. 
Whereas it is possible for changes in plenum temperature to create run-torun slot height differences, they are unexpected as Milholen noted [12]. Thermal effects in the slot flow were not observed during calibration.

Table 4.3: Flow condition repeatability.

\begin{tabular}{|c|c|c|c|c|c|c|c|c|}
\hline Group & Quantity & $P_{t}$, psia & $P_{s}$, psia & $T_{t},{ }^{\circ} \mathrm{F}$ & $q, \mathrm{psf}$ & $V$, kts & $M$ & $R e_{c}, 10^{6}$ \\
\hline \multirow{3}{*}{1} & Mean & 14.876 & 14.837 & 49.98 & 5.55 & 39.95 & 0.0609 & 0.8303 \\
\hline & $95 \% C I$ & \pm 0.019 & \pm 0.019 & \pm 0.34 & \pm 0.02 & \pm 0.08 & \pm 0.0001 & \pm 0.0017 \\
\hline & $95 \% P I$ & \pm 0.096 & \pm 0.096 & \pm 1.70 & \pm 0.12 & \pm 0.41 & \pm 0.0005 & \pm 0.0083 \\
\hline \multirow{3}{*}{2} & Mean & 14.840 & 14.602 & 53.58 & 34.10 & 100.02 & 0.1522 & 2.0342 \\
\hline & $95 \% C I$ & \pm 0.029 & \pm 0.030 & \pm 2.30 & \pm 0.15 & \pm 0.11 & \pm 0.0005 & \pm 0.0136 \\
\hline & $95 \% P I$ & \pm 0.145 & \pm 0.150 & \pm 11.50 & \pm 0.73 & \pm 0.57 & \pm 0.0024 & \pm 0.0681 \\
\hline \multirow{3}{*}{3} & Mean & 14.834 & 14.748 & 52.89 & 12.38 & 60.00 & 0.0912 & 1.2302 \\
\hline & $95 \% C I$ & \pm 0.106 & \pm 0.104 & \pm 9.31 & \pm 0.32 & \pm 0.04 & \pm 0.0008 & \pm 0.0493 \\
\hline & $95 \% P I$ & \pm 0.487 & \pm 0.477 & \pm 42.86 & \pm 1.46 & \pm 0.18 & \pm 0.0039 & \pm 0.2268 \\
\hline \multirow{3}{*}{4} & Mean & 14.835 & 14.796 & 43.73 & 5.60 & 39.97 & 0.0613 & 0.8461 \\
\hline & $95 \% C I$ & \pm 0.043 & \pm 0.043 & \pm 0.55 & \pm 0.03 & \pm 0.04 & \pm 0.0001 & \pm 0.0038 \\
\hline & $95 \% P I$ & \pm 0.235 & \pm 0.234 & \pm 2.95 & \pm 0.15 & \pm 0.24 & \pm 0.0005 & \pm 0.0203 \\
\hline \multirow{3}{*}{5} & Mean & 14.818 & 14.780 & 50.89 & 5.52 & 39.99 & 0.0609 & 0.8244 \\
\hline & $95 \% C I$ & \pm 0.042 & \pm 0.042 & \pm 5.18 & \pm 0.05 & \pm 0.04 & \pm 0.0004 & \pm 0.0136 \\
\hline & $95 \% P I$ & \pm 0.206 & \pm 0.208 & \pm 25.57 & \pm 0.26 & \pm 0.18 & \pm 0.0018 & \pm 0.0673 \\
\hline \multirow{3}{*}{7} & Mean & 14.776 & 14.738 & 53.09 & 5.48 & 39.97 & 0.0607 & 0.8165 \\
\hline & $95 \% C I$ & \pm 0.061 & \pm 0.060 & \pm 7.43 & \pm 0.10 & \pm 0.05 & \pm 0.0005 & \pm 0.0240 \\
\hline & $95 \% P I$ & \pm 0.380 & \pm 0.376 & \pm 46.64 & \pm 0.64 & \pm 0.32 & \pm 0.0029 & \pm 0.1508 \\
\hline
\end{tabular}


Table 4.3: (continued)

\begin{tabular}{|c|c|c|c|c|c|c|c|c|}
\hline Group & Quantity & $P_{t}$, psia & $P_{s}$, psia & $T_{t},{ }^{\circ} \mathrm{F}$ & $q, \mathrm{psf}$ & $V, \mathrm{kts}$ & $M$ & $R e_{c}, 10^{6}$ \\
\hline \multirow{3}{*}{8} & Mean & 14.780 & 14.549 & 65.80 & 33.15 & 100.01 & 0.1504 & 1.9416 \\
\hline & $95 \% C I$ & \pm 0.002 & \pm 0.001 & \pm 0.73 & \pm 0.07 & \pm 0.06 & \pm 0.0002 & \pm 0.0055 \\
\hline & $95 \% P I$ & \pm 0.008 & \pm 0.006 & \pm 3.31 & \pm 0.33 & \pm 0.25 & \pm 0.0007 & \pm 0.0250 \\
\hline \multirow{3}{*}{9} & Mean & 14.866 & 14.829 & 62.09 & 5.41 & 39.99 & 0.0602 & 0.7942 \\
\hline & $95 \% C I$ & \pm 0.001 & \pm 0.001 & \pm 2.44 & \pm 0.03 & \pm 0.03 & \pm 0.0002 & \pm 0.0068 \\
\hline & $95 \% P I$ & \pm 0.004 & \pm 0.005 & \pm 12.73 & \pm 0.16 & \pm 0.17 & \pm 0.0009 & \pm 0.0356 \\
\hline \multirow{3}{*}{10} & Mean & 14.618 & 14.581 & 59.63 & 5.34 & 39.96 & 0.0603 & 0.7881 \\
\hline & $95 \% C I$ & \pm 0.015 & \pm 0.015 & \pm 1.84 & \pm 0.02 & \pm 0.04 & \pm 0.0001 & \pm 0.0045 \\
\hline & $95 \% P I$ & \pm 0.070 & \pm 0.071 & \pm 8.83 & \pm 0.10 & \pm 0.20 & \pm 0.0007 & \pm 0.0216 \\
\hline \multirow{3}{*}{12} & Mean & 14.741 & 14.703 & 55.89 & 5.43 & 39.98 & 0.0606 & 0.8056 \\
\hline & $95 \% C I$ & \pm 0.005 & \pm 0.005 & \pm 4.20 & \pm 0.04 & \pm 0.02 & \pm 0.0002 & \pm 0.0118 \\
\hline & $95 \% P I$ & \pm 0.022 & \pm 0.021 & \pm 19.41 & \pm 0.20 & \pm 0.11 & \pm 0.0011 & \pm 0.0544 \\
\hline \multirow{3}{*}{13} & Mean & 14.745 & 14.707 & 54.57 & 5.47 & 40.04 & 0.0608 & 0.8117 \\
\hline & $95 \% C I$ & \pm 0.005 & \pm 0.005 & \pm 5.18 & \pm 0.05 & \pm 0.04 & \pm 0.0002 & \pm 0.0139 \\
\hline & $95 \% P I$ & \pm 0.024 & \pm 0.023 & \pm 24.79 & \pm 0.22 & \pm 0.20 & \pm 0.0012 & \pm 0.0664 \\
\hline
\end{tabular}

Table 4.4: Low pressure line temperature repeatability.

\begin{tabular}{ccccc}
\hline Group & Quantity & OP,${ }^{\circ} \mathrm{F}$ & Left LPDP,${ }^{\circ} \mathrm{F}$ & Right LPDP,${ }^{\circ} \mathrm{F}$ \\
\hline & Mean & 80.08 & 70.55 & 76.98 \\
\cline { 2 - 5 } 4 & $95 \%$ & \pm 2.95 & \pm 3.77 & \pm 3.32 \\
& \multicolumn{4}{c}{ continued on the next page } \\
\hline
\end{tabular}


Table 4.4: (continued)

\begin{tabular}{|c|c|c|c|c|}
\hline Group & Quantity & $\mathrm{OP},{ }^{\circ} \mathrm{F}$ & Left LPDP, ${ }^{\circ} \mathrm{F}$ & Right LPDP, ${ }^{\circ} \mathrm{F}$ \\
\hline & $95 \% P I$ & \pm 15.95 & \pm 20.36 & \pm 17.94 \\
\hline \multirow{3}{*}{5} & Mean & 73.55 & 68.29 & 74.70 \\
\hline & $95 \% C I$ & \pm 7.37 & \pm 6.18 & \pm 6.69 \\
\hline & $95 \% P I$ & \pm 36.38 & \pm 30.47 & \pm 32.99 \\
\hline \multirow{3}{*}{7} & Mean & 81.54 & 74.42 & 81.88 \\
\hline & $95 \% C I$ & \pm 1.50 & \pm 3.16 & \pm 3.37 \\
\hline & $95 \% P I$ & \pm 9.43 & \pm 19.82 & \pm 21.17 \\
\hline \multirow{3}{*}{8} & Mean & 81.01 & 77.48 & 84.12 \\
\hline & $95 \% C I$ & \pm 0.29 & \pm 1.02 & \pm 1.97 \\
\hline & $95 \%$ PI & \pm 1.34 & \pm 4.65 & \pm 8.98 \\
\hline \multirow{3}{*}{9} & Mean & 80.89 & 76.23 & 81.54 \\
\hline & $95 \% C I$ & \pm 1.32 & \pm 1.05 & \pm 1.25 \\
\hline & $95 \%$ PI & \pm 6.87 & \pm 5.46 & \pm 6.54 \\
\hline \multirow{3}{*}{10} & Mean & 79.48 & 71.72 & 69.67 \\
\hline & $95 \% C I$ & \pm 1.50 & \pm 0.51 & \pm 0.54 \\
\hline & $95 \% P I$ & \pm 7.21 & \pm 2.44 & \pm 2.58 \\
\hline \multirow{3}{*}{12} & Mean & 70.67 & 62.21 & 58.89 \\
\hline & $95 \% C I$ & \pm 2.51 & \pm 2.42 & \pm 3.39 \\
\hline & $95 \% P I$ & \pm 11.61 & \pm 11.17 & \pm 15.68 \\
\hline
\end{tabular}


Table 4.4: (continued)

\begin{tabular}{ccccc}
\hline Group & Quantity & OP, ${ }^{\circ} \mathrm{F}$ & Left LPDP, ${ }^{\circ} \mathrm{F}$ & Right LPDP, ${ }^{\circ} \mathrm{F}$ \\
\hline \multirow{2}{*}{13} & Mean & 70.15 & 60.23 & 57.60 \\
\cline { 2 - 5 } & $95 \%$ CI & \pm 7.05 & \pm 2.81 & \pm 4.37 \\
\cline { 2 - 4 } & $95 \%$ PI & \pm 33.74 & \pm 13.43 & \pm 20.88 \\
\hline
\end{tabular}

\subsection{Uncertainty Summary}

Though there were no pre-test goals set, overall repeatability for coefficients of lift, drag, and pitching moment are good. As is intuitive, the un-powered runs have better repeatability than the powered runs. Repeatability is generally better for more closely spaced runs and is sensitive to time-of-day. Two primary reasons contribute to this: the tunnel is un-pressurized and the HPA temperature shifts throughout the day as it is heated. There are a large number of possible sources of error that may contribute to non-repeatability in the test data; the likely sources were addressed and quantified previously in this chapter.

There are three time scales within which the data repeatability can be classified: short term, near term, and long term. These time scales refer to the elapsed time in between repeated runs and the number of model changes, if any, between repeated runs. A flap change is considered a model change. As this model has only had one tunnel entry to date, the time scales are defined different than what is in the literature. Here, short term time scale is based on run-to-run repeatability with no model changes, i.e. repeat runs either back-to-back or within the same 
day. Near term time scale is based on day-to-day repeatability with no model changes, i.e. runs separated by at least a day with no flap changes in between. Long term time scale is based on week-to-week repeatability with multiple model changes in between. Table 4.5 summarizes the repeatability over the three time scales, separated by powered and un-powered runs. A powered run is considered one where the TPS and/or the slots are blowing. The values presented are simply the averages of the $95 \%$ confidence intervals for all runs in the indicated time scale. The averages include values from repeated runs of more than two sweeps that may have a combination of two runs that fall into another time scale. I.e. the set of long-term repeats for group 7 contribute to the short term averages for runs 69 and 81, and also near term averages for runs 81 and 82 .

Table 4.5: Summary of $95 \%$ confidence force and moment coefficient repeatability as a function of time scale.

\begin{tabular}{lcccc}
\hline & & Short Term & Near Term & Long Term \\
\hline \multirow{2}{*}{ Load Residuals, } & $\Delta C_{L}$ & - & - & \pm 0.0186 \\
\cline { 2 - 5 } un-powered runs & $\Delta C_{D}$ & - & - & \pm 0.0095 \\
\cline { 2 - 5 } & $\Delta C_{m}$ & - & - & \pm 0.0158 \\
\hline \multirow{2}{*}{ Load Residuals, } & $\Delta C_{L}$ & \pm 0.0592 & \pm 0.0655 & \pm 0.0658 \\
\cline { 2 - 5 } powered runs & $\Delta C_{D}$ & \pm 0.0186 & \pm 0.0231 & \pm 0.0275 \\
\cline { 2 - 5 } & $\Delta C_{m}$ & \pm 0.0227 & \pm 0.0257 & \pm 0.0225 \\
\hline
\end{tabular}

Table 4.6 summarizes the repeatability for model pressures, wing pressure coefficients, and plenum pressures. The values in the table represent averages of $95 \%$ confidence intervals for all runs, separated by the PSI module. It is seen that model pressures are repeatable to \pm 0.045 psia on the 15 psid modules 
and \pm 0.035 psia on the 2.5 psid modules. It is expected that the uncertainty in the lower range PSI modules is smaller. Repeatability in $C_{P}$ measurements is \pm 0.335 for 15 psid modules and \pm 0.049 for 2.5 psid modules. For 15 psid modules, powered runs are repeatabile in pressure to \pm 0.043 psia and $C_{P}$ to \pm 0.436 . Unpowered runs are repeatable in pressure and $C_{P}$ measurements on the $15 \mathrm{psid}$ modules to \pm 0.051 psia and \pm 0.066 , respectively. Pressure repeatability for group 3 is the largest across all individual runs at \pm 0.102 psia for both modules, thus contributing to the inflated averages on un-powered runs. Module 3, a 15 psid module, was populated with the plenum pressure tubes. Averages between the leading- and trailing-edges shows the leading edge pressures are slightly more repeatable at \pm 0.061 psia compared to the trailing edge pressures at \pm 0.104 psia. These averages are higher than the overall model pressure confidence intervals. This is to be expected as the plenum pressures are sensitive to more parameters like line temperature and nozzle exit pressure. Isolated trailing edge blowing runs showed confidence levels similar to the combined blowing trailing edge averages, at \pm 0.106 psia. This is to be expected because the trailing edge pressures for the combined blowing runs were used to set on-condition during the isolated trailing edge blowing runs. Looking at individual plenum repeatability, the TEIB and LEIB plenums consistently had the largest confidence intervals. These plenums have the highest flow rates and pressure levels. The LEIB plenum pressures were repeatable to $\pm 0.076 \mathrm{psia}$ and the TEIB plenum pressures were repeatable to \pm 0.135 psia. 
Table 4.6: Repeatability of model pressures at $95 \%$ confidence.

\begin{tabular}{llll} 
& & \multicolumn{2}{c}{ Module } \\
\cline { 2 - 3 } & & 2.5 psid & 15 psid \\
\hline \multirow{2}{*}{ Model Pressures, psia } & Powered & \pm 0.029 & \pm 0.043 \\
\cline { 2 - 4 } & Total & \pm 0.035 & \pm 0.045 \\
\hline Wing $C_{P}$ & Un-powered & \pm 0.026 & \pm 0.066 \\
\cline { 2 - 4 } & Powered & \pm 0.056 & \pm 0.436 \\
\cline { 2 - 4 } & Total & \pm 0.049 & \pm 0.335 \\
\hline & Leading Edge & - & \pm 0.061 \\
\cline { 2 - 4 } Plenum Pressures, psia & Trailing Edge & - & \pm 0.104 \\
\hline
\end{tabular}




\section{Chapter 5}

\section{Aerodynamic Performance}

\section{Results}

This chapter presents a summary of basic model aerodynamic performance results obtained during the AMELIA wind tunnel test, completed in February, 2012. Before the results are discussed, some general comments on the wind tunnel test are in order. The model performed extremely well throughout the test. All test objectives, including ten critical test points, were successfully completed. Direct measurement of skin friction using the FISF method was employed for each critical test point. Six different surface oil-flow visualization and two smoke-wand visualization runs were completed. The test matrix incorporated sets of repeat runs at different model configurations and tunnel conditions. The test provided low-speed experimental force and moment data for the N+2 AMELIA model, including surface pressure and acoustic measurements. This is the first wind tunnel test of a full-span model incorporating leading- and trailing-edge blowing wing circulation control and engine simulators. It is also the first comparison of isolated trailing edge blowing aircraft performance versus combined leading- 
and trailing-edge blowing aircraft performance. The objective is to utilize the test data to improve CFD tools for modeling $\mathrm{N}+2$ configurations. Table 5.1 presents several test statistics regarding relevant run numbers and days over which AMELIA was tested. The wind-on phase spanned from 12/21/2011-2/15/2012; factoring in all tunnel facility activities, the total user occupancy hours is 617.5.

Table 5.1: Relevant test statistics as organized by model configuration.

\begin{tabular}{cccc} 
Model Configuration & Run Numbers & Useful Data Runs & Wind-On Days \\
\hline Low Pylon & $18: 171$ & 151 & 20 \\
High Pylon & $172: 203$ & 29 & 5 \\
Clean Wing & $204: 270$ & 64 & 5 \\
TE-Only & $271: 312$ & 41 & 2 \\
\hline
\end{tabular}

\section{Isolated Trailing Edge Blowing Performance}

Momentum coefficient sweep data are presented in Figures 5.1 to 5.3 for the $60^{\circ}$ flap deflection and $40 \mathrm{kts}$ tunnel speed. In Figure 5.1, $C_{L}$ increases with angle of attack across the slot sweep range. There is a noticeable drop-off in $C_{L}$ with increasing $C_{\mu}$ at $\alpha=10^{\circ}$, though. Here, the wing has stalled at the leading edge and becomes ineffective at generating lift through increased circulation from blowing. Recall the discussion related to Figure 3.4 for the lift curve at these conditions. The region at low $C_{\mu}$ where the increase in $C_{L}$ with each increment of blowing is the highest is referred to as the separation control region [12]. The separation control region is where the separation point is quickly moved to the trailing edge of the flap as blowing is increased. For this configuration at $\alpha=0^{\circ}, C_{\mu}<0.05$ characterizes this region. Beyond separation control is the super circulation region. Here, lift continues to increase but it is not as efficient 
because the separation point has been fixed at the trailing edge of the dual radius flap. Figure 5.2 shows an increase in angle of attack corresponds to an increase in drag coefficient across the momentum coefficient sweep range. This effect is consistent across the other positive flap deflections. However, for the $0^{\circ}$ flap deflection (note $60^{\circ}$ flap data is shown, see Figure 5.5 for $0^{\circ}$ flap data.), there is a noted slot thrust (negative drag) due to the orientation of the slot jet in line with the drag axis. Pitching moment data, Figure 5.3, shows a decrease in pitching moment as angle of attack is increased.

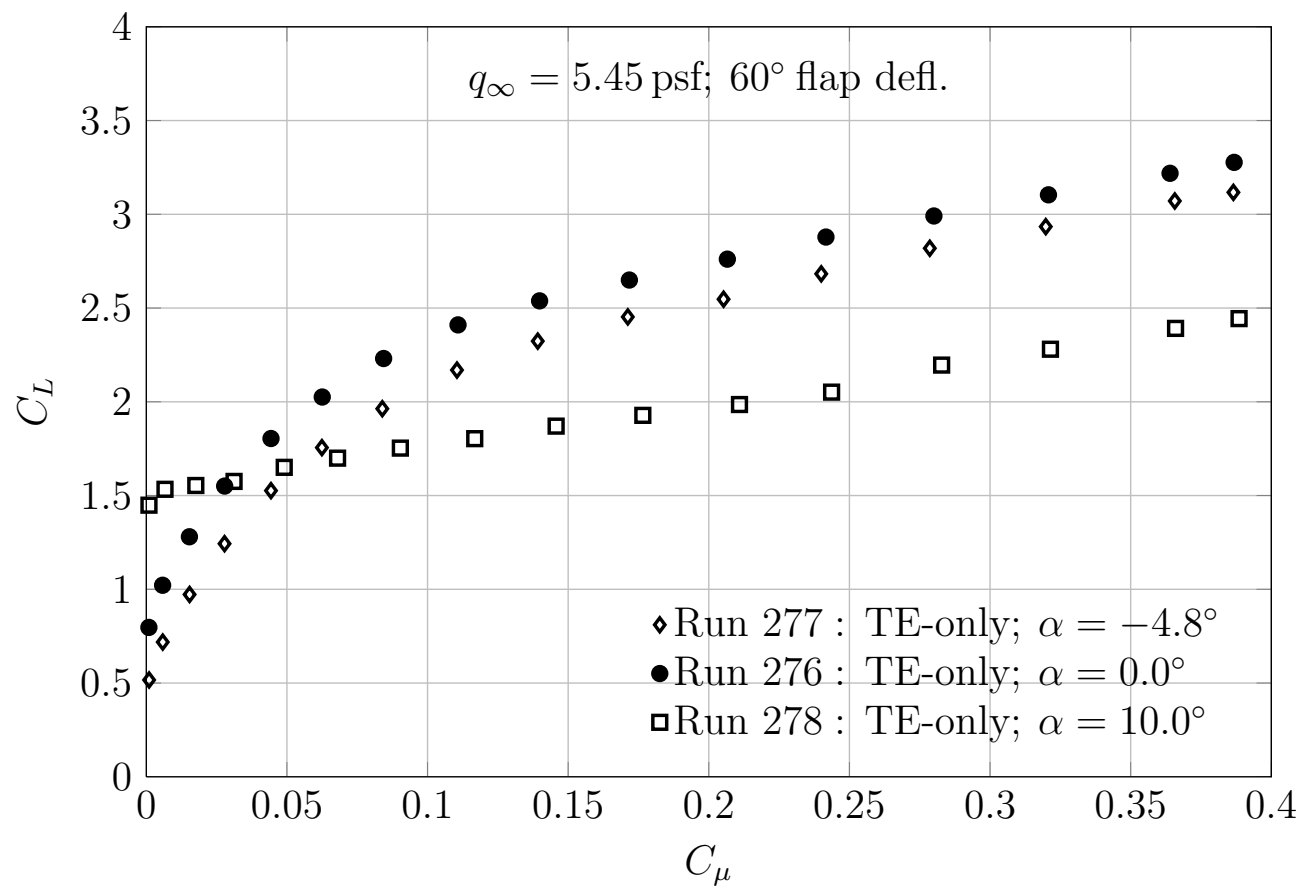

Figure 5.1: Effect of isolated trailing edge blowing on model lift coefficient performance.

\section{Ineffectiveness of the $80^{\circ}$ Flap}

Figure 5.4 presents clean wing model lift coefficient performance at the full slot power setting, with multiple curves for varying flap deflections. Lift curve data shows the $80^{\circ}$ flap to be ineffective at high angles of attack. At 40 kts, 


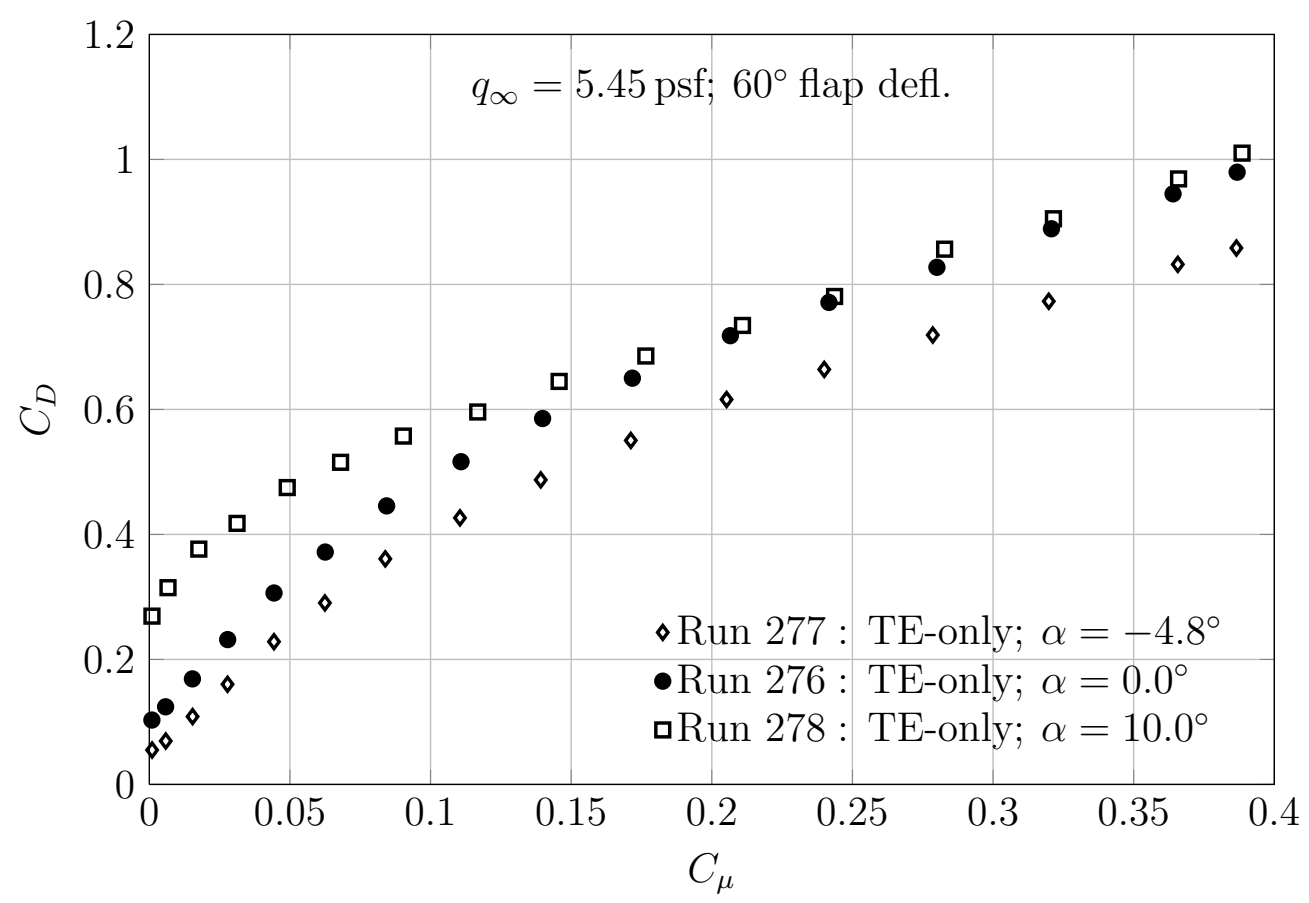

Figure 5.2: Effect of isolated trailing edge blowing on model drag polar.

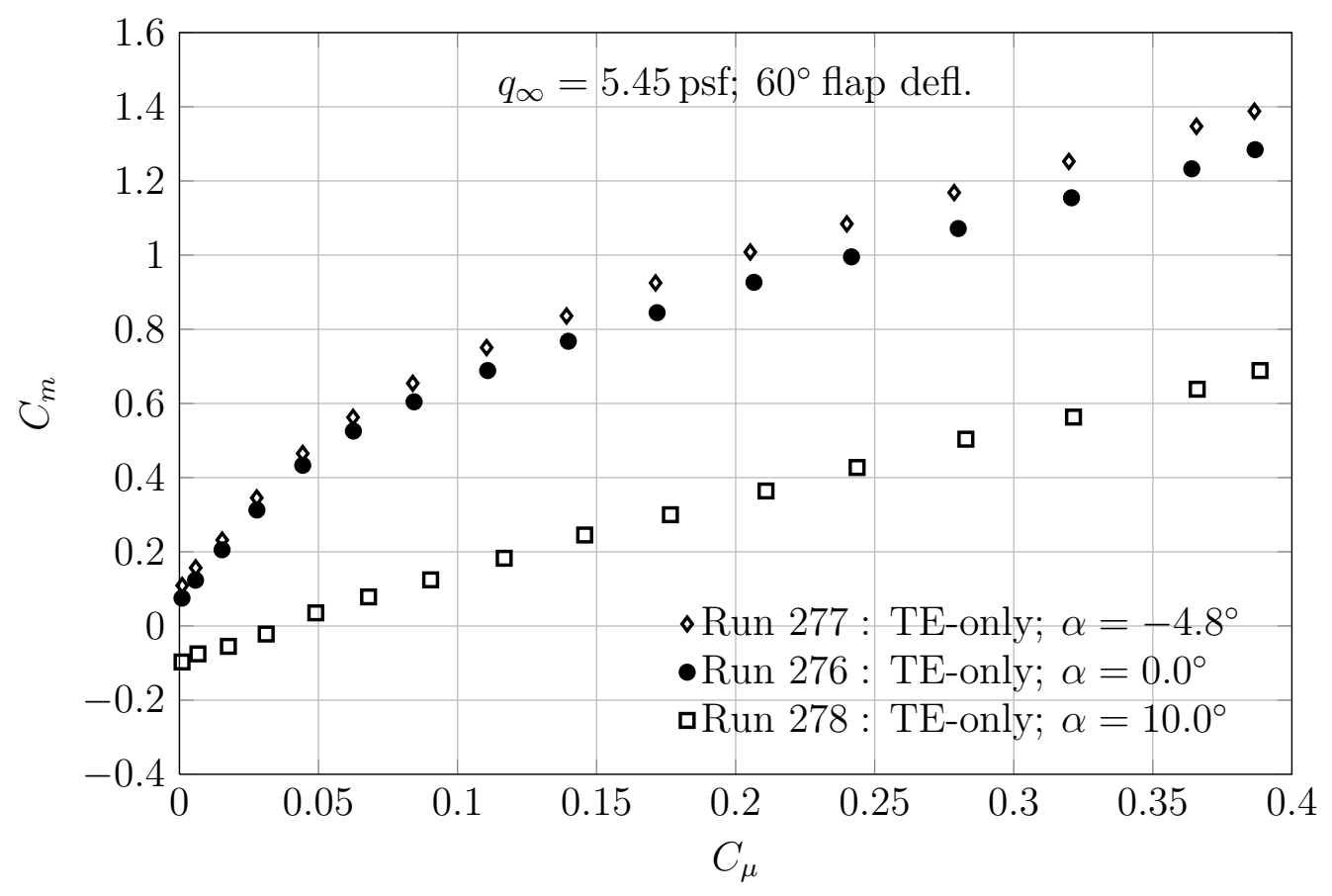

Figure 5.3: Effect of isolated trailing edge blowing on model pitching moment performance. 
the $80^{\circ}$ flap stalls and has a lower maximum $C_{L}$ compared to the $60^{\circ}$ flap. As freestream velocity increases, the $80^{\circ}$ flap becomes less effective across the entire angle of attack range. At the low speeds this result is not entirely expected as early predictions and previous work suggested a nearly constant offset between all flap deflections [6]. At high speeds though, this is possibly explained by needing a higher $C_{\mu}$ to maintain the offset. Figure 5.5 shows increased drag as flap deflection is increased. The slot thrust from the $0^{\circ}$ flap is seen. Higher drag and reduced lift is consistent with flap stall.

Figures 5.6 to 5.7 present the lift curve and drag polar with the TPS-on. Here, the $80^{\circ}$ flap cannot maintain lift augmentation over the $60^{\circ}$ flap at high blowing and angle of attack. The noted stall suggests that the low pylon isn't effective at deflecting engine exhaust at the $80^{\circ}$ flap deflection. Drag polars are consistent with clean wing data and show a consistent offset between flap deflections.

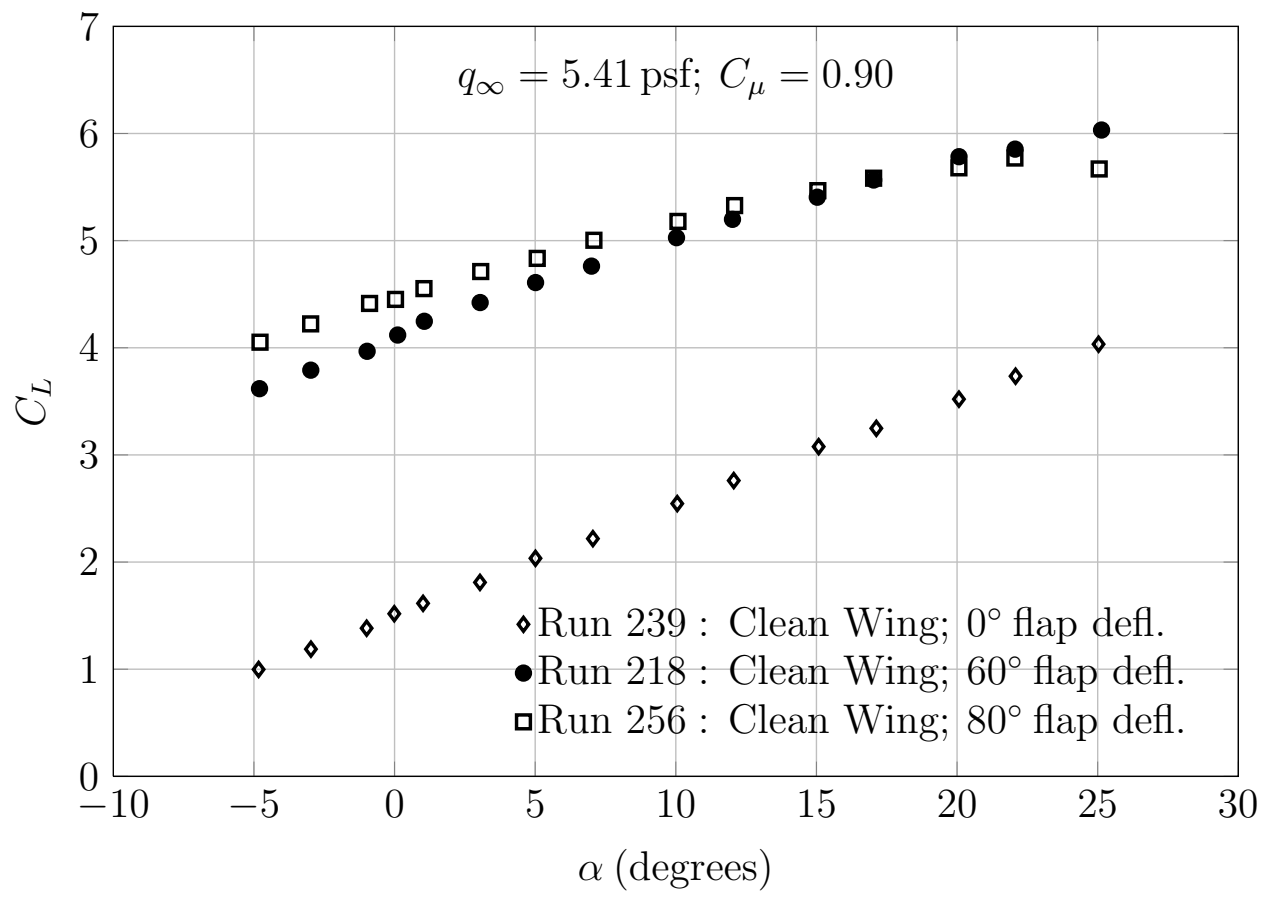

Figure 5.4: Effect of increasing flap deflection on clean wing configuration lift coefficient. 


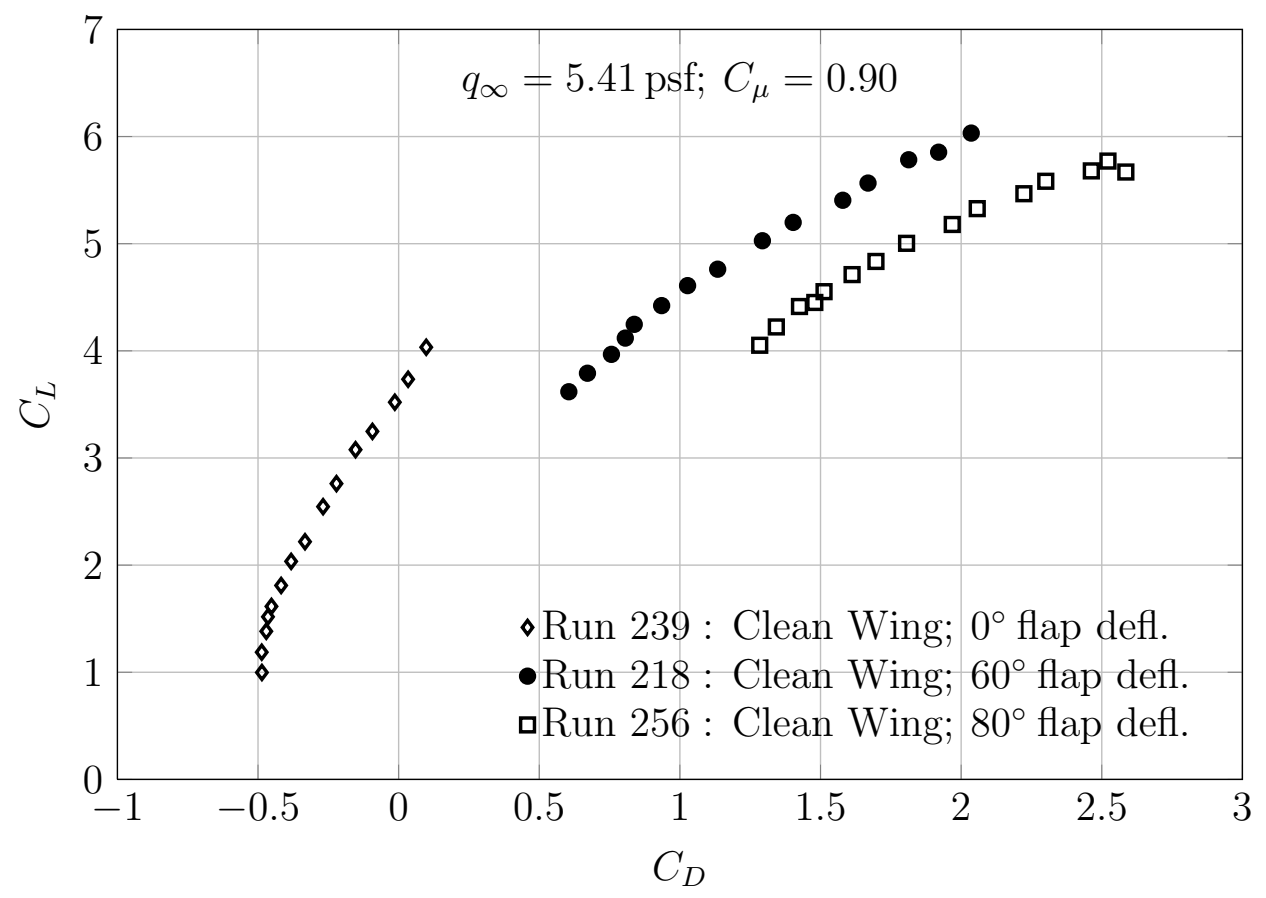

Figure 5.5: Effect of increasing flap deflection on clean wing configuration drag polar.

\section{Powered Lift Matrix}

Figure 5.8 examines the effects of variations in the powered-lift matrix and their effect on lift performance at a fixed tunnel speed and flap deflection. The powered-lift matrix represents variations in the slot and TPS power setting, defined by:

1. slots off and TPS off

2. slots off and full TPS

3. full slots and TPS off

4. full slots and full TPS

The multiple curves in the figure illustrate the build-up effect that the poweredlift matrix points have on model performance. It is seen that the engine-on 


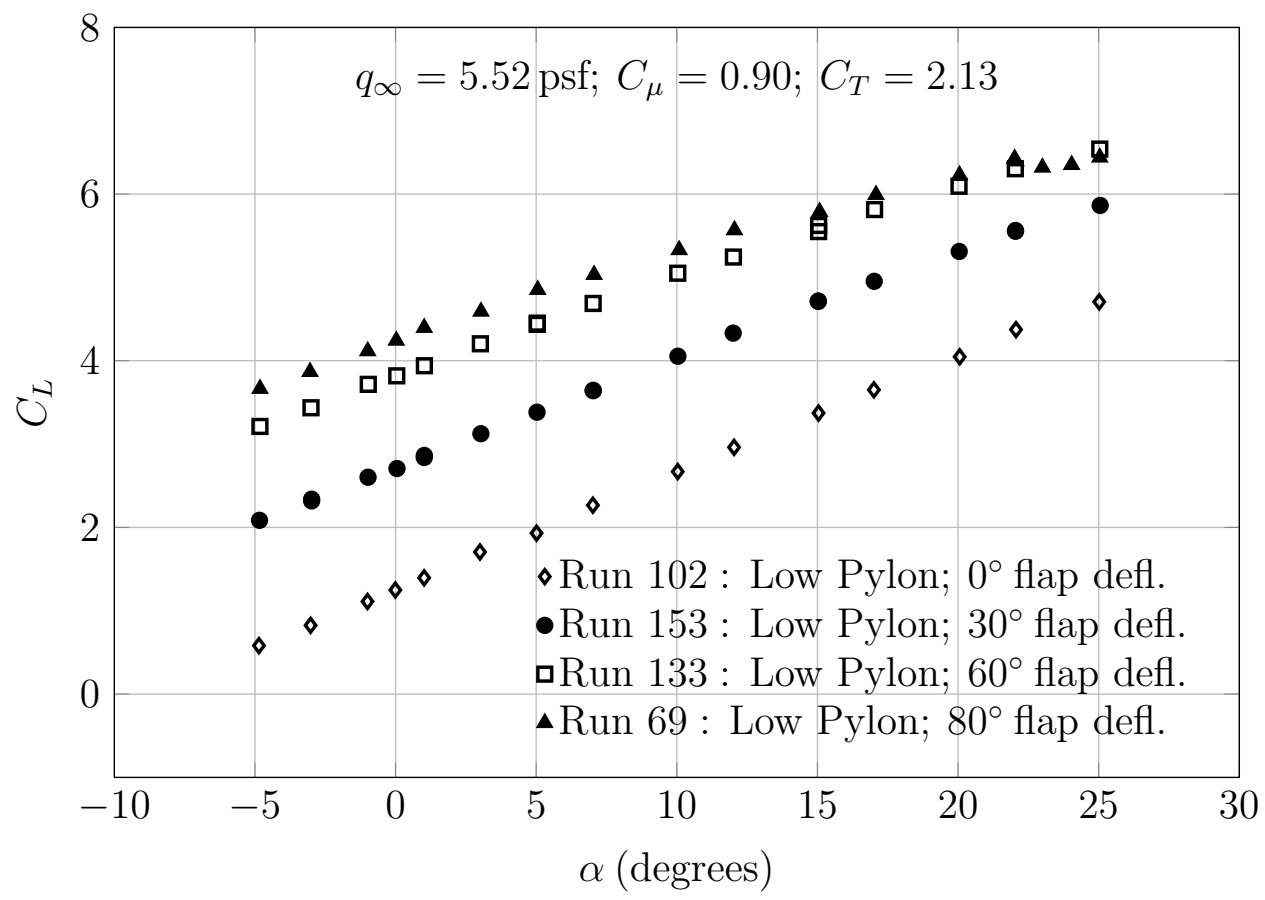

Figure 5.6: Effect of increasing flap deflection on low pylon configuration lift coefficient.

does contribute to higher lift. Performance benefits from this increased engine exhaust deflection are primarily noticed at high angles of attack, though. For the $60^{\circ}$ flap deflection at $40 \mathrm{kts}$, the application of engine thrust is responsible for an increase in the maximum lift coefficient of greater than 1. Again, the application of thrust increases the lift curve slope due to the $C_{T} \cdot \sin \left(\alpha+\delta_{j e t}\right)$ component in the data. The increase in lift is not so much due to the thrust deflection angle, but more so the increased upper surface velocities that result from deflecting the engine exhaust onto the wing upper surface. Other general trends for like data sets show increased freestream speed and increased flap deflection contributing to earlier stall. Figure 5.9 shows the effect of the powered-lift matrix for the $60^{\circ}$ flap deflection at $100 \mathrm{kts}$. It is seen that the addition of engine thrust, though it does contribute to higher lift and delayed stall, is not enough to prevent stall. A point to note is a comparison of the lift curves when $C_{\mu}=0$. The wing appears to stall, 


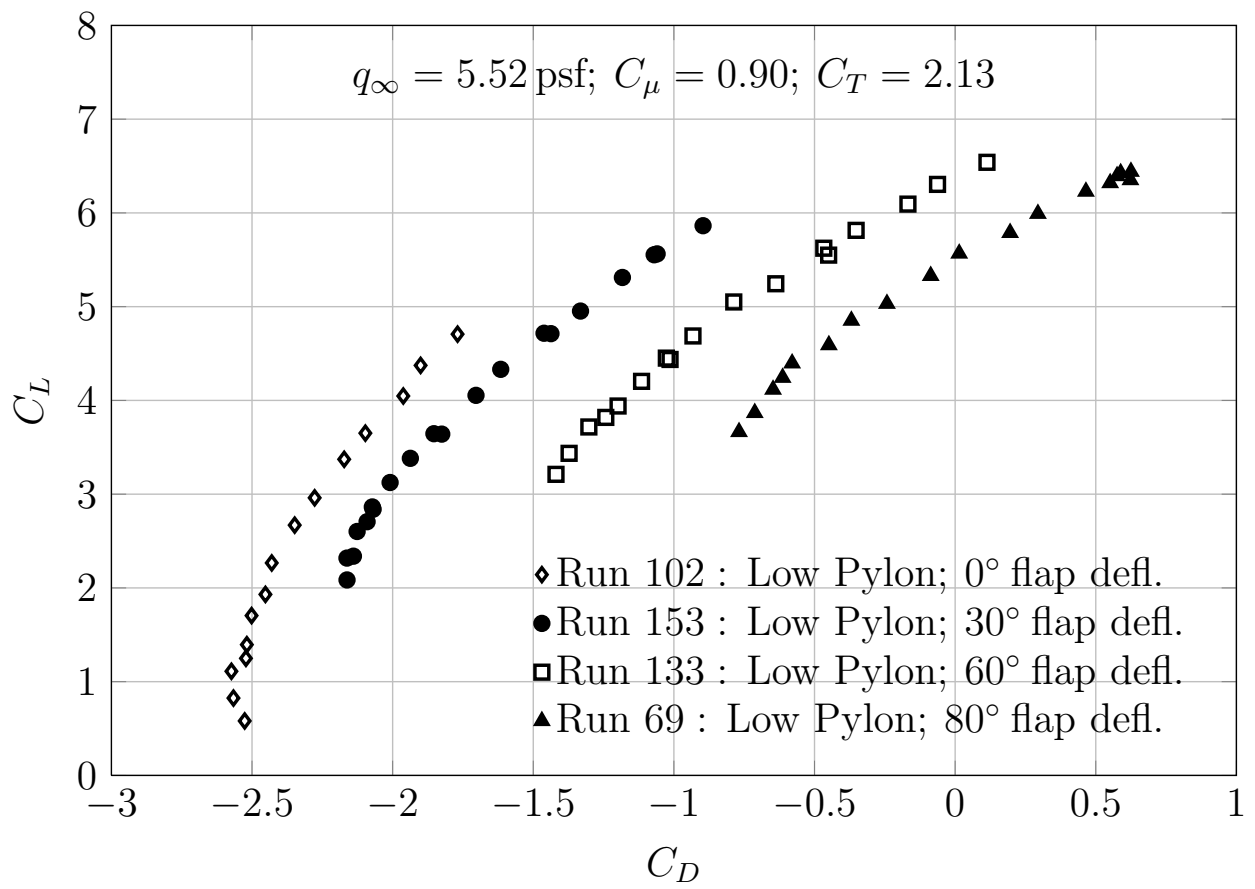

Figure 5.7: Effect of increasing flap deflection on low pylon configuration drag polar.

noted by the leveling off between $\alpha=7^{\circ}$ and $10^{\circ}$, followed by a sharp increase in lift generation. It is believed that the deflected engine exhaust velocities are responsible for this effect, but the flow physics are not entirely understood. Flap stall was the initial hypothesis, but the $0^{\circ}$ flap data shows a similar leveling off and increase in the lift coefficient, which would seem to indicate that flap stall is not the cause.

\section{Effect of TPS on Model Performance}

Figures 5.10 to 5.15 present data from sweeps of TPS power setting at constant $C_{\mu}$. The sweep in Figures 5.10 to 5.12 was conducted differently than others; the model was held at a fixed angle of attack and data points were taken at 3 different values of thrust coefficient before pitching to the next angle. Thrust 


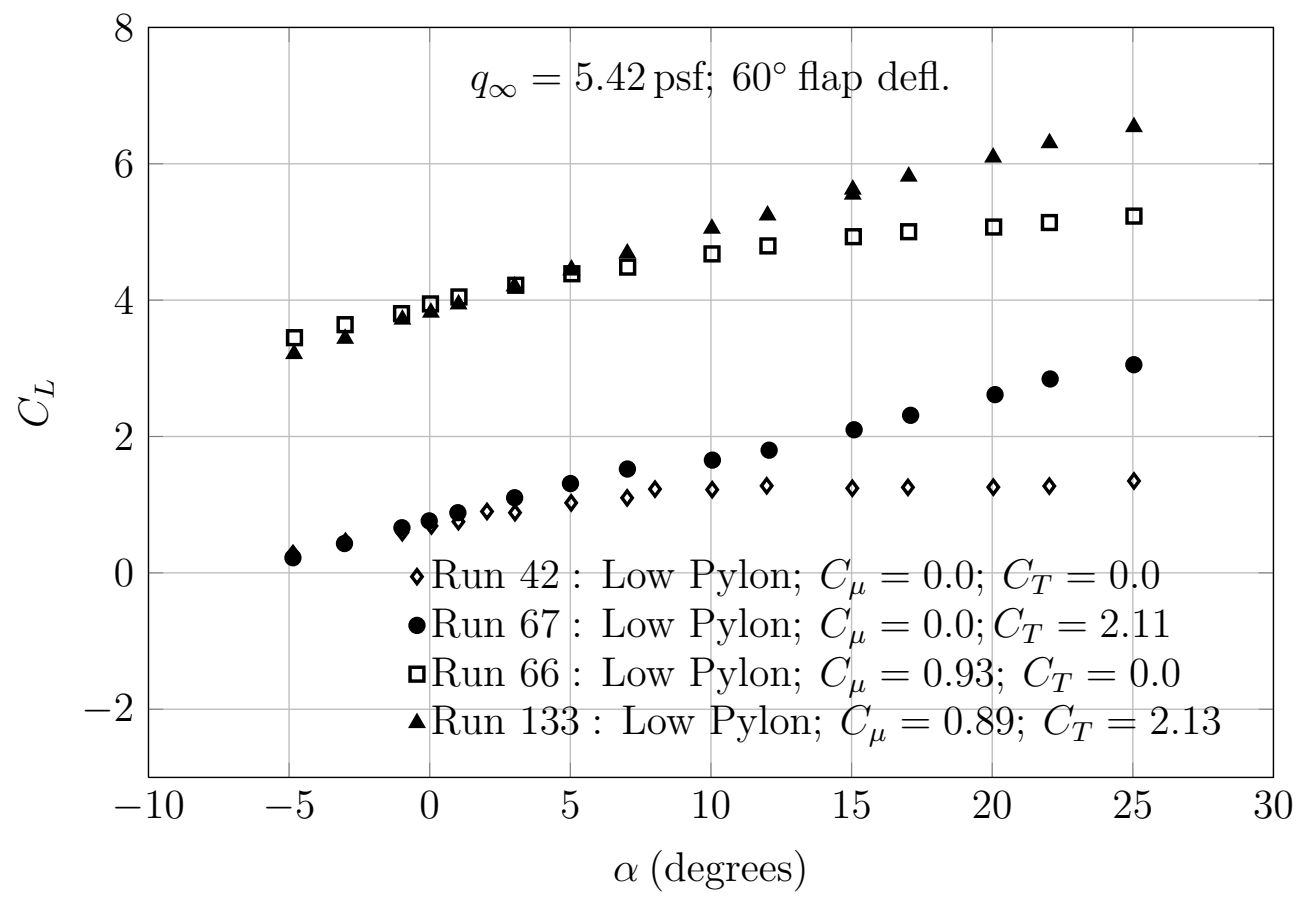

Figure 5.8: Powered-lift matrix lift coefficient performance for the low pylon configuration.

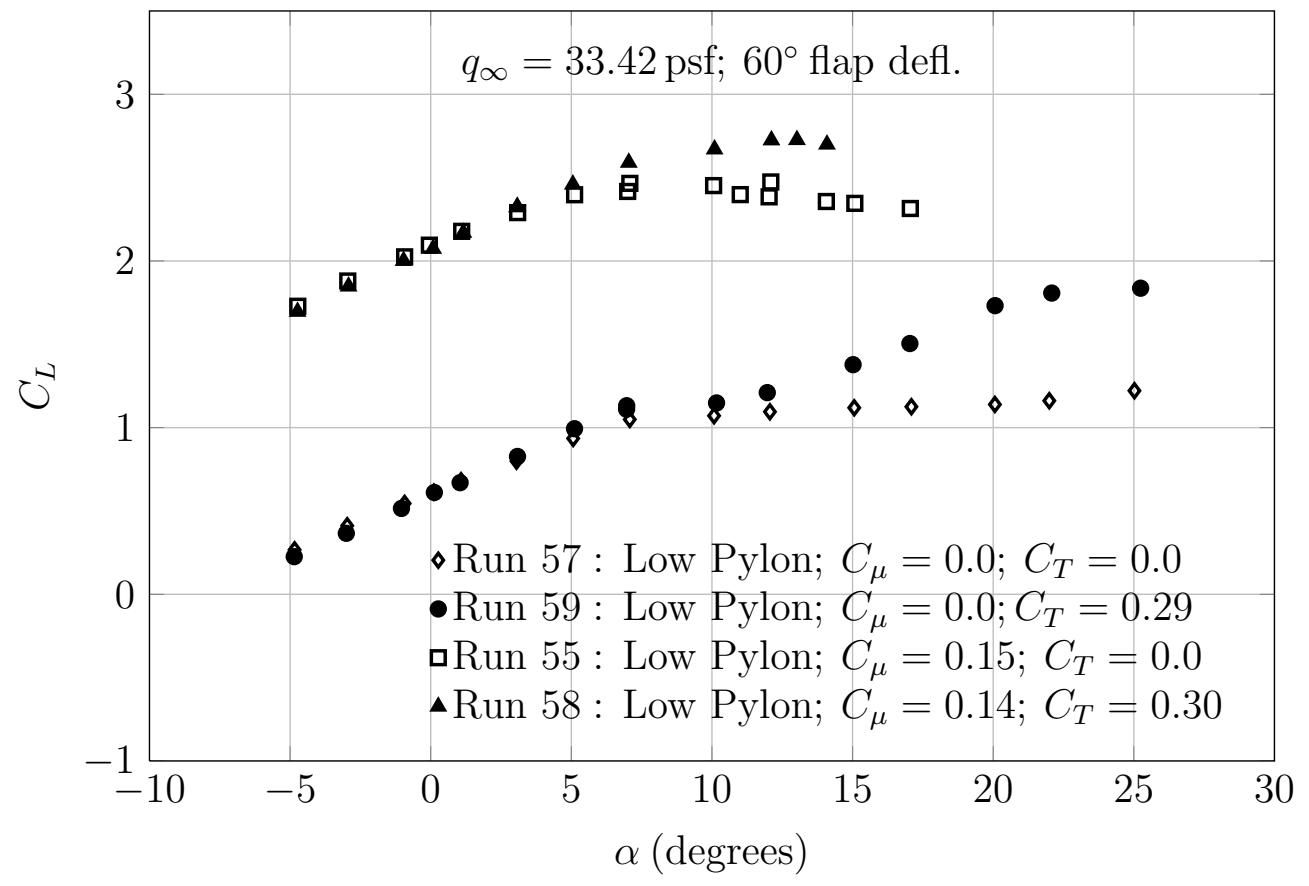

Figure 5.9: Powered-lift matrix lift coefficient performance for the low pylon configuration. 
coefficients correspond to $0,2 / 3$, and full RPM conditions. The figure shows that engine-on does contribute to higher lift and prevents stall to beyond $\alpha=25^{\circ}$. It is seen that going from the $2 / 3 \mathrm{RPM}$ setting $\left(C_{T}=1.45\right)$ to the maximum RPM setting $\left(C_{T}=2.11\right)$ provides only slightly better lift performance though; $\Delta C_{L}=0.35$ for $\Delta C_{T}=0.66$. At $60 \mathrm{kts}$ and $80^{\circ}$ flap deflection, Figure 5.13 shows a similar benefit to $C_{L}$ provided by the TPS. $\left(C_{T}=0.24\right.$ corresponds to the $20 \%$ RPM setting and $C_{T}=0.90$ corresponds to the full RPM setting.) Though this increased engine deflection does account for a delay in stall of $4^{\circ}$ at a $\Delta C_{L}=0.5$, it is not enough to prevent stall entirely. Figures 5.11 and 5.14 show that as $C_{T}$ is increased, higher thrust recovery is seen. Recall this is because the thrust axis is aligned to $C_{D}$ in the wind axis system. Pitching moment results show expected trends with increased thrust coefficient creating more pitching moment. Note the alpha sweeps in Figures 5.13 to 5.15 were acquired in the more typical way described in Section 2.4.1.

Testing at the high and low pylon heights was intended to characterize the highly coupled CCW and over-the-wing mounted engines. Prior to the manufacturing of AMELIA, Georgia Tech Research Institute was contracted by Cal Poly to conduct a smaller scale wind tunnel test of a 2-D CCW model (isolated trailing edge blowing with a removable leading edge slat) with a 3-D propulsion simulator. The test data, which is summarized by Englar [6], showed a strong coupling between the location of the propulsion simulator, with respect to both vertical height and chordwise location, and the model's STOL performance. This data provided the basis for which the pylon locations on AMELIA were designed.

Figures 5.16 to 5.18 present performance curves for the high and low pylon heights at $40 \mathrm{kts}$ and $80^{\circ}$ flap deflection. The data shows higher lift across the angle of attack range in the high pylon configuration. For this low speed, this 


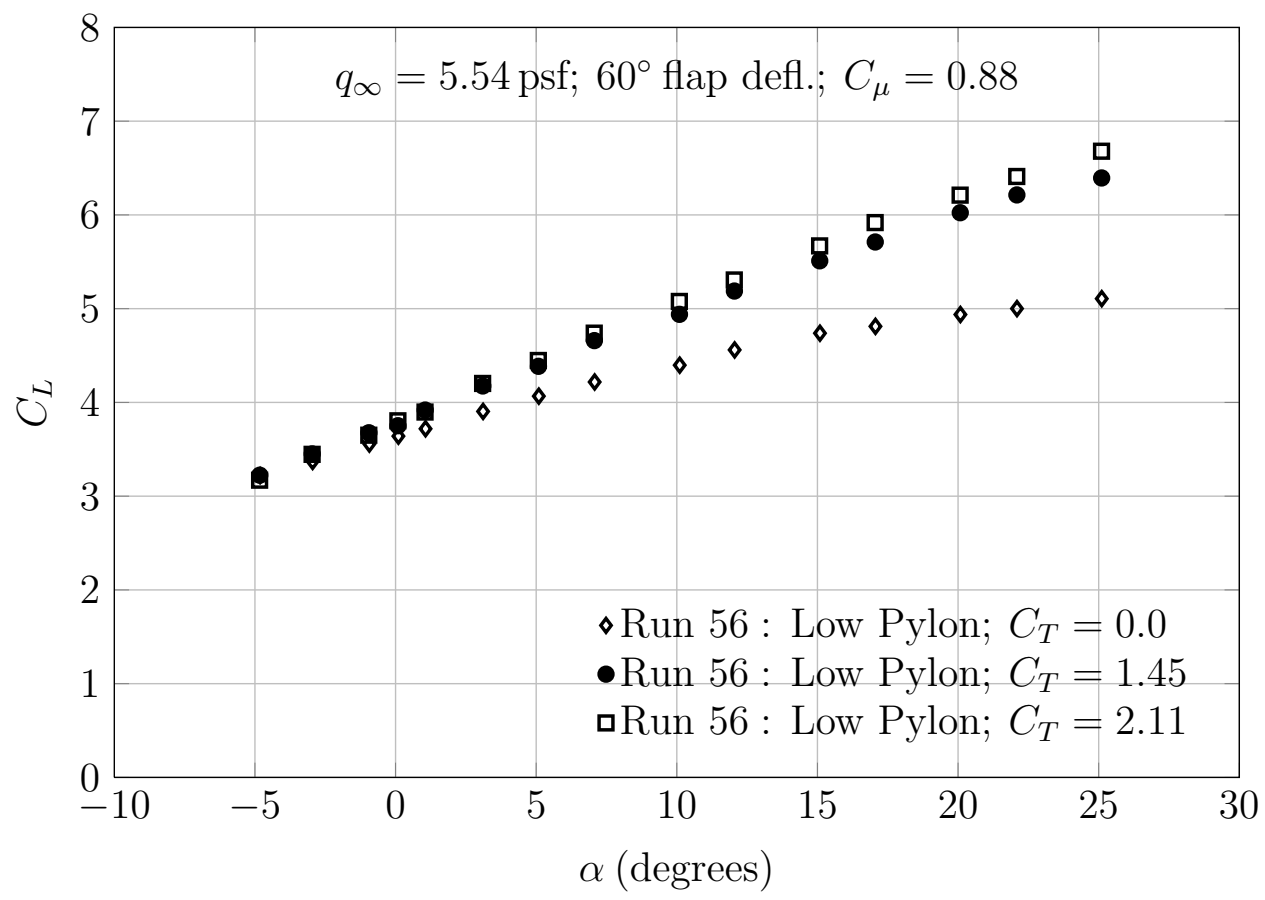

Figure 5.10: Effect of variations in thrust coefficient on low pylon configuration lift coefficient.

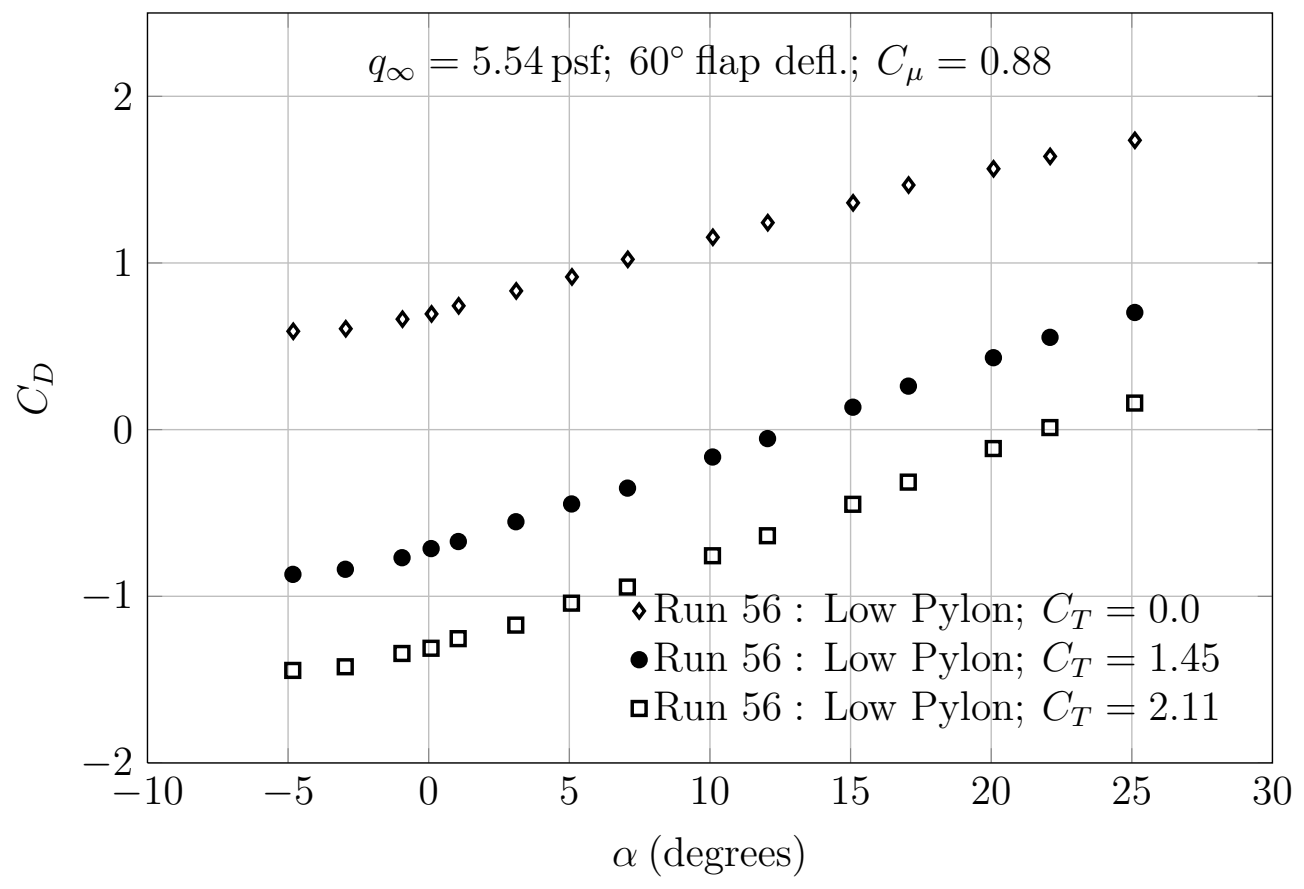

Figure 5.11: Effect of variations in thrust coefficient on low pylon configuration drag coefficient. 


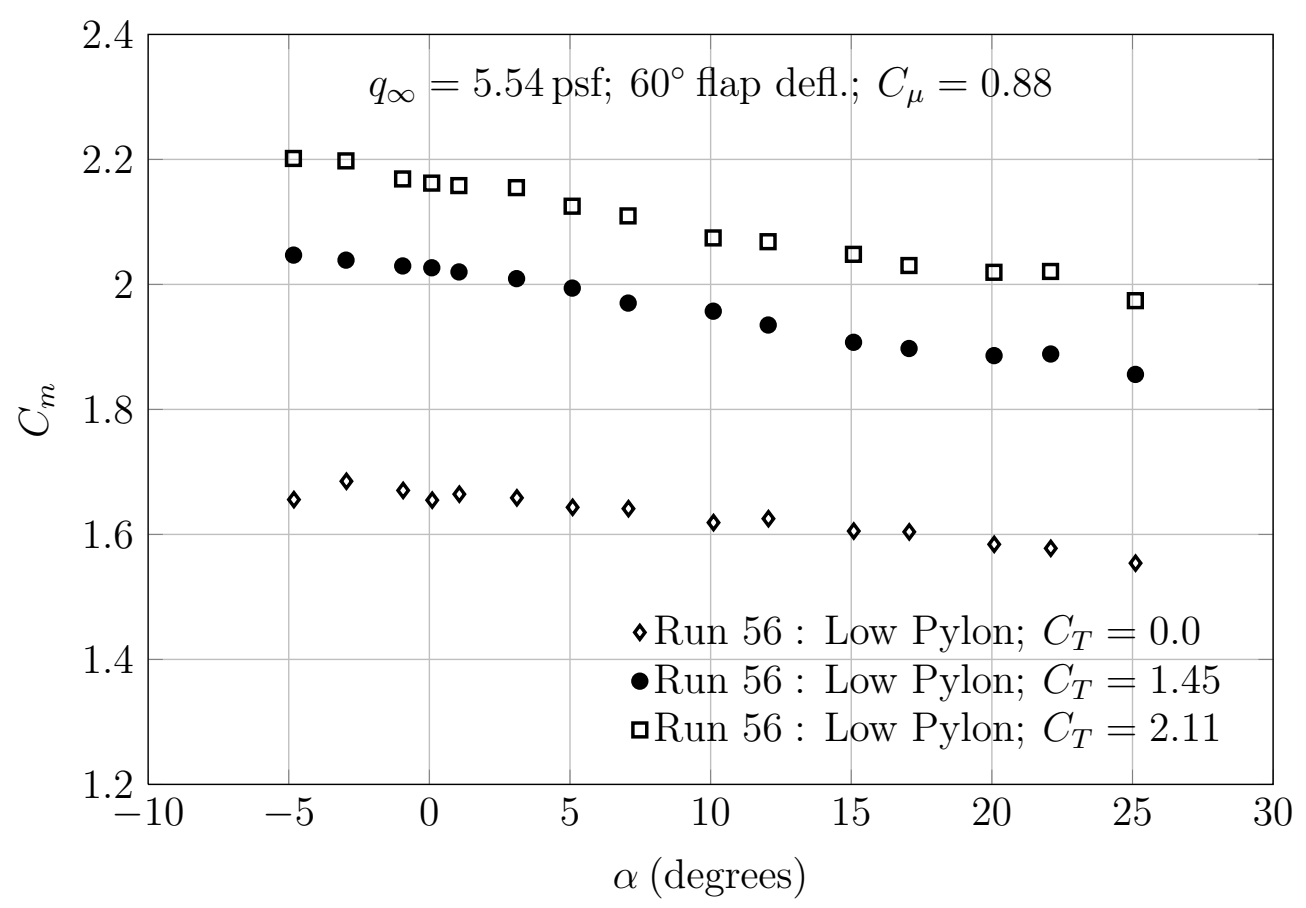

Figure 5.12: Effect of variations in thrust coefficient on low pylon configuration pitching moment.

result is not entirely expected; for a constant, $C_{\mu}=0.9$ the low pylon height should result in more engine exhaust deflection, creating greater lift and better performance at high angles of attack. The greater lift curve slope for the low pylon height suggests there is a greater thrust component present in the lift data which would seem to support the expected result. Drag data presented in Figure 5.17, though, does not support this as there are negligible differences between the pylon heights. Higher drag in the low pylon would indicate more scrubbing drag due to increased exhaust deflection. Wing pressures on the TPS centerline show unremarkable differences between the pylon heights at the above conditions. At higher tunnel speeds, the differences in pylon height become less noticeable. At higher speeds this can be explained by a fixed mass flow rate between the three tested tunnel speeds - as $q_{\infty}$ increases, $C_{\mu}$ decreases. Because the relationship between increased engine exhaust deflection is tightly coupled to the value of $C_{\mu}$, 


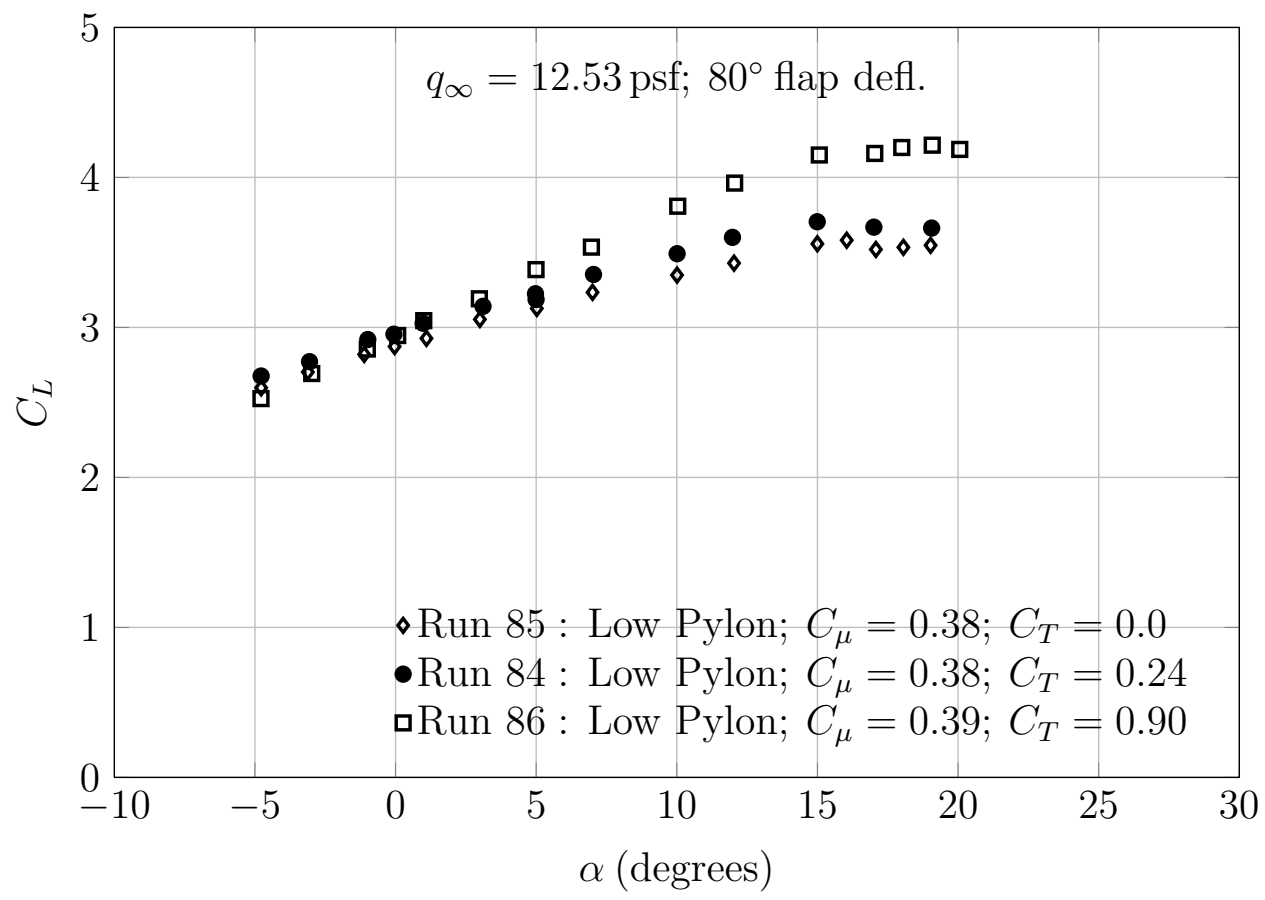

Figure 5.13: Effect of variations in thrust coefficient on low pylon configuration lift coefficient.

without more mass flow rate or increased jet velocity (this could be achieved at a fixed mass flow rate by reducing the local slot height), the expected trends are not seen for the lower values of $C_{\mu}$. The other explanation as to why the expected coupling was not seen is that either the low pylon isn't low enough or the high pylon isn't high enough (pardon the use of colloquial language). This conclusion is supported in the test data, where the lift curves for varying flap deflections (via Figures 5.4 and 5.6) showed the $80^{\circ}$ did not result in effective deflection of engine exhaust.

\section{Combined Configuration Performance}

A comparison of the model configurations, with each component at its respective maximum power setting, is shown in Figures 5.19 to 5.21. The figures show 


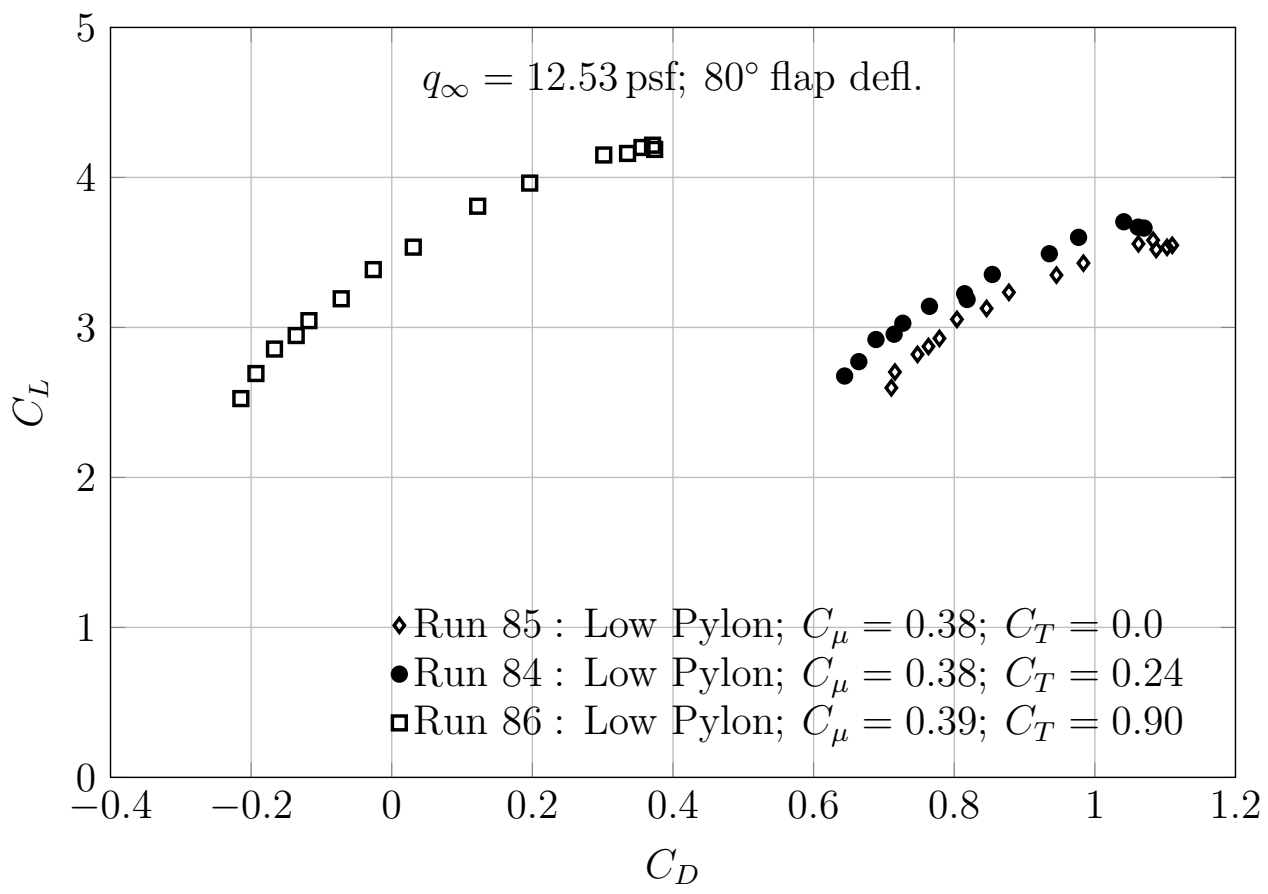

Figure 5.14: Effect of variations in thrust coefficient on low pylon configuration drag coefficient.

how each model configuration adds to the baseline unpowered performance. It is seen that the addition of leading edge blowing results in delay of wing stall to greater than $25^{\circ}$ angle of attack. The maximum lift coefficient is increased from 3 to 6 with the addition of leading edge blowing. With the application of thrust there is an increase in the lift curve slope, illustrating the effect of the thrust component in the data. This figure highlights the differences in stall behavior that were observed during testing. When the blowing is isolated to the trailing edge, the stall behavior is significantly more harsh, indicative of leading edge stall. However, when there is combined leading- and trailing-edge blowing, the stall behavior is much more docile, indicative of trailing edge stall.

The impact of leading edge blowing is seen in more detail on the wing pressure profiles, presented at $\alpha=0^{\circ}$ and $\alpha=25^{\circ}$, in Figures 5.22 to 5.23. Figure 5.22 shows the data for the inboard-most pressure port row, $\eta=0.179$, and Figure 5.23 


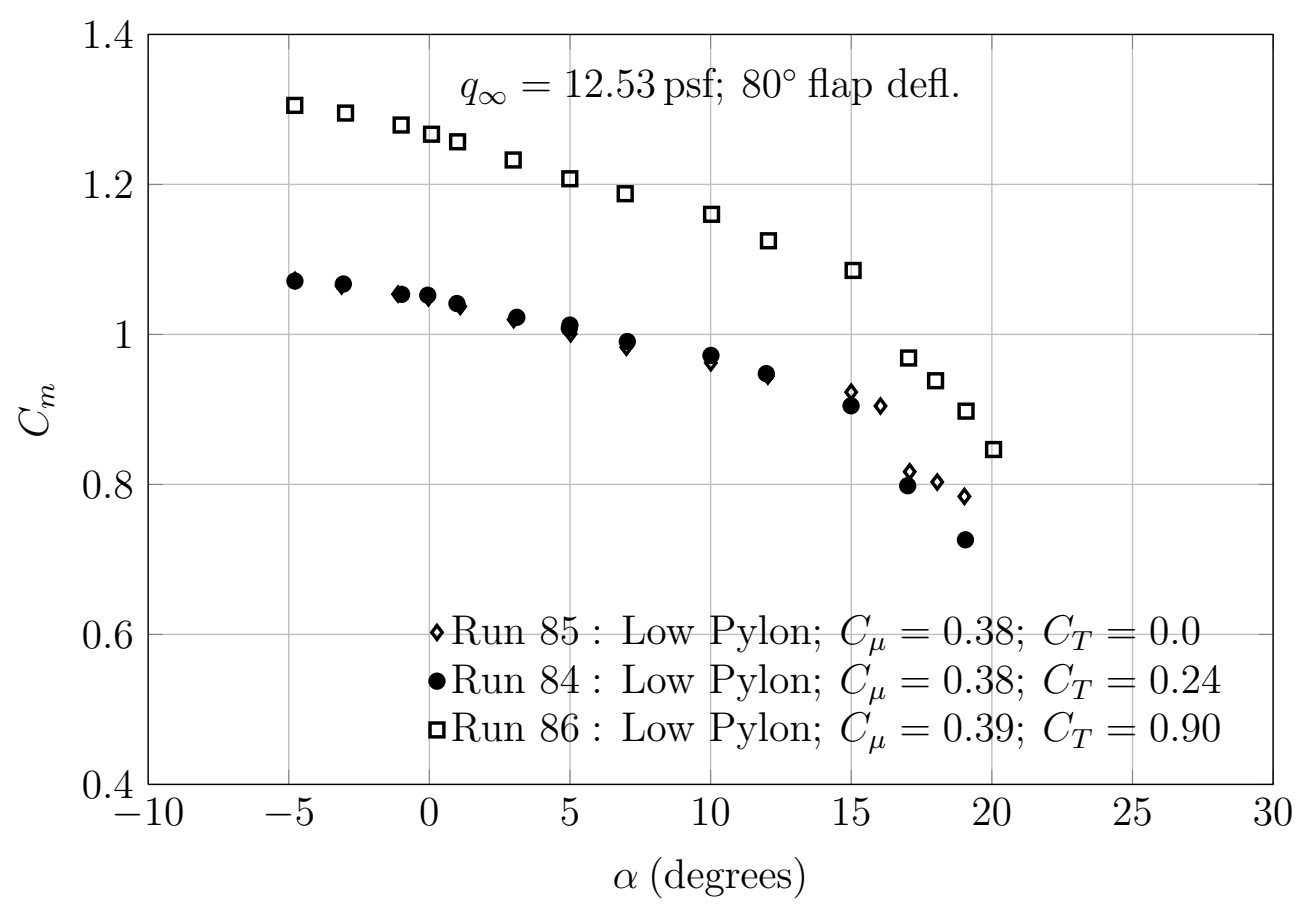

Figure 5.15: Effect of variations in thrust coefficient on low pylon configuration pitching moment.

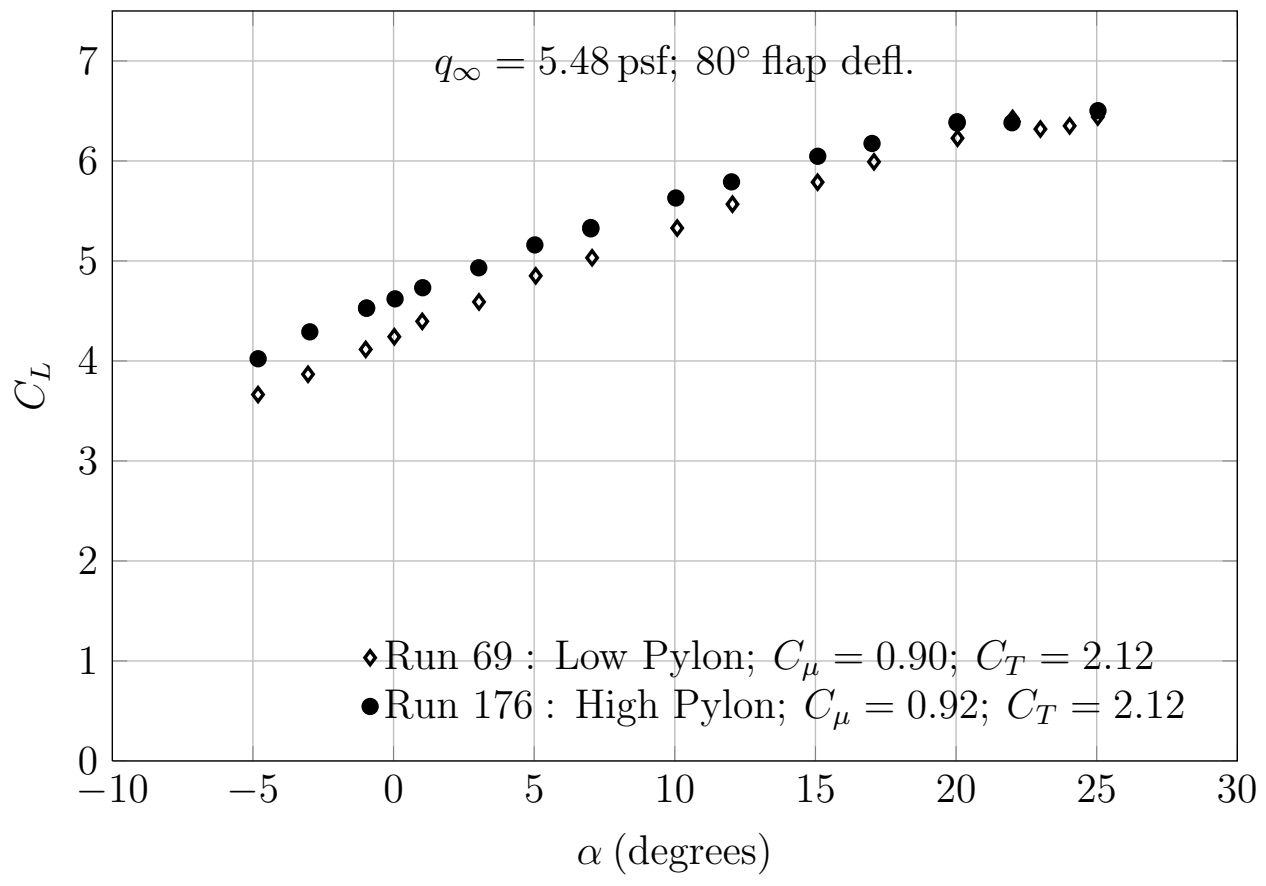

Figure 5.16: Lift coefficient performance for high and low engine pylon heights at high blowing rate. 


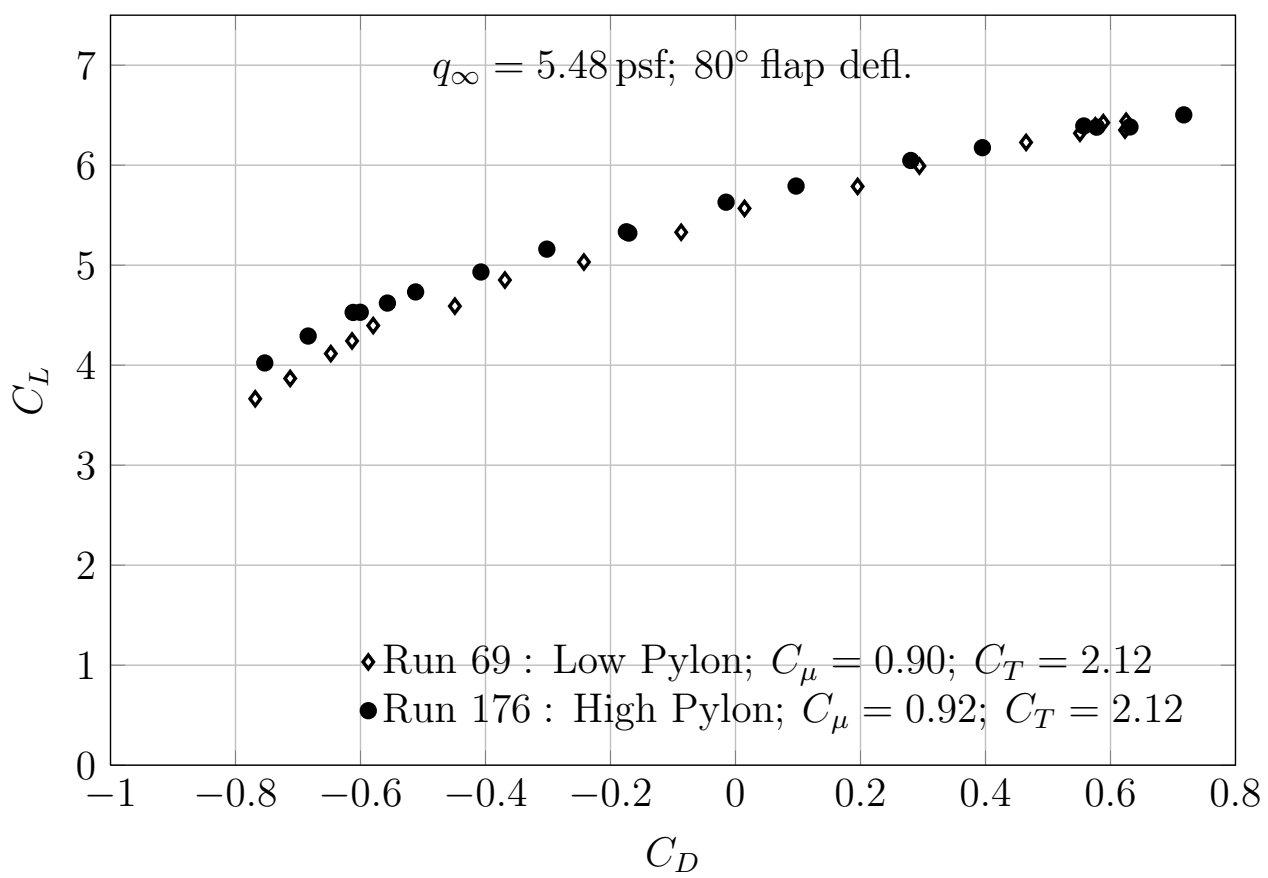

Figure 5.17: Drag polar performance for high and low engine pylon heights at high blowing rate.

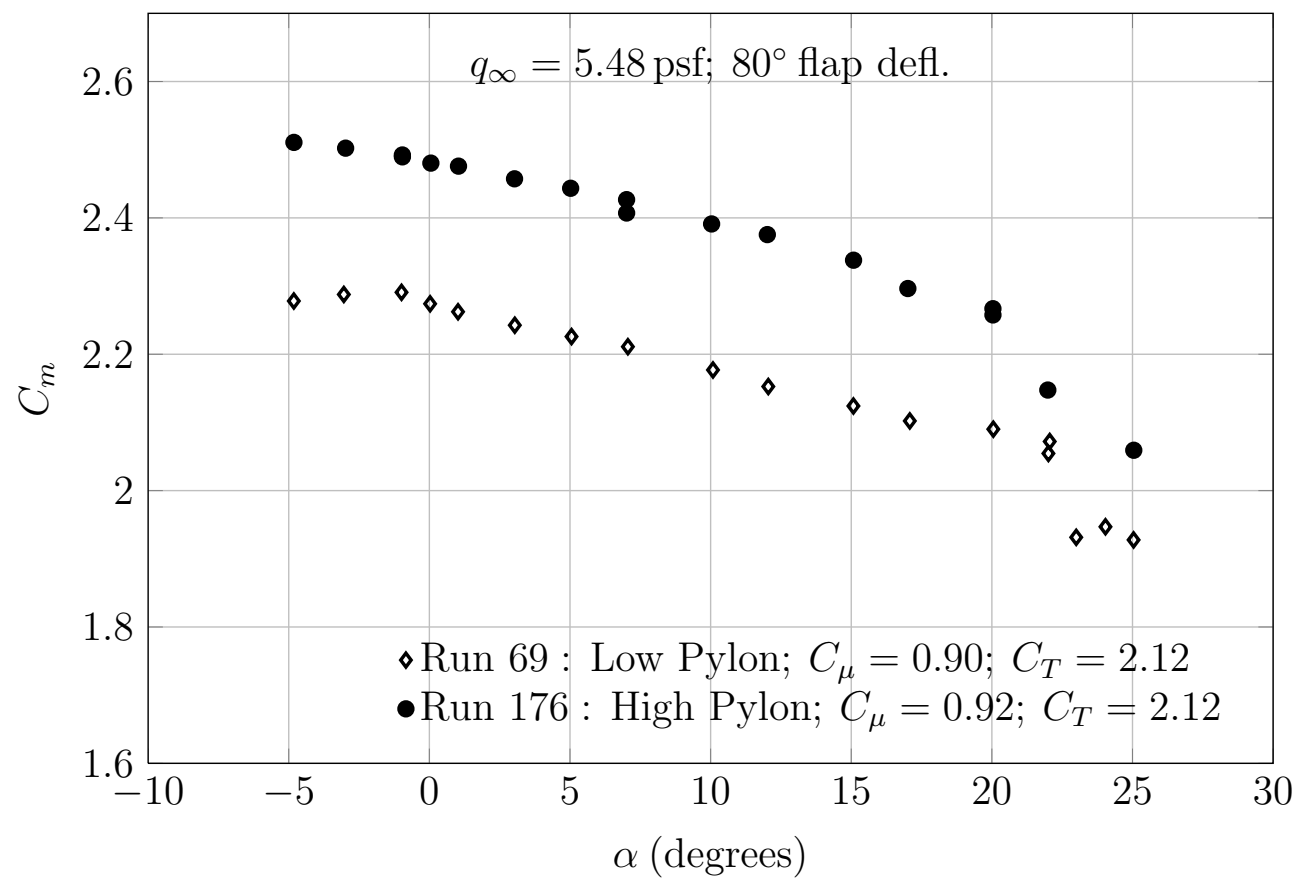

Figure 5.18: Pitching moment coefficient performance for high and low engine pylon heights at high blowing rate. 


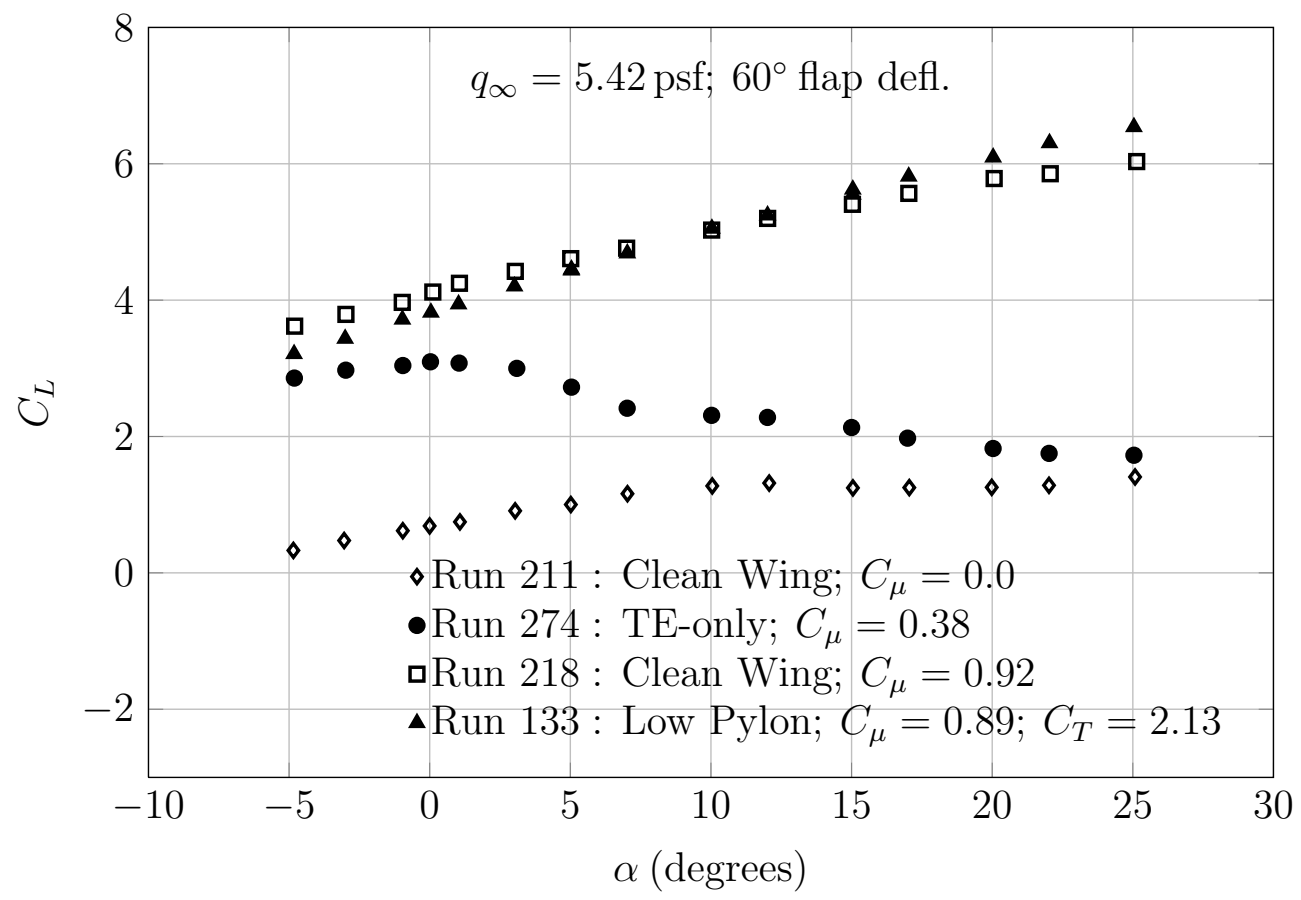

Figure 5.19: Effect of isolated trailing edge blowing on model lift coefficient performance.

shows data for the pressure port row located at the middle of the outboard wing, $\eta=0.758$. The test section dynamic pressure is $5.4 \mathrm{psf}$ and the $60^{\circ}$ flap deflection is attached; the plots are individually annotated with the local critical pressure coefficient for sonic flow, $C_{P}^{*}$. At $25^{\circ}$ angle of attack, the inboard wing section is producing lift for both isolated trailing edge blowing and combined blowing configurations. The wing section at $\eta=0.18$ is an unblown wing section, meaning it is inboard of the wing plenums; despite this, its pressure profiles are still affected by blowing. Increased velocities from leading edge blowing contribute to higher lift - when leading edge blowing is present, the flow is across the wing due to the flow direction being normal to the slot face. Looking to Figure 5.23 at the outboard wing section, $\eta=0.76$, the onset of wing stall is seen for the isolated trailing edge blowing configuration. As the angle of attack increases to $25^{\circ}$, the high streamline inflow angle causes stall to occur without the additional blowing 


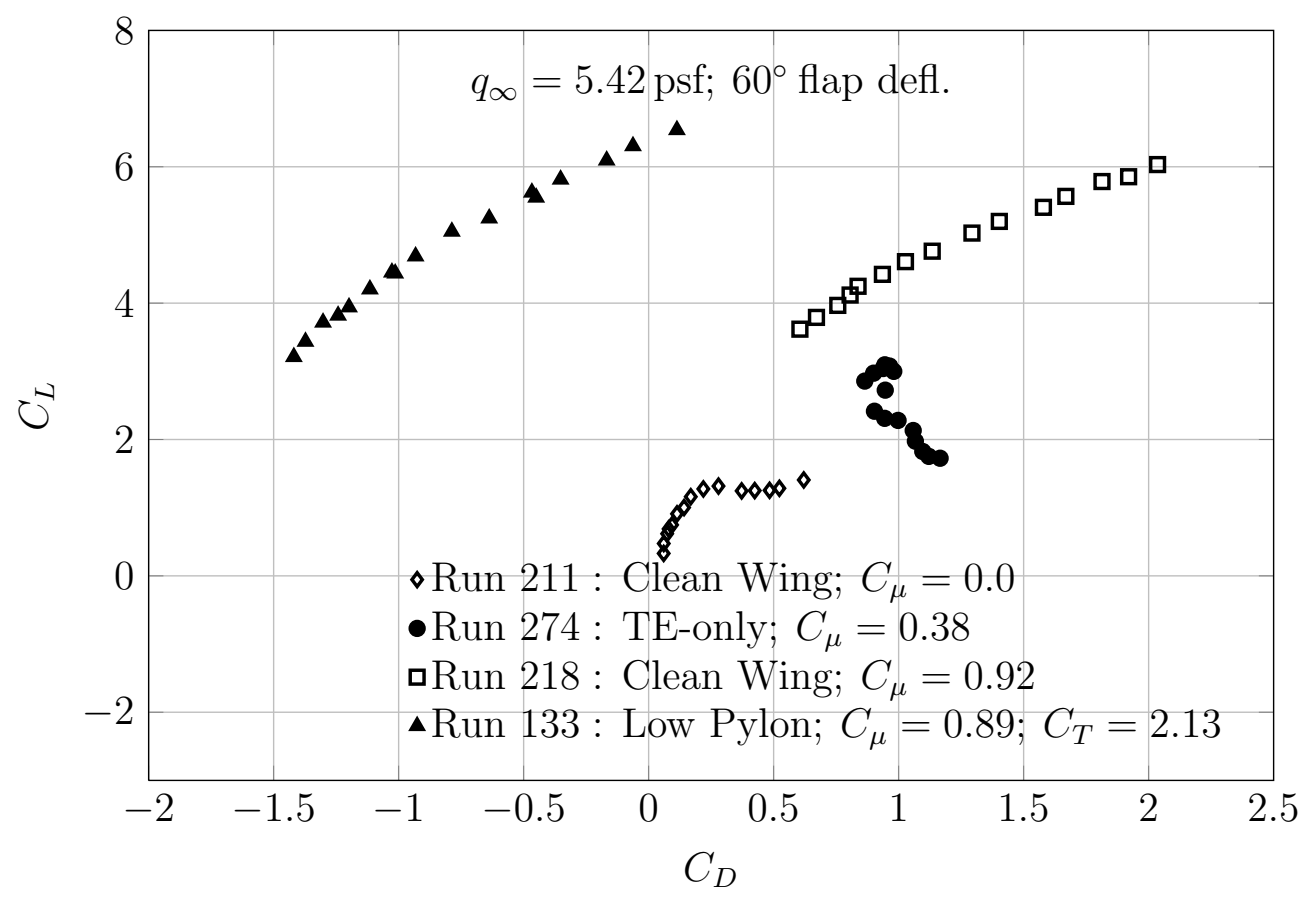

Figure 5.20: Effect of isolated trailing edge blowing on model drag polar.

momentum at the leading edge. The additional momentum from the leading edge blowing contributes to lift generation at low and high angles of attack as the flow maintains attachment through the acceleration around the nose- see Figure 5.19 for the model lift curves for these conditions. Note the remarkably negative $C_{P}$ values; this is due to the ratio of the dynamic pressure between the local slot flow and the freestream flow. The slot flow is nearly sonic (as noted by the $C_{P}$ being close to the critical pressure at the slot face), while the freestream flow is less than 0.15 Mach. 


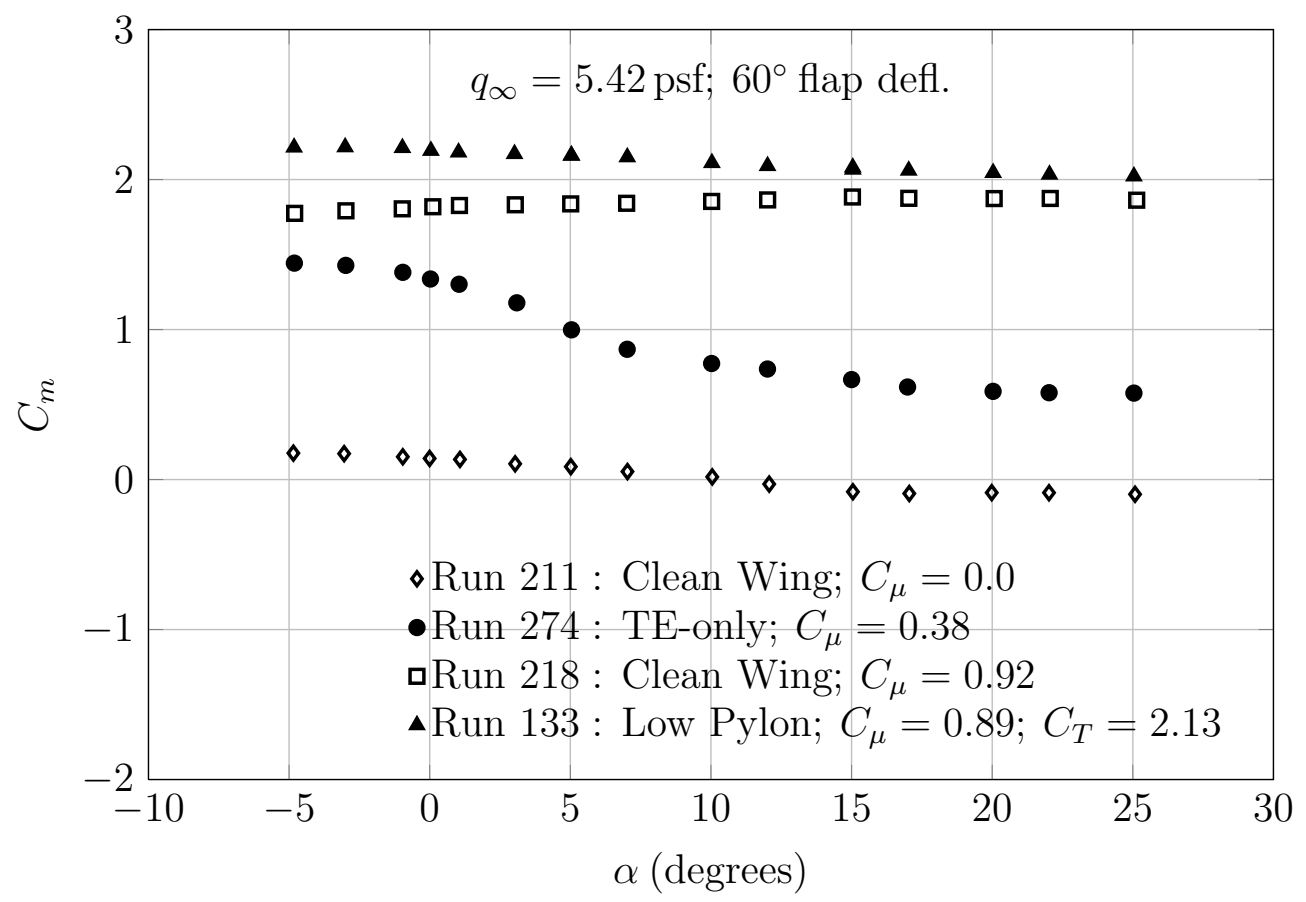

Figure 5.21: Effect of isolated trailing edge blowing on model pitching moment performance. 

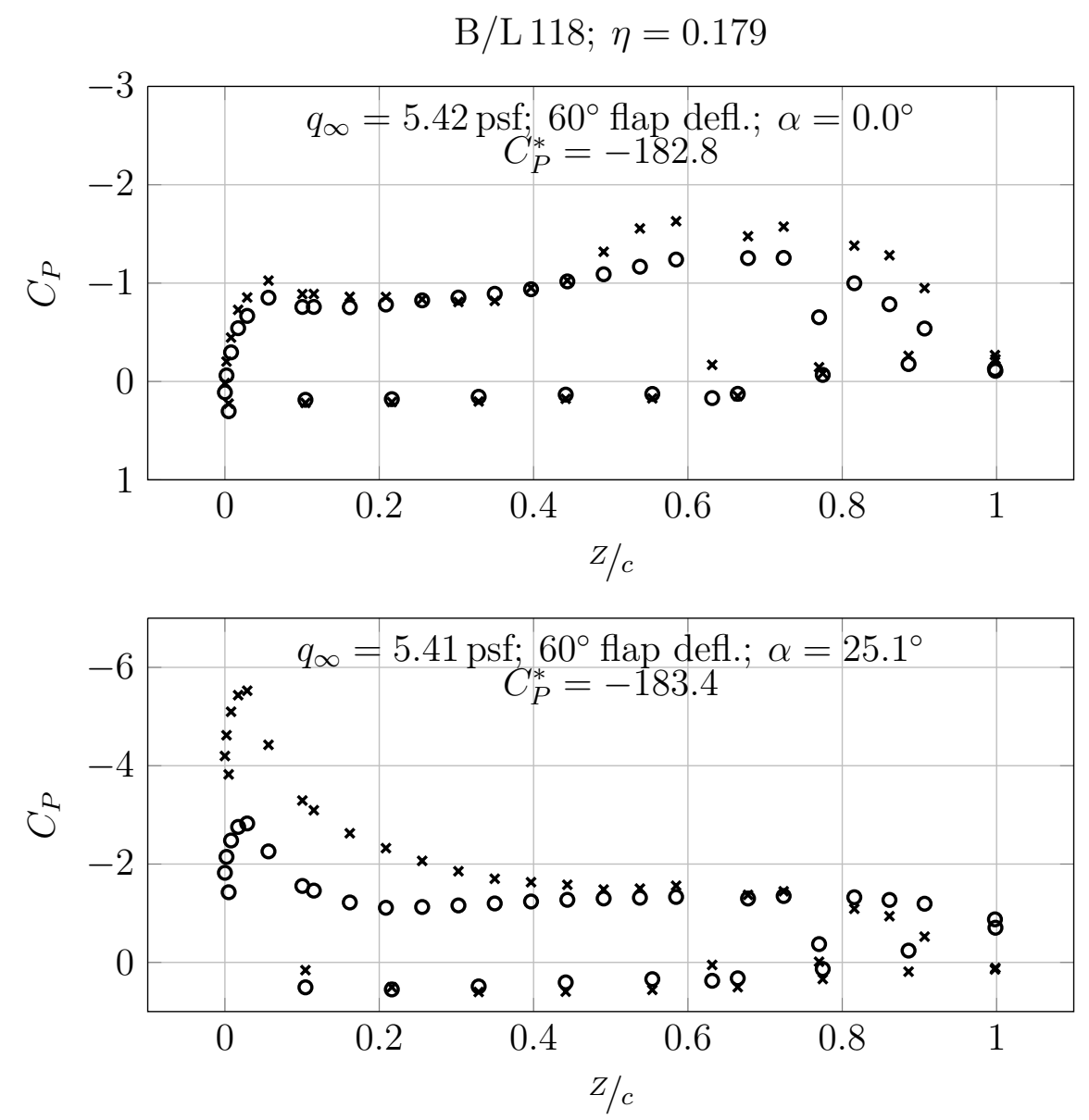

× Run 218: Clean Wing; $C_{\mu}=0.92$

○Run 274 : TE-only; $C_{\mu}=0.39$

Figure 5.22: Comparison of inboard wing section pressure coefficients for the addition of leading edge blowing. 

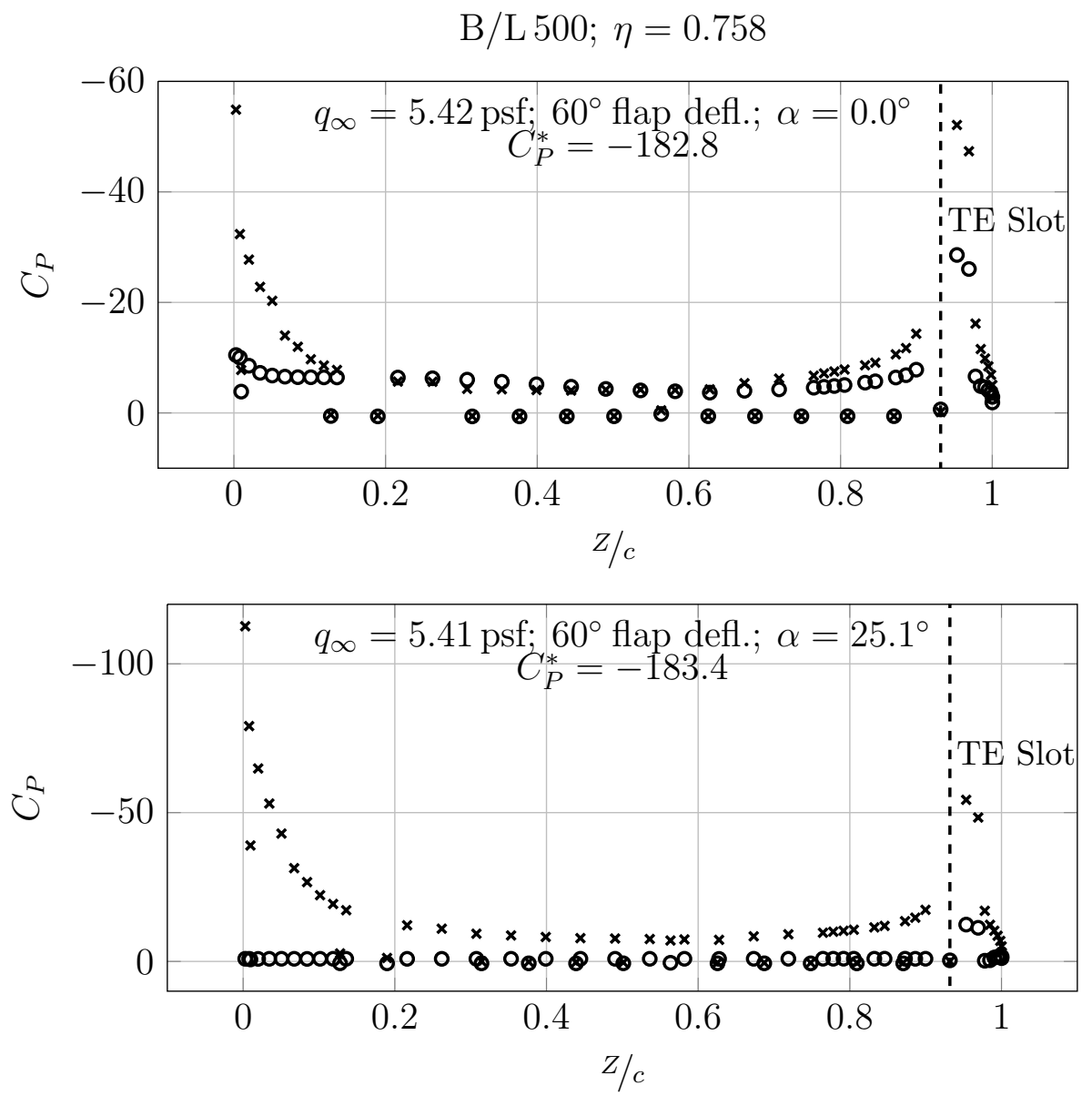

×Run 218 : Clean Wing; $C_{\mu}=0.92$

oRun 274 : TE-only; $C_{\mu}=0.39$

Figure 5.23: Comparison of outboard wing section pressure coefficients for the addition of leading edge blowing. 


\section{Chapter 6}

\section{Conclusions and Suggestions for}

\section{Future Work}

The preceding discussion has served to provide a summary of the test results obtained from the recently completed wind tunnel test of the Advanced Model for Extreme Lift and Improved Aeroacoustics, AMELIA. This thesis is just a small part of Cal Poly's efforts towards advancing the state-of-the-art in prediction methods and evaluating technologies that will enable the next generation of commercial airliners to integrate into the existing infrastructure of today's airports. It has presented only a small set of all of the data generated during the test, and serves as a supplement to Reference [28].

This is the first large-scale full-span wind tunnel test of its kind. Testing of the Cal Poly model proved successful and was the culmination of a 5 year NASA Research Announcement funded by the Fundamental Aeronautics Program. All of the pre-test objectives were met, including ten critical test points where direct measurement of skin friction was acquired. The test data provides low-speed 
experimental force and moment data, model surface pressures, smoke and oil flow visualization, acoustic measurements, and skin friction data. The test data is open source and is intended to generate validation data for the CFD and acoustic modeling communities. The data generated from the test should provide a wealth of new data for modelers attempting to validate the tools used to design the next generation commercial transport.

Testing was completed in four different model configurations, including two engine pylon heights. Test data showed that in order to achieve significant lift augmentation and sufficient angle of attack performance, leading edge blowing is needed. Without leading edge blowing, stall occurred at low angles of attack and was more harsh than when leading edge blowing is present-likely due to the location of stall switching from the leading edge to the trailing edge when the LE slots are blowing. Testing saw little to no improvement gained using the $80^{\circ}$ flap deflection over the $60^{\circ}$ flap. Whereas, it was expected that a higher flap deflection would result in both increased lift and drag, only an increase in drag was seen. Testing also did not show the expected coupling between the CCW and over-the-wing mounted engine simulators. It was expected that the lower engine height would result in increased lift and high angle of attack performance, but test data showed no significant impact on the aerodynamic data.

Though this test did produce a multitude of new data for the CFD community to validate tools and improve the ability to predict performance for these types of configurations, there are suggestions for further work that can build on this already expansive data set. As with any test intended for CFD, more detailed measurements are always desired. Admittedly, more detailed measurements of the overall flow field would be difficult for a model of this scale (both with respect to available wind tunnels and measurement capabilities), however more detailed 
measurements can be made in the regions most critical to the CFD: the boundaries. Furthering the work that Paciano [15] discussed could serve the greatest benefit. These could include hot wire measurements in the slot to provide velocity profiles to match the existing total pressure profiles, and a more extensive traverse setup will enable slot profiles to be acquired closer to the LE slot.

As was discussed briefly, a post-test calibration of the fan flow to characterize its flow rate would provide more complete TPS measurements. As it stands, the RPM and inlet static taps are the only measurements defining the inlet fan flow. A reasonably accurate fan flow calibration can be obtained with CFD, or other numerical methods.

The isolated trailing edge blowing data proved to be a critical addition to this data set. Not only did it provide a comparison with historical CCW data, it provided isolated component performance. Isolated component performance allows for a better understanding of the $\Delta$ 's in the data and allow for further characterization of overall model performance. Isolated leading edge blowing data would be the logical next data set to acquire. The test data showed a strong coupling between slot blowing and model pitching moment. A better understanding of the contribution from the leading edge slots alone would allow for a more optimum blowing configuration to be assessed, the goal of which would be to obtain a trimmed configuration through blowing, or to obtain a better understanding of the extents to which the center of pressure can be shifted through varying blowing rates between the leading- and trailing-edges.

A second isolated component test would be to reduce the slot height and test at the same mass flow rate. This would test the hypothesis that a higher $C_{\mu}$ would create the performance differences between the high and low pylon heights that were originally anticipated. 


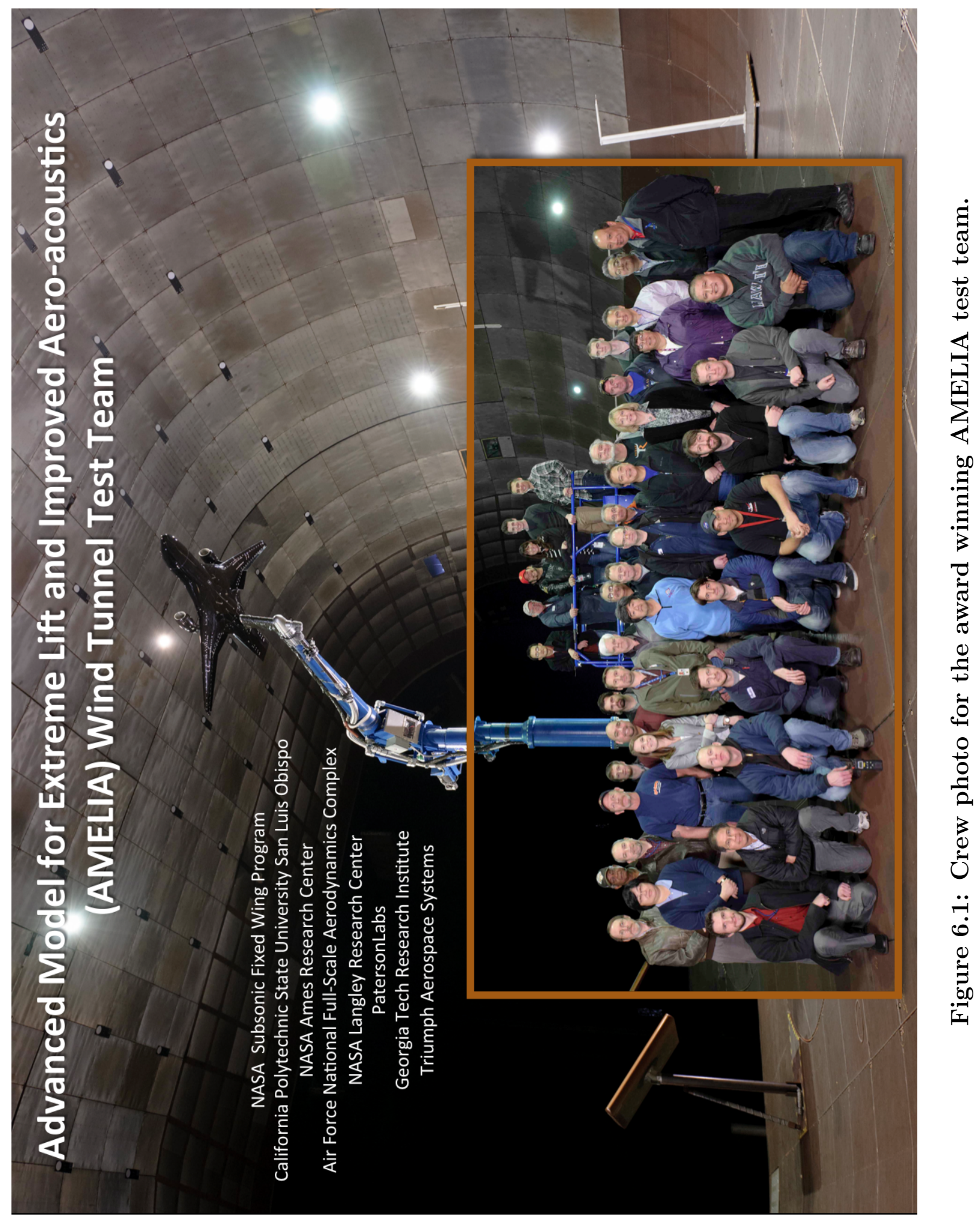




\section{Bibliography}

[1] J. Zuk, R. K. Callaway, and D. A. Wardwell. Adaptive Air Transportation System - A Catalyst for Change. Technical Report 4576, American Institute of Aeronautics and Astronautics, November 2002.

[2] D. Marshall and K. Jameson. Overview of Recent Circulation Control Modeling Activities at Cal Poly. Technical Report 348, American Institute of Aeronautics and Astronautics, January 2010.

[3] P. L. Johnson, K. M. Jones, and M. D. Madson. Experimental Investigation of a Simplified 3D High Lift Configuration in Support of CFD Validation. Technical Report 4217, American Institute of Aeronautics and Astronautics, August 2000 .

[4] G. S. Jones, J. C. Lin, B. G. Allan, W. E. Milholen, C. L. Rumsey, and R. C. Swanson. Overview of CFD Validation Experiments for Circulation Control Applications at NASA. Technical report, International Powered Lift Conference, July 2008.

[5] R. J. Englar, G. S. Jones, B. G. Allan, and J. C. Lin. 2-D Circulation Control Airfoil Benchmark Experiments Intended for CFD Code Validation. Technical Report 902, American Institute of Aeronautics and Astronautics, January 2009. 
[6] R. J. Englar, R. J. Gaeta, W. J. Lee, and V. Leone. Development of Pneumatic Over-the-Wing Powered-Lift Technology; Part I: Aerodynamic/Propulsive. Technical Report 3942, American Institute of Aeronautics and Astronautics, June 2009.

[7] K. C. Pfingsten and R. Radespiel. Experimental and Numerical Investigation of a Circulation Control Airfoil. Technical Report 533, American Institute of Aeronautics and Astronautics, January 2009.

[8] C. M. Cagle and G. S. Jones. A Wind Tunnel Model to Explore Unsteady Circulation Control for General Aviation Applications. Technical Report 3240, American Institute of Aeronautics and Astronautics, June 2002.

[9] D. Wetzel, J. Griffin, F. Liu, and L. Cattafesta. An Experimental Study of a Circulation Control Airfoil Trailing Edge Flow Field. Technical Report 4576, American Institute of Aeronautics and Astronautics, June 2010.

[10] S. W. Collins, B. W. Westra, J. C. Lin, G. S. Jones, and C. H. Zeune. Wind Tunnel Testing of Powered Lift, All-Wing STOL Model. The Aeronautical Journal, 113(1140):129-137, February 2009.

[11] J. C. Lin, G. S. Jones, B. G. Allan, B. W. Westra, S. W. Collins, and C. H. Zeune. Flow-Field Measurement of a Hybrid Wing Body Model with Blown Flaps. Technical Report 6718, American Institute of Aeronautics and Astronautics, August 2008.

[12] W. E. Milholen, G. S. Jones, D. T. Chan, and S. L. Goodliff. High-Reynolds Number Circulation Control Testing in the National Transonic Facility (Invited). Technical Report 103, American Institute of Aeronautics and Astronautics, January 2012. 
[13] K. K. Jameson, D. D. Marshall, R. S. Ehrmann, E. N. Paciano, R. Golden, and D. Mason. Design and Wind Tunnel Testing of Cal Poly's AMELIA 10 Foot Span Hybrid Wing-Body Low Noise CESTOL Aircraft. Technical report, 27th International Congress of the Aeronautical Sciences, 2010.

[14] N. R. Alley, J. Steele, J. C. Neidhoefer, R. J. Englar, and G. Blaylock. Development of a Cruise-Efficient Extreme-STOL-Capable Demonstrator UAV. Technical Report 3450, American Institute of Aeronautics and Astronautics, April 2010.

[15] E. N. Paciano, J. A. Lichtwardt, K. K. Jameson, D. D. Marshall, and R. K. Fong. Flow Uniformity Calibration of AMELIA's Circulation Control Wings. Technical Report 975, American Institute of Aeronautics and Astronautics, January 2013.

[16] D. Booth and N. Ulbrich. Calibration and Data Analysis of the MC-130 Air Balance. Technical report, 8th International Symposium on Strain-Gauge Balances, May 2012.

[17] R. S. Ehrmann. Development of Measurement Methods for Application to a Wind Tunnel Test of an Advanced Transport Model. Master's thesis, California Polytechnic State University, San Luis Obispo, August 2010.

[18] R. S. Ehrmann, J. A. Lichtwardt, E. N. Paciano, and K. K. Jameson. Global Skin Friction MMeasurement on a Circulation Control Airliner in the NFAC. Technical Report 977, American Institute of Aeronautics and Astronautics, January 2013.

[19] J. M. van Aken and L. Yang. Development of a new State-of-the-Art Data Acquisition System for the National Full-Scale Aerodynamics Complex Wind 
Tunnels. Technical Report 1346, American Institute of Aeronautics and Astronautics, January 2009.

[20] N. Burnside and W. Horne. Acoustic Surveys of a Scaled-Model CESTOL Transport in Static and Forward Speed Conditions. Technical Report 2231, American Institute of Aeronautics and Astronautics, June 2012.

[21] AIAA. Calibration and Use of Internal Strain-Gage Balances with Application to Wind Tunnel Testing. Standard AIAA-R-091-2003, American Institute of Aeronautics and Astronautics, 2003.

[22] AIAA. Nomenclature and Axis Systems for Aerodynamic Wind Tunnel Testing. Guide G-129-2012, American Institute of Aeronautics and Astronautics, March 2012.

[23] P. T. Zell and K. Flack. Performance and Test Section Flow Characteristics of the National Full-Scale Aerodynamics Complex 40- by 80-Foot Wind Tunnel. NASA Technical Memorandum 101065, NASA, February 1989.

[24] A. L. Braslow and E. C. Knox. Simplified Method for Determination of Critical Height of Distributed Roughness Particles for Boundary-Layer Transition at Mach Numbers from 0 to 5. NACA Technical Note 4363, NACA, 1958.

[25] R. A. Wahls, J. B. Adcock, D. P. Witkowski, and F. L. Wright. A Longitudinal Aerodynamic Data Repeatability Study for a Commercial Transport Model Test in the National Transonic Facility. NASA Technical Paper 3522, NASA, August 1995.

[26] AIAA. Assessment of Experimental Uncertainty with Application to Wind Tunnel Testing. Standard S-071A-1999, American Institute of Aeronautics and Astronautics, 1999. 
[27] Ministry-Industry Drag Analysis Panel Study Group. Guide to In-Flight Thrust Measurement of Turbojets and Fan Engines. Standard AGARDAG-237 (Also AD A065 939), Advisory Group for Aerospace Research \& Development, January 1979.

[28] D. D. Marshall, K. K. Jameson, R. K. Fong, J. A. Lichtwardt, and E. N. Paciano. Advanced Model for Extreme Lift and Improved Aeroacoustics (AMELIA) Technical Memorandum. In accordance with the requirements outlined by NASA Aeronautics Subsonic Fixed Wing Program Contract \#NNL07AA55C fulfilled by California Polytechnic State University in collaboration with Georgia Tech Research Institute. (Under review at time of publication), March 2013. 